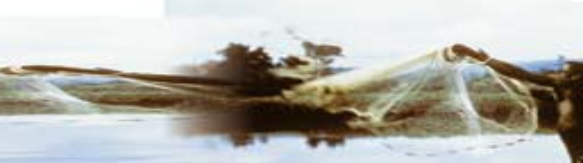

M.Sc. Thesis in International Studies in Aquatic Tropical Ecology

\title{
"Variability and community organization in moderately exposed tropical rocky shore algal communities as influenced by different consumer groups"
}

\author{
Presented by Edison Roi D. Macusi \\ Presented to the University of Bremen, Faculty for Biology \& Chemistry \\ Supervisors:
}

Prof. Dr. Kai Bischof

University of Bremen

Dr. Habil. Thomas Brey

Alfred Wegener Institute for Marine and Polar research
Dr. Gray A. Williams

The University of Hong Kong

Bremen, August 2008

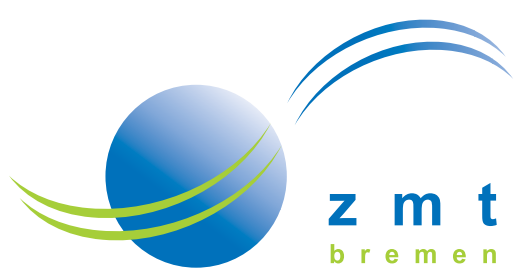


Statement according to $\S 6$ (8) Final Examination Regulations of the University of Bremen for the Master's Degree "ISATEC"

I herewith confirm that I have elaborated my Master' thesis entitled

\section{"Variability and community organization in moderately exposed tropical rocky shore algal communities as influenced by different consumer groups"}

single-handed and without using other resources than mentioned therein. 
P a g e | 3

TO MY PARENTS 


\section{Acknowledgements}

I am immensely grateful for the scholarship grant from DAAD (the German Academic Exchange Scholarship) which gave me this opportunity to study and bring my family with me to Germany. Special thanks to Ms. Marita Palmer who took pains for processing the papers of my wife and baby.

I want also to express my sincerest thanks to Prof. Dr. Kai Bischof and Dr. Thomas Brey for patiently commenting on my thesis and guiding my data analyses as well as being there as my referees.

I give my sincerest gratitude to my field supervisor and sponsor in Hong Kong for my thesis, Dr. Gray Williams for his tenacious patience during the fieldwork, data corrections, and discussions as well as in advising me of the many things I needed to do for my thesis. I certainly learned many things from you Gray!

My deepest thanks to Apostolos Khotsaftis, my field buddy in Cape d' Aguilar for a lot of help during the field work,

I am most grateful for the one month stay of Ms. Sujitra Samakraman of Thailand for helping me a lot in the field as well as inside the laboratory when the going gets tough.

I would like to thank: the Hong Kong Agriculture and Fisheries Conservation Department (AFCD) for allowing me access to the Cape d'Aguilar marine reserve of Hong Kong, without which I would not have any thesis,

The Hong Kong Observatory (HKO) which provided easy data access from their website for the most needed data--tides, tide tables and the Hong Kong Environmental Protection Department (EPD) for providing advance copy of marine water quality data for the sampling months of the experiment,

Mr Frankie Chan, Mr. Lee and Amy of the Electron Microscope Unit of the Hong Kong University Pathology unit for helping me in the preparation of my rock chip samples for Scanning Electron Microscopy

Mr. Chan of the Prisons security group and the Stanley Prisons Authority for ease of access to the Stanley grounds and shores,

Patrick for sharpening the chisels which are often dulled by the rocks we chip out,

Cecily for reminding me of the details of the laboratory work as well as what to do and what not to do inside and outside the SWIMS Marine laboratory,

Vivian Wei Wei Bao for the cuvettes she gave me during the chl $a$ analysis as well as Liu Min for the Glutaraldehyde which I used to fix my rock chip samples, 
I benefitted a lot from discussions with James True as well as the rocky shore ecology group of HKU, Hong and Ming, for driving me to the field and help in the fieldwork at various times,

Acheun Ng and Wai Tak Cheung, Solomon, June Leung, Damgy Chan, Stephen Cartwright for help in the set-ups,

Ms. Sylvia for arranging the details of our transport to Stanley prison as well as faxing all of our permits and letters to the necessary authorities in the area,

Simon and Simon's wife for making a home out of our residence, cleaning out our old stuffs as well as servicing often our kitchen which we leave untidy most often times,

To the Jesus Loves You Church of Hong Kong for Sunday fellowships and being there as part of my family,

To our ISATEC coordinator and staff Iris Freytag, Stephanie Jost, Christoph Driemel, Wolfgang Ludwig and Anna Maria Stein for providing all the support in many ways, I am very grateful,

To my ISATEC colleagues and friends, especially to Ashoka, Bandara, Mojib, Fadli and Mizan for all the jokes, companionship, and hot Sri-Lankan foods, Bangladesh menu and Indonesian noodles. I hope to visit all your countries one day.

This world would have been bluer than blue, It would have simply vanished into thin air, Lost in bytes and pieces, lost in oblivion, Yet the flicker of burning light, the pulsating warmth of love, All this changed into glory, because of you...

Because of a loving wife and a baby...you're my sweetest dreams! 
P a g e $\mid 6$

Prologue

"The grass lives and feeds the world;

The world is green..." 


\section{Abstract}

Tropical rocky shores have been described as diverse and having a complex variety of consumers. This wide array of consumers has been studied to shed light on the different roles of consumers, particularly grazers on rocky shores and how they affect the relative abundance and distribution of sessile algal prey. One of the aims of ecology is to clarify factors that regulate and structure the abundance, growth and relationship of predators and preys in each habitat. Grazing is known as one of the most important determinants of growth and distribution of rocky shore communities. In this study a comparison between the different effects of fishes, crabs and molluscan herbivores on the relative abundances of microalgae and macroalgae from micro (hundreds of microns) to medium (tens of meters to kilometers) scales of spatial variability was conducted. At the start of the experiment several hypotheses were forwarded: 1) that herbivores will reduce the density of microalgae and macroalgal cover causing a barren appearance and ultimately reducing algal diversity where grazing intensity is highest across treatments, sites and shores; 2) and where grazing pressure is low, algal cover and diversity will be high; 3 ) and that fishes and crabs contribute significantly to maintaining a high grazing pressure in the area and that fishes control the algal assemblage in benign environments. These were evaluated by exclusion experiments and quadrat counts to determine the effects of grazers on different functional groups of algae. Microalgal density was assessed indirectly by measuring chlorophyll $a$ from rock chips taken from the treatment plots. Microspatial variability of different sites was assessed by scoring digital micrographs of rock chips also taken from treatment plots. Algal cover of treatment plots was assessed by using digital photos taken during forthnightly visits in all sites. The univariate and multivariate results show significant differences across treatments, sites and shores and even significant temporal differences. Microalgal abundance and erect algal cover in fenced plots were significantly different compared to the other treatments. Grazer removal effectively caused a completely different algal assemblage to develop through time in cage and fenced treatments while maintaining a mostly barren cover in most open and control set-ups. Species which are not typically present in shores have grown inside cage and fenced treatments during the period of manipulation. Molluscan herbivores are the most effective grazers in these shores and control the relative distribution of algae by restricting the recruitment success of algal sporelings particularly erect macroalgae. Herbivorous fishes and crabs do not directly influence algal sporelings since the early stages of algae are too small for them to handle. But both consumers complement the removal of turf forming algae. The observed over all grazing effects show that molluscs have greater impact than fishes and crabs combined; the effect of either fishes or crabs are equal. Hence, the impact of crabs and fishes on these shores are minimal, mainly affecting turf forming algae. Moreover, the observed spatial variability in algal assemblage from micro to medium scales is mainly driven by high grazing intensity. Thus, grazing acts as a highly effective top down control mechanism in these shores during the cool winter season.

Keywords: Grazing, top-down control, molluscs, fishes, crabs, recruitment, macroalgae 


\section{List of Abbreviations}

1. Chl $\boldsymbol{a}=$ chlorophyll $a$

2. SEM = Scanning Electron Microscope

3. CAP = Cape d' Aguilar rocky shore

4. STAN $=$ Stanley rocky shore

5. CAP 1 = Cape d' Aguilar site 1

4. CAP 2 = Cape d' Aguilar site 2

5. STAN $1=$ Stanley site 1

6. STAN 2 = Stanley site 2

7. $\mathbf{C P C e}=$ Coral Point Count with Excel extensions

8. SNK test $=$ Student-Newman-Keuls tests

9. $\mathbf{n M D S}=$ non-metric multidimensional scaling

10. ANOSIM= Analysis of Similarities

11. AFCD = Agriculture, Fisheries and Conservation Department of Hong Kong

12. EPD = Environmental Protection Department

13. ENSO = El Niño Southern Oscillation 


\section{TABLE OF CONTENTS}

Dedication 3

Acknowledgement $\quad 4$

Prologue $\quad 6$

$\begin{array}{ll}\text { Abstract } & 7\end{array}$

List of Abbreviations 8

Table of Contents 9

List of Tables $\quad 11$

List of Figures 13

$\begin{array}{lll}1.0 & \text { Introduction } & 16\end{array}$

$\begin{array}{lll}1.1 & \text { Background studies } & 19\end{array}$

$\begin{array}{lll}1.2 & \text { Objectives of the research } & 19\end{array}$

$2.0 \quad$ Materials and Methods 21

$\begin{array}{lll}2.1 & \text { Study sites and conditions during set-up } & 21\end{array}$

$\begin{array}{lll}2.2 & \text { Physical variables } & 24\end{array}$

$\begin{array}{lll}2.3 & \text { Treatment } & 24\end{array}$

2.3.1 Grazer effect experiments 24

2.3.2 Consumer effects study 25

$\begin{array}{lll}2.4 & \text { Microalgal abundance } & 28\end{array}$

2.5 Scanning Electron Micrograph and scoring of rock chip percent cover 29

2.6 Grazer pressure in the study sites 30

$\begin{array}{lll}2.7 & \text { Aquarium observations } & 30\end{array}$

$\begin{array}{lll}2.8 & \text { Data analyses } & 30\end{array}$

$2.9 \quad$ Multivariate analyses 32

$\begin{array}{lll}3.0 & \text { Results } & 34\end{array}$

3.1 Effects of removal of molluscs on microalgal abundance 34

3.2 Effects of fishes and crabs on microalgal abundance 36

$\begin{array}{lll}3.3 & \text { Physical variables } & 37\end{array}$

3.4 Grazer pressure in the study sites 41

3.5 Grazer intruders in the fenced treatments 46

3.6 Direct assessment of spatial variation in microalgal cover using the Scanning Electron Microscope $\quad 48$

3.7 Variable consumer effects on microalgal cover of rock chips 53 
3.8 Percent cover in treatment plots $\quad 55$

$\begin{array}{lll}3.9 & \text { Multivariate analyses } & 62\end{array}$

$\begin{array}{lll}3.10 & \text { ANOSIM of assemblage cover }\end{array}$

3.11 Percent cover of treatment plots (consumer effects study) 64

$\begin{array}{lll}3.12 & \text { Multivariate analyses (consumer effects study) }\end{array}$

$\begin{array}{ll}3.13 & 72\end{array}$

$\begin{array}{lll}4.0 & \text { Discussion } & 73\end{array}$

$\begin{array}{lll}4.1 & \text { Grazing and Microalgal abundance } & 73\end{array}$

4.2 Grazing from micro to macrospatial scales of variability 76

$\begin{array}{lll}4.3 & \text { Top down regulation and shift in assemblage } & 78\end{array}$

4.4 Effects of limpets and coiled gastropods in fenced treatments 82

$\begin{array}{lll}4.5 & \text { The world is green but also yellow } & 84\end{array}$

$\begin{array}{lll}4.6 & \text { Consumer effects on algal abundance and distribution } & 87\end{array}$

$\begin{array}{lll}4.7 & \text { Conclusions and broader implications } & 92\end{array}$

$\begin{array}{lll}4.8 & \text { Recommendations } & 94\end{array}$

$\begin{array}{ll}\text { Epilogue } & 95\end{array}$

$\begin{array}{lll}5.0 & \text { References } & 96\end{array}$

6.0 Appendix and supplementary mateials (please find $C D$ at the back cover) 


\section{LIST OF TABLES}

No. Description

Page

1 Locations and positions of the four study shores

2 Treatments used in the study and their procedural controls

3 Comparison using 3-way ANOVA of Chlorophyll $a$ on 4 sites (Sites CAP1 to STAN2), on five sampling times (dates) during winter 2007

4 Comparison using 2-factorial ANOVA of Chlorophyll $a$ among seven treatments to separate the effects of fish and crabs on microalgae during winter 2007.

5 Pearson's correlation coefficients for comparisons between measures of microalgal abundance (chlorophyll a concentration) and various physical variables at the four study sites

6 Comparison using 2-way ANOVA for grazer abundance in the four study sites (Site) on different sampling dates (Time) during winter 2007

$7 \quad$ List of species of grazers, presence/absence in the four study sites

8 Comparison using 2-way ANOVA for grazer counts inside fence treatments in two sites (STAN1 and STAN1) on different sampling dates (Time) during winter 2007 through January 2008

9 Pearson's correlation coefficients for comparisons between measures of microalgal abundance (chlorophyll a concentration), rock chip algal cover and various groups of grazers found inside fence treatments at the two Stanley sites. COILEDG: Coiled gastropods, TOTG: Total grazers

10 Summary of comparisons using nested ANOVA for various functional groups of microalgae in experimental treatments ( $\mathrm{Tr}$ ) at 4 sites (Si), on 2 shores (Sh) and on 5 sampling dates (Ti) within winter 2007

11 Summary comparisons of ANOVA for various algal covers in separating the effects of different consumers

12 Summary of comparisons using nested ANOVA for various algal covers in experimental treatments ( $\mathrm{Tr}$ ) at 4 sites (Si) and on 2 shores (Sh), on 9 sampling dates (Ti) within winter 2007

13 Summary table of Global $R$ values from different species assemblage in all sites 
14 Summary table of $R$ values from pairwise tests between sites ( $C 1=C A P 1$,

$\mathrm{C} 2=\mathrm{CAP} 2, \mathrm{~S} 1=\mathrm{STAN} 1, \mathrm{~S} 2=\mathrm{STAN} 2)$ and between treatments $(\mathrm{F}=$ fenced, $\mathrm{P}=$ partial fence, $\mathrm{O}=$ open)

15 Univariate and multivariate summary of comparisons using a two factorial ANOVA for various algal covers to determine effects of various experimental treatments $(\mathrm{Tr})$ sampled on 9 sampling dates (Ti) within winter 2007

16 Monthly variation in global $R$ values for treatments from a One way ANOSIM of treatments

17 Summary table of $\mathrm{R}$ values from pairwise tests between treatment groups, fenced $(F)$, partial fence $(P)$, open $(O)$, full cage $(C)$, cage control $(C C)$, roof $(R)$ and roof control $(\mathrm{Rc})$

18 Summary comparison of ANOVA tests for the two diversity indices for various algal covers in separating the effects of different consumers 


\section{LIST OF FIGURES}

No. Description

1 Map showing the locations of the four study sites in Hong Kong Island. The yellow push pins show the location of sites within each study shore (CAP stands for Cape d' Aguilar and STAN stands for Stanley).

2 A closer look at the four study sites; the two Stanley sites show some growth of green alga before the start of the experiment while the two sites at Cape d' Aguilar look conspicuously barren (treatment plots were located at the mid shore level).

3 Photos of the seven treatments used in the study of separation of the effects of different consumer groups. The first three treatments were mainly used to study the effect of molluscan grazers on algal communities at the mid-shore level.

$4 \quad$ Overview of a fence set-up: each set-up is labeled and each study site mapped so that replacement of any missing fences or set-ups would be easier (photo courtesy of Dr. Gray Williams).

5 Microalgal abundance in the four study sites as measured using chl $a$. (Error bars represent $\pm S E)$. Rise and fall of fence treatment values reflect the effect of grazing intruders in the two sites of Stanley site 1 and site 2 (see discussion for further explanation). Note the differing initial values showing the relative abundance of biofilm in each site at the beginning of set-up.

6 Mean chlorophyll a concentration ( \pm SE) for the seven treatments in the first two months of study to estimate the biofilm standing stock

$7 \quad$ Selected physical factors recorded during the field experiments that can potentially affect sites and treatments at Cape d' Aguilar and Stanley rocky shores, Hong Kong Island (courtesy of Hong Kong Observatory).

8 Comparison of water and nutrient parameters data between the two shores of Stanley and Cape' d Aguilar collected from 1998-2006 ( $1^{\text {st }}$ row, charts A and B above) and during the winter 2007 experiment ( $2^{\text {nd }}$ row, charts $C$ and $D$; note the change in scale). Bar on top represents mean of total counts, + SE. (Courtesy Hong Kong Environmental Protection Department).

9 Different grazer species and abundance found in Cape d' Aguilar sites 1 and 2 (CAP1 and CAP2). In each site, two different grazers dominate with the limpet $C$. toreuma in CAP1, and the snail $M$. labio in CAP2. Bar on top represents mean of total counts (+SE) of molluscan grazers.

10 Different grazer species and abundance found in Stanley sites 1 and 2 (STAN1 and STAN2). In both sites, the limpet $C$. toreuma dominates while two other small snails $P$. sulcatus and E. radiata follows closely. Bar on top represents mean of total counts (+SE) of molluscan grazers. 
11 Mean grazer abundance classified into different functional groups of grazers showing from October to December 2007 in the four study sites (CAP1 to STAN2). Bar on top shows mean abundance + SE.

12 Total mean abundance of grazers found inside fenced treatments during the whole duration of experiment in each study site. Bar on top shows mean abundance +SE.

13 Results of rock chip algal cover in Cape d' Aguilar study sites 1 and 2 (CAP1 \& CAP2). Experimental treatment effects were significantly different between the three treatments with the fence treatment having the most abundant erect algal cover in both sites.

(*Herbivore legend is common to all charts).

14 Results of rock chip algal cover in Stanley study sites 1 and 2 (STAN1 \& STAN2).

Experimental treatment effects were significantly different between the three treatments with the fenced treatment having the most abundant erect algal cover in both sites.

(*Herbivore legend is common to all charts).

15 Results from rock chip algal cover for separating the effects of different consumers. Cage and fenced treatments were not significantly different from each other although the cage treatment has larger erect algal cover than the fence treatment. Both treatments have the largest erect algal cover compared to all the other treatments

16 The left column depicts the percent change of area colonized by erect and encrusting algae in each treatment through time while the right column shows changes of algal composition in these treatments through time. (CAP1: total erect algal cover $=9.94 \%$ and total encrusting $=75.96 \%$ algal cover,$p<0.05 ;$ Fence $>$ Control $=$ Open $p<0.05$ )

17 The left column depicts the percent change of area colonized by erect and encrusting algae in each treatment through time while the right column shows changes of algal composition in these treatments through time. (CAP2: total erect algal cover $=20.93 \%$ and total encrusting $=65.35 \%$ algal cover, $p<0.05$; Fence $>$ Control=Open $p<0.05$ )

18 The left column depicts the percent change of area colonized by erect and encrusting algae in each treatment through time while the right column shows changes of algal composition in these treatments through time. (STAN1: total erect algal cover $=13.53 \%$, $p<0.05$ and total encrusting $=73.81 \%$, ns; Fenced $>$ Control=Open $p<0.05$ )

19 The left column depicts the percent change of area colonized by erect and encrusting algae in each treatment through time while the right column shows changes of algal composition in these treatments through time. (STAN2: total erect algal cover $=6.09 \%$, $p<0.05$ and total encrusting $=67.56 \% \mathrm{~ns}$; Fenced $>$ Control $=$ Open $p<0.05$ )

20 nMDS plots of similarities in algal recruitement for Cape d' Aguilar sites (C1 and C2) and Stanley sites (S1 and S2). Data represent spatial variation between treatment groups, fenced $(F)$, partial fence $(P)$, open $(O)(n=5)$. 
21 The left column shows the change in area of total erect and encrusting algae in the seven treatments used to separate the effects of different herbivores in Cape d' Aguilar shore. It shows that cage and fenced treatments were not statistically significant in algal cover; it also shows that the encrusting algal cover and free space dominates in all the control and roof treatments. The right column depicts colonization of various groups of algae in each treatment plots. Erect algal cover arrives first followed by foliose algae such as Ulva and Porphyra. In terms of green turf cover, cage and fence treatments were statistically different from each other

22 nMDS plots of similarities in algal recruitement for consumer effects study in Cape d' Aguilar site. Data represent spatial variation between treatment groups, fenced $(F)$, partial fence $(P)$, open $(O)$, full cage $(C)$, cage control $(C c)$, roof $(R)$ and roof control $(R c)(n=5)$. 


\subsection{Introduction}

Tropical rocky shores have been described as diverse and have a complex variety of consumers. These rocky shores are believed to be fish-dominated, fish being the number one predator that regulates the number of invertebrate prey in such area like in Panama (Menge et al. 1986a, 1986b). These shores are characterized by highly stressful conditions, the mid and high intertidal zones are often exposed to intense heat from the sun year round during low tide and summer conditions are much worse than during other parts of the year. The presence of subtidal predators such as fishes and crabs can cause a patchy distribution of intertidal sessile preys such as algae, gastropods and barnacles (Menge and Lubchenco 1981; Garrity and Levings 1981 and 1986; Menge et al. 1986a). Escape from predation can only occur as a result of hiding or by means of predatory avoidance mechanisms (Garrity and Levings 1981; Garrity 1984; Garrity et al.1986). On other shores such as on a seasonal tropical rocky shore like Hong Kong, cracks, crevices, pools as well as the cool winter season offer relief to many sessile prey species such as barnacles and algae (Williams 1993a, 1993b, 1994).

One of the main goals of ecology is to unravel the regulatory mechanisms that underlie why a system behaves as it does. The predictive power of ecology however is a consequence of compiled and verified results from various scales, regions and even latitudes of comparative studies finding the same results over and over. Predation and herbivory are factors that continue to alter the way we perceive our ecosystem. These two factors constitute the main biological structuring forces in rocky shore communities, e.g. Dayton (1971) and Paine $(1966,1994)$. One way predation can structure a community is by limiting the foraging power of gastropods by forcing them frequently into predator avoidance behavior (Garrity and Levings 1981; Garrity et al.1986; Power et al. 1989). On the other hand, grazing by herbivorous fishes and molluscs can reduce the biomass of algal covers, smother young recruits and open spaces for other recruits (Underwood 1980 and 1981; Petraitis 1983; Underwood et al. 1993; Freidenburg et al. 2007). Scaled up and repeated studies of comparable design on tropical rocky shores however are lacking, which indicates an imbalance of efforts compared to temperate shores. Although grazer and consumer studies were conducted earlier such as those by Menge et al. (1986), Sauer Machado et al. (1996) and Vinueza et al. (2006), these studies show inconsistent results. Although the grazer-alga food chain is important, it is not the sole structuring force in tropical rocky shores; it can be 
affected by other factors such as oceanographic forcing like ENSO (El Niño Southern Oscillation) cycles (Vinueza et al. 2006), by seasonal cycles (Williams 1993a, 1993b, 1994), number of recruits (Kaehler and Williams 1997), predators (Menge et al. 1986a) and complex interactions (Sauer Machado et al. 1996). In temperate rocky shores, grazers are also affected by nutrient subsidies (Bustamante et al. 1995), the availability of recruits (Freidenburg et al. 2007), desiccation and high winds (Bazterrica et al. 2007), disturbance such as storms, sand and ice scour (McQuaid and Dower 1990; McCook and Chapman 1991, 1993; Underwood 1999), upwelling and oceanographic conditions (Menge et al. 2003).

Given these many factors that can affect the rocky shores, it is not surprising to find many inconsistent results and highly variable effects depending on latitude, site replications and study design. The Hong Kong rocky shores have been much studied on grazer-alga interaction such as on the effects of seasonality (Williams 1993, 1994), recruitment of erect and encusting algae (Kaehler and Williams 1997), grazer pressure (Harper and Williams 2001; Hutchinson and Williams 2003a; Wai and Williams 2006), typhoon (Hutchinson and Williams 2003b), cyanobacteria (Nagarkar and Williams 1997), and succession (Williams et al 2000). However the system was much studied, scale up of these previous studies remains rare and effects of processes at work at the scale of tens of meters to hundreds of meters may not work in the scale of thousands of meters; the findings remain limited to the areas of study. In ecology, unless a consistent result emerges at different times and using the same method of study, then patterns remain elusive and clear understanding of processes remain obscured (Underwood et al. 2000). Thus, site level replications and examinations of spatio-temporal variations of ecological processes at different times and places are needed.

One of the main findings of the previous consumer studies by Menge et al. (1986a) is the applicability of the environmental stress models in tropical rocky shore systems which states that under benign environments, predation prevails over the basal species (preys). This means that species of high trophic status (i.e. predators) would be regulated primarily by competition while species of low trophic status (basal species i.e. algae and barnacles) should be regulated primarily by predation. Brosnan (1992), relying on the results of earlier works by Menge et al. (1985, 1986a, 1986b) and Menge and Sutherland (1976 and 1987) predicted that shores of both temperate and tropical latitudes have the same ecological interaction but the relative contribution of each to community structure varies across latitudes. She specifically referred to the importance of competition among basal sessile species versus the 
effects of consumer species (especially fish) as structuring agents of algal assemblages. In the tropics, herbivorous fish forage in the intertidal zone and Brosnan (1992) concluded that these grazers were primarily responsible for patterns of algal distribution and abundance. Fishes as consumers in temperate rocky shores have a much more limited role when compared to fishes in tropical rocky shores. The author points that, where grazing fishes are abundant (i.e. in the tropics), algal growth rates will not compensate for herbivory, and shores will appear barren or dominated by resistant crustose forms. In contrast to this prediction, recent findings in tropical rocky shores show that we cannot generalize the findings in Panama bay into other tropical rocky shore systems. In Brazil, rocky shores where fishes are abundant, show that basal species such as algae are not regulated or controlled by fish predation but mainly by competition among these species (Sauer Machado et al. 1996). Another study by Vinueza et al. (2006) demonstrates that consumer effects can be limited and highly variable while other physical factors such as changes in nutrient productivity as influenced by El Niño could exert a stronger influence on the community. Rilov and Schiel (2006a, 2006b) also demonstrated that in temperate rocky intertidal areas, fish and crabs can influence the cover of sessile invertebrates where subtidal reefs are found or near.

These different results on consumer driven effects on sessile preys in rocky intertidal shores reflect the need for more comprehensive tests of previous studies. Repeating similar studies in other parts of the world can give us an even more comprehensive view of such complex systems. Sometimes seemingly important mechanisms such as top-down control may actually be of less significance than other, indirect factors (Guidetti and Dulcic 2007). The general models of community organization such as those by Menge and Sutherland $(1976,1987)$ stand there for us to further develop or incorporate new factors and ideas. Most likely, not all the generalizations made would apply to tropical rocky shore systems given the complexity of such systems from consumers to habitat structure in general. Shima (1999) writes, "multiple processes can act together to determine the abundance of organisms and structure of communities."Although it is generally understood that natural populations fluctuate in abundance at different scales of space and time, few studies have scaled up their previous results in order to separate the factors that can be inherent or unique to such experimental settings. Context dependency is well understood but few investigators go on to continue and expand their previous investigations owing to resources and amenable study areas (Underwood and Petraitis 1993;Underwood 2000a; Benedetti-Cecchi et al. 2001). Scale up 
studies provide the possibilities to generalize findings over several regions or areas and times making the results more comprehensive and applicable to similar areas (Benedetti-Cecchi 2000; Benedetti-Cecchi et al. 2001).

\subsection{Background studies}

Various studies on consumer driven effects (Williams 1993a, 1993b, 1994; Kaehler and Williams 1996; Kennish et al. 1996; Nagarkar and Williams 1997; Hutchinson and Williams 2001 and 2003a) were already conducted in Hong Kong rocky shores but not to site level and shore level replications which can allow us to generalize on a much broader scale. In addition, although it is mentioned in most of the previous studies done in the area that fishes have no effect on these shores (see Kaehler and Williams 1996; Hutchinson and Williams 2001), caging experiments separating the effects of molluscs and fishes have not been demonstrated in the area. Previous studies by Williams (1993a, 1993b and 1994) showed that grazers do not exert strong influence on microalgal and macroalgal abundance at the midintertidal zone although this zone is known to be relatively more diverse in terms of grazer abundance and sessile algal preys (Hodgkiss 1984).

\subsection{Objectives of the research}

The main research goal of the study was to evaluate top-down control mechanism in regulating the shores during the winter season in Hong Kong and to pinpoint which consumer mainly affects the abundance of algae. A greater understanding of what regulates the community such as whether top-down control or bottom up or a combination of other factors affect the distribution and abundance of intertidal algae in these shores. To do so, we: (1) evaluated spatial and temporal variation in top down effect of molluscan grazers (2) quantified responses of benthic microalgae and macroalgae (3) quantified the density of grazers in each study site to determine grazer pressure (4) examined the effects of different consumers on algal abundance and distribution. Large-scale studies of grazing have been done on many shores in higher latitudes (Jenkins et al. 2001; Coleman 2002; Coleman 2006; Freidenburg et al. 2007) to examine this grazer alga relationship but most tropical rocky shore studies have been limited to single experiments. This experiment was therefore started 
to examine micro and medium scale variability of grazing and the influence of slow moving and fast moving consumers in tropical rocky shore algal communities at Cape d' Aguilar and Stanley shores, Hong Kong. It is hoped that by separating the effects of different consumer groups using the comparative experimental approach (Dayton 1971; Menge 1986a; Menge 1999; Menge et al. 2002) this will help us identify the major groups of consumers and species that can directly or indirectly impact the settlement, growth and distribution of algae. This approach allows us to directly compare sites, shores and treatments over a large area and to generalize results to similar shores. Here, the effects of molluscan grazers on benthic microalgae and macroalgae from four study sites nested on two shores were compared. Although limpets were abundant in the study area, our experiments did not focus only on limpets but included all possible herbivores as there are many other herbivores in the area which can cause and limit algal growth. This study focused on the following questions: 1) Do patterns found in previous studies (Williams 1993a, 1993b, 1994) in the area reflected in the present larger scale grazer-alga study? 2) How do top-down grazer effects vary at different spatial scales from smaller to larger i.e. by rock chips (microns) treatments-plots (tens of centimeters), sites (tens of meters) and shores (hundreds of meters to kilometers) 3) Which model best reflects the dynamics of this system-is it top-down, bottom up or both? 4) Which consumer group exerts the greatest effect on algal distribution and abundance? 5) Do fishes and crabs have any effect on algal community structure in these shores? 


\subsection{Materials and Methods}

\subsection{Study sites and conditions during set-up}

The field experiments were conducted at two localities in Hong Kong Island, one at Cape d' Aguilar marine reserve area and another at Stanley. On both locations two semi-exposed sites were selected and herbivore exclusion fences were installed at the midshore level. The site was determined as semi-exposed based on previous studies in the area by Kaehler and Williams (1996) and Hutchinson (1999) where previous shore level markings were left-out permanently with screwed plastic markers unto the rock. Whenever present, the band of Kyrtuthrix maculans served as an additional guide to install fences at the mid-shore level which is from 1.3 to 1.5 meters above Chart Datum. Sites used at the Cape d' Aguilar shore were chosen based on accessibility and logistics allowing a regular sampling period to be conducted. The mid-shore level was chosen based on previous studies in the area showing higher abundance and diversity of herbivores at this level (Williams and Morrit 1995; Hutchinson and Williams 2003a).

The Cape d' Aguilar sites were separated by 100 meter distance from each other and the Stanley sites by about 40 meters to ensure sites would be independent from each other. The two shores face the South China Sea directly and conspicuous bands of oysters and barnacles can be found in both locations. During the initial set-up, no visible erect macroalgal cover was observed in Cape d' Aguilar although some green turfs were observed growing patchily at the two sites in Stanley. A band of Kyrtuthrix maculans visibly separates the mid-shore level from the low shore level in Cape d' Aguilar site; no such bands can be seen in Stanley site except for the mixed barnacle and oyster bands found in the area. Moreover, the Cape d' Aguilar rocky shore has been part of the marine protected area of Hong Kong and monitored daily by the Agriculture, Fisheries and Conservation Department (AFCD) of Hong Kong since 1996.

Snorkel and Scuba dive assessments within the area have shown that there is a sizable biomass of fishes located within this reserve area. During a few times of the study period, we observed illegal fishers who entered and fished within the area. The Stanley rocky shores were assumed protected as this part of the Stanley shore is covered by the Stanley Prisons Authority of Hong Kong giving limited and private access to a few ones. The experiment was set-up just about the summer months would end in Hong Kong and the cool winter season 
would begin. This was done to keep the effect of thermal stress to a minimum level and to ensure that the observed changes in macroalgal cover would primarily be due to the effect of grazers.

During the study, grazer density was assessed before installing cages and fences in each area using ten $25 \times 25 \mathrm{~cm}$ quadrats randomly located in the midshore at $1.5 \mathrm{~m}$ above Chart Datum (C.D.). All treatment plots used were chosen based on the following criteria: 1) aspect of the treatment plot must be on a horizontal level $\left(0-30^{0}\right.$ slope $\left.) 2\right)$ no small rock pools within the plot and 3) no cracks and deep cut crevices (only a depth and width of $1-3 \mathrm{~cm}$ of crack was accepted).

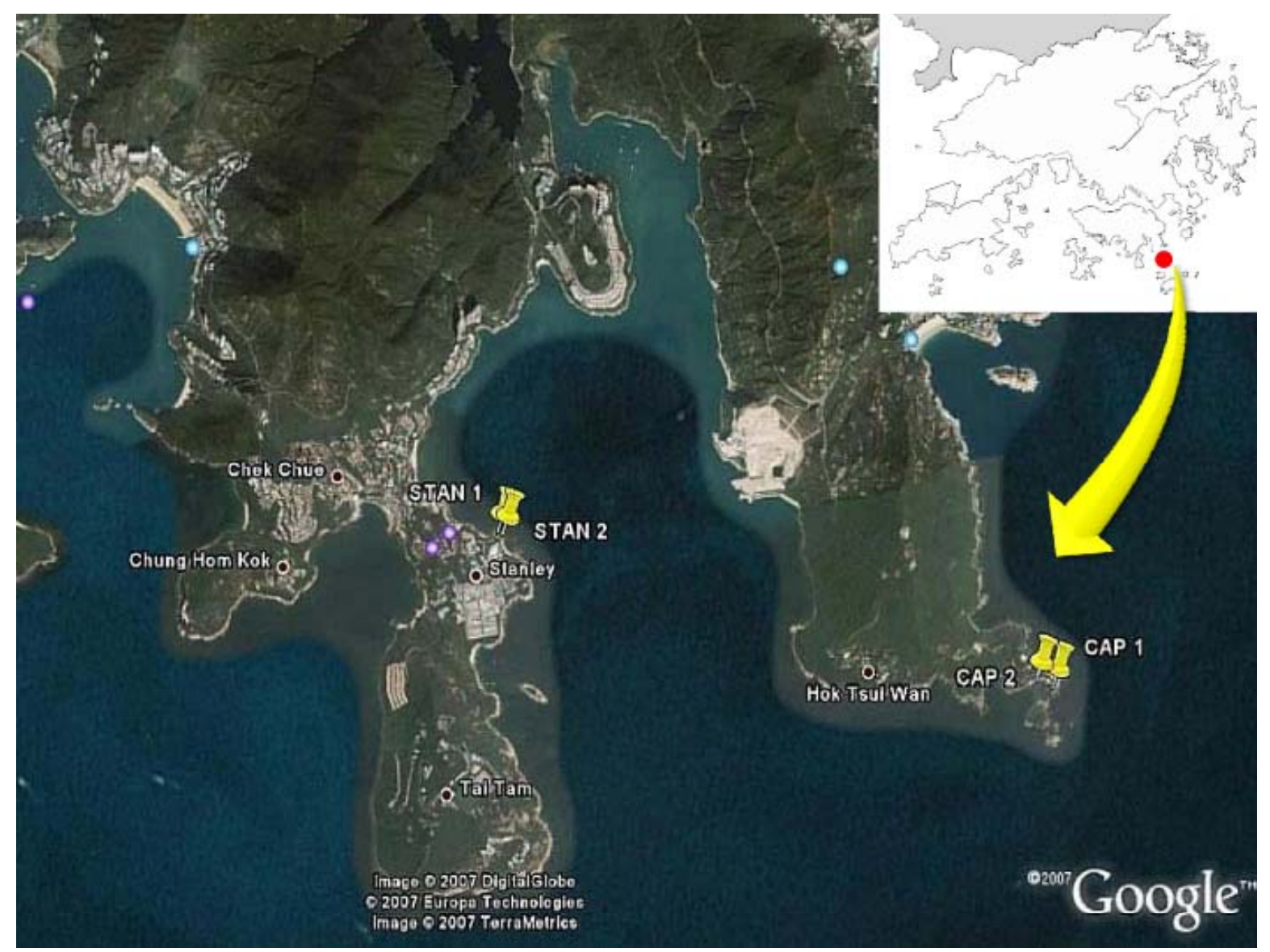

Fig. 1. Map showing the locations of the four study sites in Hong Kong Island. The yellow push pins show the location of sites within each study shore (CAP stands for Cape d' Aguilar and STAN stands for Stanley). 


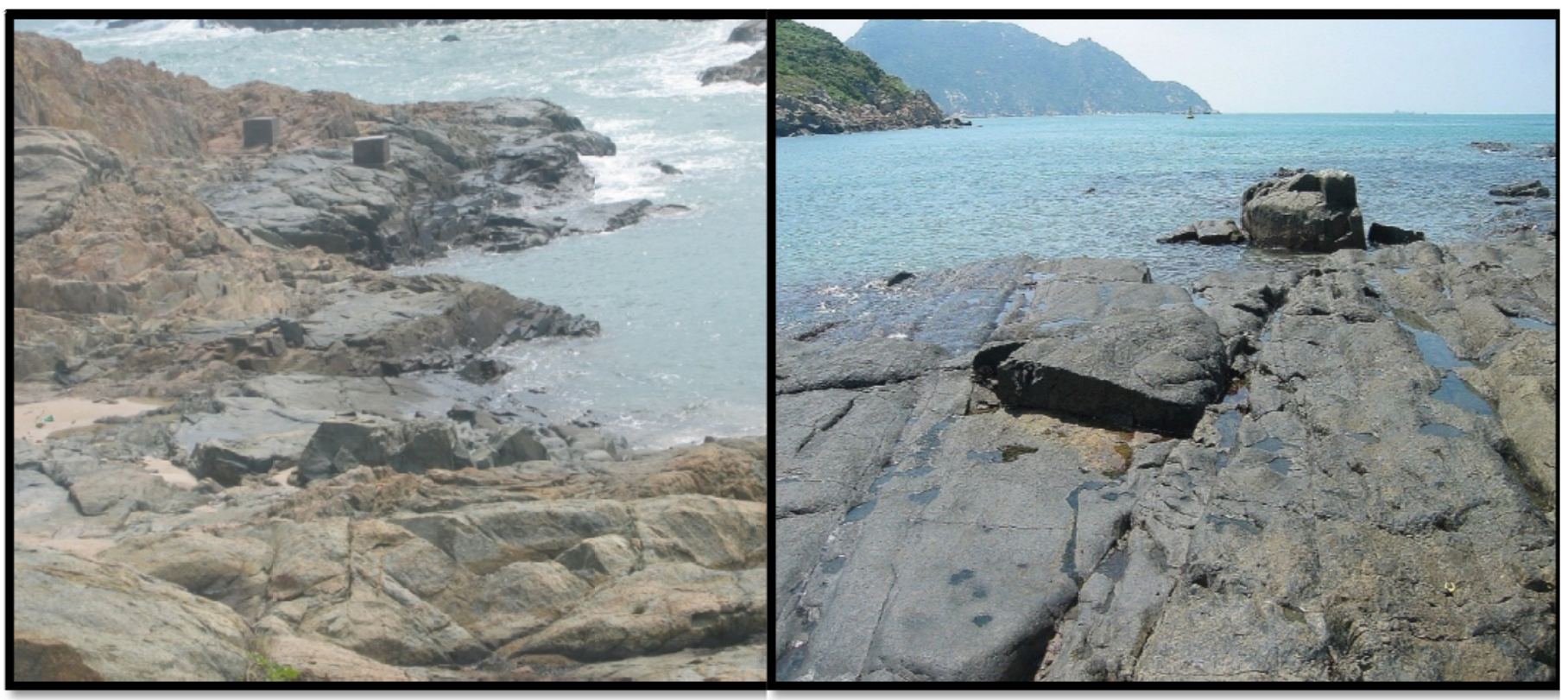

A. Cape d' Aguilar site 1

B. Cape d' Aguilar site 2

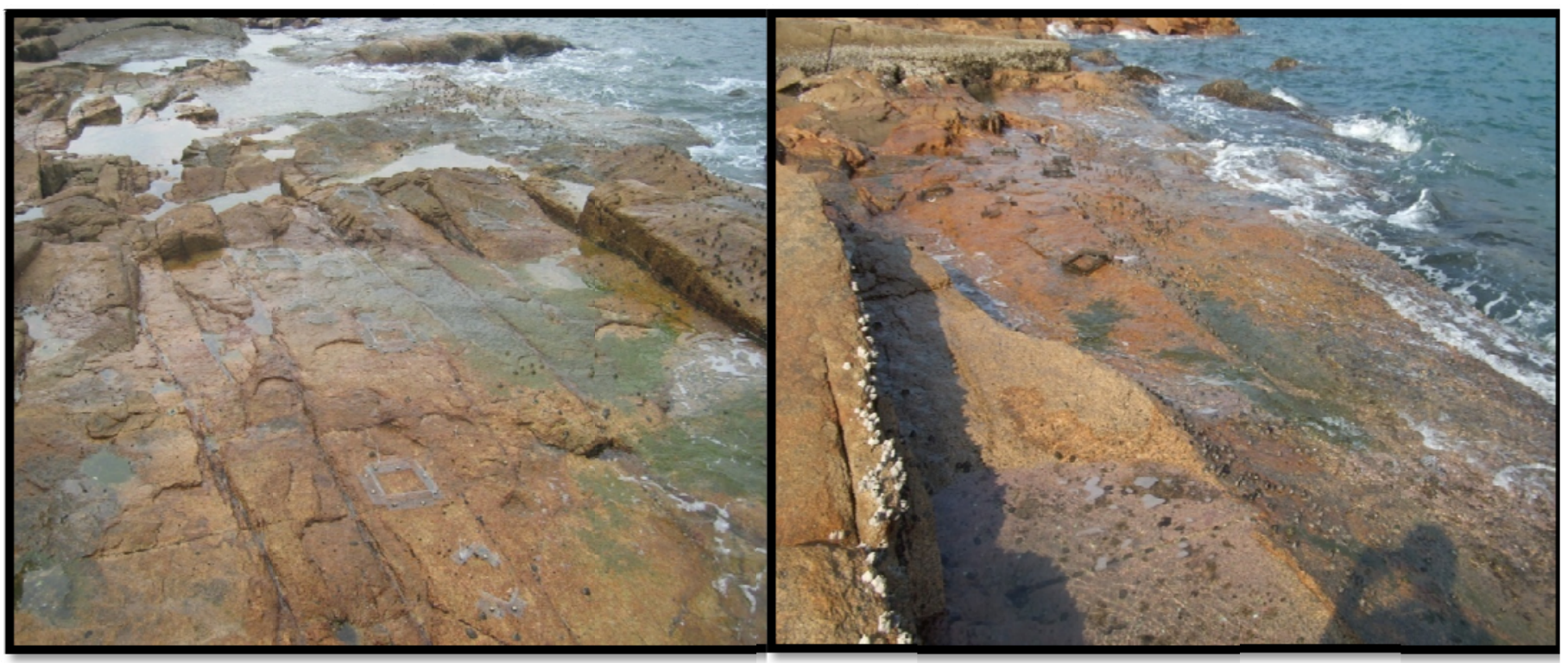

C. Stanley site 1

D. Stanley site 2

Fig. 2. A closer look of the four study sites; the two Stanley sites show some growth of green alga before the start of the experiment while the two sites at Cape d' Aguilar look conspicuously barren (treatment plots were located at the mid shore level). 
Table 1. Locations and positions of the four study shores

\begin{tabular}{|c|c|c|c|}
\hline Location & Shores & Position & $\begin{array}{l}\text { For further } \\
\text { descriptions } \\
\text { see: }\end{array}$ \\
\hline \multirow[t]{2}{*}{$\begin{array}{r}\text { A. Cape d' } \\
\text { Aguilar } \\
\end{array}$} & CAP 1 & $\begin{array}{l}22^{\circ} 12^{\prime} 25.89^{\prime \prime} \mathrm{N} \\
114^{\circ} 15^{\prime} 37.32^{\prime \prime} \mathrm{E}\end{array}$ & $\begin{array}{l}\text { Williams } 1993 \\
\text { and } 1994\end{array}$ \\
\hline & CAP 2 & $\begin{array}{l}22^{\circ} 12^{\prime} 27.33^{\prime \prime N} \\
114^{\circ} 15^{\prime} 33.02^{\prime \prime} \mathrm{E}\end{array}$ & $\begin{array}{l}\text { Williams } 1993 \\
\text { and 1994; } \\
\text { Nagarkar and } \\
\text { Williams } 1996\end{array}$ \\
\hline \multirow[t]{2}{*}{ B. Stanley } & STAN 1 & $\begin{array}{l}22^{\circ} 12^{\prime} 59.61^{\prime \prime} \mathrm{N} \\
114^{\circ} 13^{\prime} 12.30 " \mathrm{E}\end{array}$ & This study \\
\hline & STAN 2 & $22^{\circ} 12^{\prime} 59.15^{\prime \prime N}, 114^{\circ} 13^{\prime} 13.73^{\prime \prime E}$ & This study \\
\hline
\end{tabular}

\title{
2.2 Physical variables
}

\begin{abstract}
Air and sea temperatures, organic and non-organic nutrients including the mean sea chlorophyll $a$ and silica content of the water were taken from the records of Hong Kong Environmental Protection Department. These data were recorded in the nearest station adjacent to both locations and were plotted in graphs to detect whether nutrients and temperature were correlated in the two localities.
\end{abstract}

\subsection{Treatments}

\subsubsection{Grazer effect experiments}

There were two studies conducted, the first one deals mainly with the subject of spatial variation and grazing and whether grazing can affect spatial variation in algal communities in the rocky shore and as to what extent the observed variation can be attributed to grazing by molluscs. To answer questions related to the effect of herbivores on the relative abundances of sessile prey species and its biodiversity and compare the variation of grazing pressure in the study sites, three treatments were set-up on a rocky shore bench stretching at least 10 meters to each site. From October 2007 to March 2008, we studied grazer effects on the midshore of four study sites nested on two shores in Hong Kong Island. The four sites were Cape d' Aguilar site 1 and 2 (hereafter CAP1 and CAP2) and Stanley sites 1 and 2 (hereafter STAN1 and STAN2) and the two shores, Cape d' Aguilar and Stanley. In each site, 15 plots 
measuring $22 \times 22 \mathrm{~cm}$ were haphazardly marked and assigned randomly to three different treatments: fence, partial fence and open. The fence treatment has all of its sides closed $(5 \mathrm{~cm}$ high) and with $2 \mathrm{~cm}$ out-turned lip at the top meant to exclude all molluscan grazers or crabs that would attempt to enter through. To avoid any fence effects or to control for any artifacts, the procedural control has an L-shape partial fence which allows all molluscan grazers to freely enter its plot and the third treatment was a marked open area. Five plots were each assigned to these treatments. Exclusion treatments consisted of galvanized wire mesh (mesh size $=0.5 \mathrm{~cm})$ and were anchored into the substratum with stainless-steel screws inserted into rawl plugs in the rock.

Table 2. Treatments used in the study and their procedural controls

\begin{tabular}{|r|c|c|c|c|}
\hline \multicolumn{2}{|l|}{ Consumers } & Materials \\
\hline Treatments & Molluscs & Fish and crabs & Roof & Fence \\
\hline Fence & - & + & - & + \\
\hline Half-fence & + & + & - & - \\
\hline Open marked & + & + & + & - \\
\hline plot & & - & & \\
\hline Roof set-up & + & + & $1 / 2 *$ & - \\
\hline Roof control & + & - & + & + \\
\hline Cage & - & + & + & - \\
\hline
\end{tabular}

$*=$ half roof

$* *=$ half fence

\subsubsection{Consumer effects study}

The second study deals with consumer effects mainly to answer the question whether fishes or crabs or both can regulate the algal community. Hence, additional treatments (roofed 
fence or cage, roof and controls for cage and roof) were established at Cape d' Aguilar site 2 in tandem with the other three treatments already present. Five plots were each assigned and distributed randomly to cage, roof, cage control and roof control. This manipulation of consumers was established at the mid-shore level (1.5m above C.D.) and increased the number of treatments to seven at CAP2 (refer to Table 2 for summary list and Fig. 3. for photos of treatments). The two experiments ran from October 2007 to March 2008 and were maintained by fortnightly visits. During each visit, grazers found within exclusion treatments were counted and recorded to serve later in grazing pressure assessment of plots. Grazer counts on the shore were also conducted and digital photos of treatment plots were taken for scoring in the laboratory; all oxidized fences were replaced. 


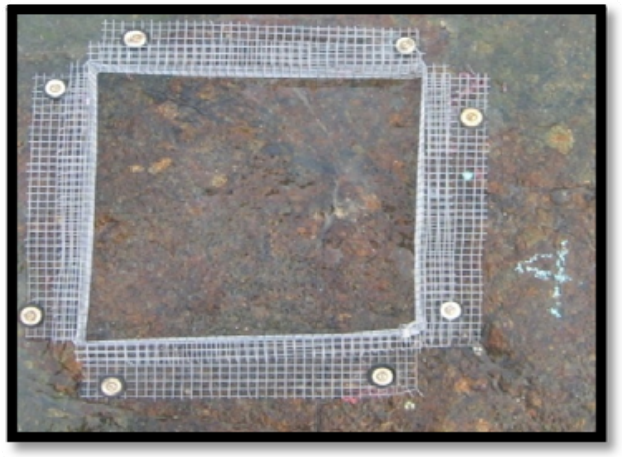

\section{Fence}

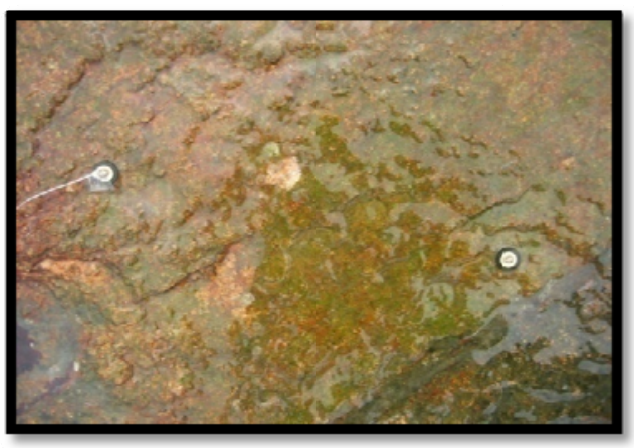

3. Open

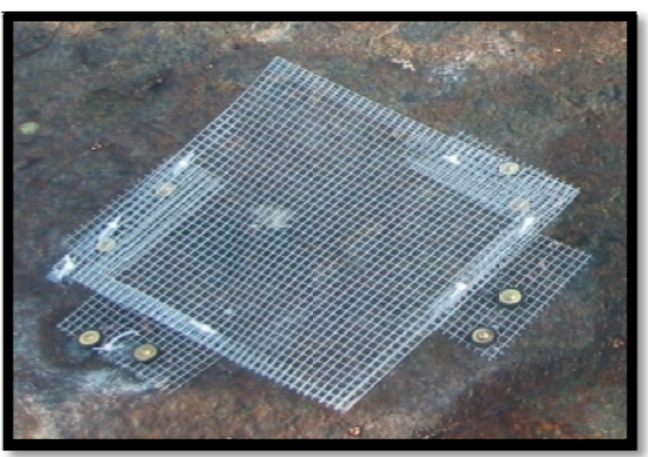

5. Cage control

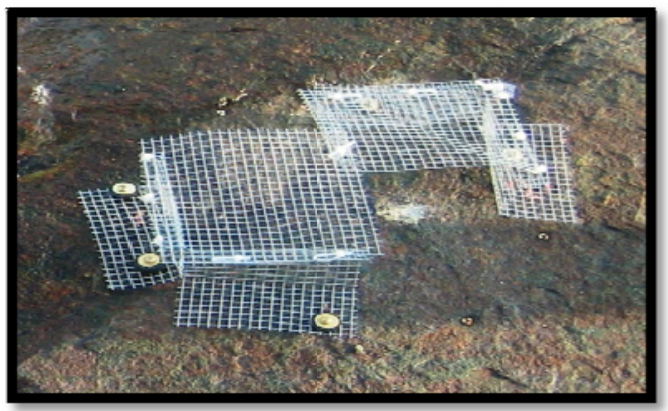

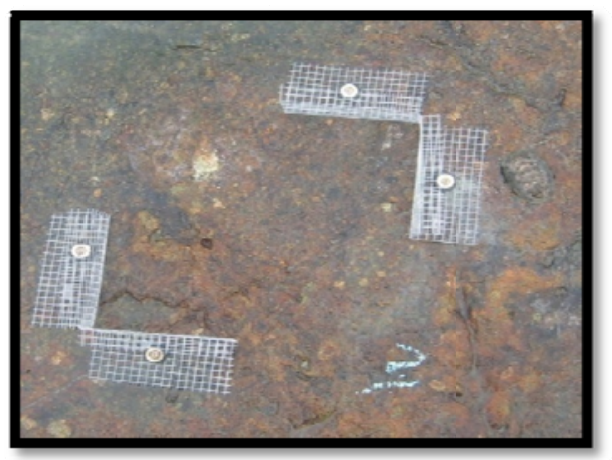

\section{Partial fence}

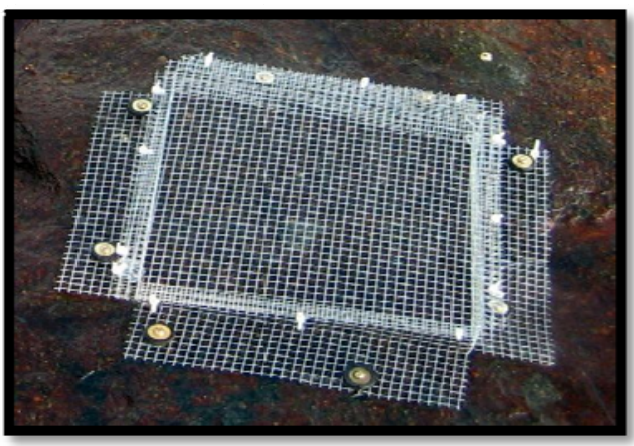

4. Cage

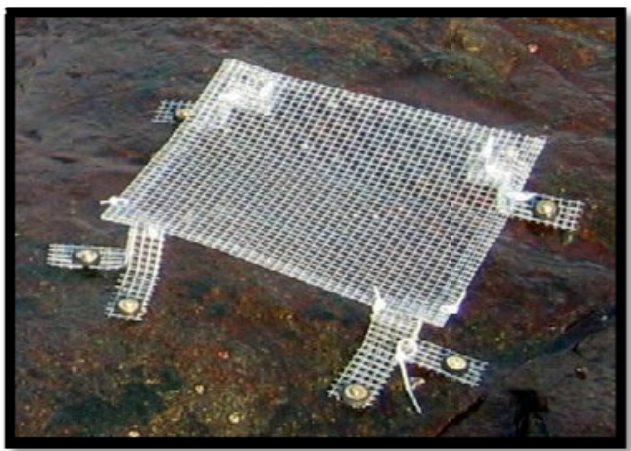

6. Roof

\section{Roof control}

Fig. 3. Photos of the seven treatments used in the study of separation of the effects of different consumer groups. The first three treatments were mainly used to study the effect of molluscan grazers on algal communities at the mid-shore level. 


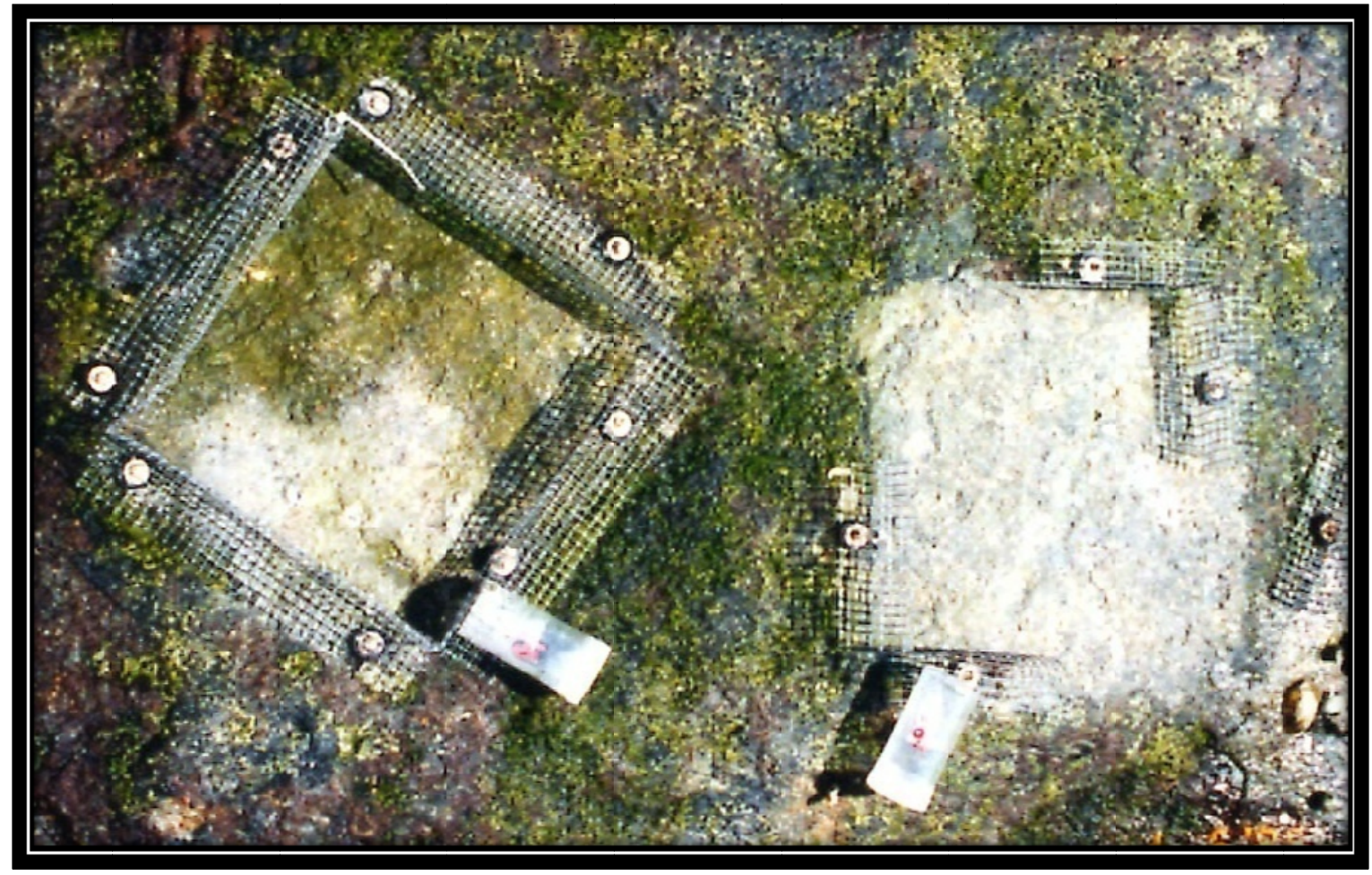

Fig.4. Overview of a fence set-up: each set-up is labeled and each study site mapped so that replacement of any missing fences or set-ups would be easier (photo courtesy of Dr. Gray Williams).

\subsection{Microalgal abundance}

During the initial stages of the experiment, measured chlorophyll $a$ values were taken as a means to indirectly count microalgal abundance and standing stock in each study site. This was done since biofilm cover can hardly be recognized during the initial months of the study; another reason was speedy scoring of treatment plots in the field can quite often lead to erroneous scores of biofilms when one can hardly recognize it. The sampling period for microalgal standing stock lasted for 60 days until visible microalgae can be scored in the field. Rock chips of the size $1-3 \mathrm{~cm}^{2}$ were randomly taken from the internal $20 \times 20 \mathrm{~cm}$ of each treatment plot at time zero (during set-up) and every after visit of 10 to 15 days until the 60 th day when recognizable erect filaments begun to appear in all study sites. The first appearance of erect algal cover occurred 2 weeks after the set-up but this was limited to two sites so that taking rock chips was continued until day 60. Chlorophyll $a$ was extracted using cold methanol (Nagarkar and Williams 1997) which allows more chlorophyll $a$ to be recovered after soaking the rock chips overnight inside the cooler. Absorbance reading of the 
resulting solution was taken at 665 and $750 \mathrm{~nm}$. The surface area of each rock chip was determined by wrapping around aluminum foil while carefully tracing around each edge and then removing the extra foil. This was then spread-out on a white paper, photographed and traced by using the CPCe software (Coral Point Count with Excel extensions) which can calculate the surface area (Kohler and Gill 2006). After this, the level of the chl $a$ was calculated per unit area of rock surface (see HMSO 1986 for details of calculations).

\subsection{Scanning Electron Micrographs and scoring of rock chip percentage cover}

Digital scanning electron micrographs (SEM) of rock chips were also taken to test and compare the total percentage cover of algae to that of the chlorophyll $a$ data. The same software used above was also utilized in scoring the percentage cover of the electron micrographs. In order to accommodate the maximum number of rock chips from each study site that covers all the period of sampling, and finish within the time available for SEM work, only three rock chips per treatment from each site were photographed instead of the original five rock chips per treatment. The number of field views photographed was also reduced into three to reduce cost of time and to assess all the rock chips from all sites. Due to this, the number of replicates and the number of fields photographed or observed per rock chip was also reduced to only three fields of views rather than five fields of views as planned earlier so all in all there are $3 \times 1$ rock chip x 3 replicates $\times 3$ treatments $\times 5$ sampling dates $=135$ field views per site. Fields were selected randomly on each examined rock chip and then photographed under 500X magnification using a Cambridge S440 Scanning Electron Microscope (Scanning electron microscope Stereoscan 440). The percentage cover of algae was then scored by overlaying a uniform grid of 50 points over each digital photograph using the CPCe software. All algal data codes used were customized based on the species present in all the study sites. As much as possible, these algal species are thrown into functional groups or broad groupings of algae (Littler and Littler 1980; Steneck and Watling 1982; Steneck and Dethier 1994) such as green algal turfs, diatoms, encrusting algae and free space for easier scoring, organizing and data processing. 


\subsection{Grazer pressure in the study sites}

Grazer abundance represents the abundance data taken from quadrat counts using a $25 \times 25 \mathrm{~cm}$ quadrat distributed randomly along a $10 \mathrm{~m}$ transect positioned parallel to the waterline in each study site. Data were taken during every visit or at least twice each month until December. In the data analysis of grazers, these were grouped into limpets, coiled gastropods, chitons and total grazers (this group includes all grazers plus other uncategorized grazers). Chitons had to be excluded from further variance analysis since this group does not satisfy the assumptions of normality of distribution and homogeneity of variances even after data transformations were applied.

\subsection{Aquarium observations}

To check if crabs and small fishes could enter the roof set-up, an aquarium observation set-up was put in place in the laboratory. All the procedural control set-ups were tested by using small blenny fishes which are commonly found in the area. All set-ups can be easily entered through by the small fishes. Entry of crabs to control set-ups was also tested by putting them in tanks containing the procedural controls. Results show that these set-ups can be entered through by the crabs easily. Moreover, personal, direct field observations were also done by keeping a 10 meter distance from the set-ups. Personal observations confirm that the crab Grapsus albolineatus can easily enter through any roof set-up including the other control setups. This crab is the main herbivore crab in the study shores which has been a subject of another study done previously so I do not need to discuss it further here (Kennish and Williams 1996).

\subsection{Data analyses}

Univariate analyses were done using multifactorial mixed model ANOVAs. The Kolmogorov-Smirnov test was used to check for the normality of data and Cochran's test was used to test for the homoscedasticity of variance. Whenever needed, data transformations were done in order to satisfy the assumptions of ANOVA. In some cases where it is impossible to get a normally distributed data (even after applying data transformations) but 
variances are homogeneous, data were still analyzed with ANOVA as ANOVA models are robust to moderate violations of the assumptions of ANOVA given large sample sizes and number of treatments (Underwood 1997; Williams et al 2000; Quinn and Keough 2002; Benedetti-Cecchi et al 2003). The software packages STATISTICA 7 (Statsoft, Tulsa, Oklahoma) and Systat 12 (Systat Software Inc., San Jose, California) were used in the data analyses.

To test for the effects of grazers on microalgal abundance and standing stock (chlorophyll $a$ ), a three factor ANOVA was used but interactions of the three factors were not tested. The three factors were site, time and treatments. All analyses were balance and tested for normality of distribution and homoscedasticity of variances (Cochran's test, $P>0.05$ ); when normality of distribution was violated this was $\log$ transformed to the form $\log (\mathrm{Y}+0.1)$ as used in a previous study (Williams 1994). Student-Newman-Keuls (SNK) post hoc multiple comparisons were used to determine whether means of the treatments differed. To test the hypothesis that grazing causes barren appearance for these shores and sites first at the microassemblage level (hundreds of microns) and then at the macro-assemblage level (size of adult plant), the percentage cover data (rock chip algal cover and treatment plot algal cover) of different groups of algae were analyzed using a nested model ANOVA. Sites were nested within shores, time was nested within sites and treatment was nested within time. A t-test was used to compare between shores, sites and treatments using the macro-assemblage cover data and SNK tests were used for multiple comparisons tests of treatments that differ. To check for the effect of grazing on diversity, Shannon's and Simpson's diversity indices were calculated for the macro-assemblage data using PRIMER-E software (Roborough Plymouth, UK). A two way ANOVA test was used with site and treatment as factors to test for possible effects of grazing on diversity.

To find out how shores, sites and fenced treatments differ in terms of grazing intensity, a three way ANOVA was used with site and time as the main factors and a SNK test was then performed to compare the means of significant factors. Initial observations during the sampling period showed that exclusion fences found in STAN1 and STAN2 sites were not efficient in excluding grazers. Since these tiny grazers can affect the outcome of the experiment in the short and long term, grazers found inside fences were recorded and analyzed for their effects on algal growth. For purposes of statistical analyses, only the data of grazer infestation from STAN1 and STAN2 were analyzed for their effects on algal cover 
to check if these organisms are the main cause of lack of obvious visual cover in fence treatments in these two sites. Differences across sites and time were tested using two-way ANOVA model to assess the responses of limpets, coiled gastropods and total grazers. Data were transformed by $\log (\mathrm{Y}+1)$ to meet the assumptions of normality and homogeneous variance. SNK tests were also performed on significant factors. Spearman and Pearson correlations were performed between groups of intruding grazers (limpets, littorinids and coiled gastropods) to chlorophyll $a$ and rock chip cover found in the fence treatments at Stanley. A Pearson correlation between treatments (fence, partial fence, open) and the physical factors (temperature, sunshine and total evaporation) was also calculated to check for other contributory causes and relationships of chlorophyll $a$ decline in some of the sites. Chitons (Acanthupluera japonica), another group of grazers, were not included in the analysis since it violates both the assumptions of normality and homogeneous variance.

To test the null hypothesis that fishes and crabs do not contribute to grazing pressure in the area and thereby do not control the algal assemblage in these shores, a two factor ANOVA was used to analyze rock chip algal cover (to test effects on micro-assemblage) and treatment plot (to test effects on macro-assemblage) using time and treatments as factors. SNK tests and Tukey HSD (honestly significant differenced) tests were then performed on factors which were significantly different.

\subsection{Multivariate analyses}

Although univariate statistical tests would be sufficient to show variation between treatments, a more visually compelling analysis using nMDS (non-metric multidimensional scaling) plots would better illustrate differences occurring each month in each treatment. In this way, succession occurring in each plots and interactive effects between factors can be assessed using ANOSIM. Thus, monthly plots of similarities in assemblage recruitment of all study sites were graphed to detect clusters and spatial variations in each site. The Global $R$ values from tests across sites and across treatments were then tabulated. Significant factors were further analyzed by pairwise comparisons between sites and treatments using ANOSIM $R$ values which were then summarized in a table. The $R$ statistic calculated using ANOSIM is known to be useful for comparative measure of the degree of separation between treatments and it is used here in that context (Clarke 1993; Anderson and Underwood 1997). Primer E 
for Ecologists software package was used for multivariate data analyses such as nMDS plots of assemblage structure for the four study sites and ANOSIM for a more specific pairwise comparison of sites and treatments and dates. 


\subsection{Results}

\subsection{Effects of removal of molluscs on microalgal abundance}

ANOVA results of measured chlorophyll $a(\mathrm{chl} a)$ values showed significant differences across sites, sampling times and treatments (Table 3). The fence treatments were effective in preventing access of grazers in the study sites during the whole duration of chlorophyll $a$ sampling. Moreover these significant differences suggest that there is high spatial variability of microalgal standing stock between treatments, sites and even during the sampling dates. Multiple comparisons using SNK tests of sites reveal that CAP2 has the highest mean chl $a$ $(0.80 \mathrm{ug} / \mathrm{cm} 2)$, followed in descending order by STAN1, CAP1 and STAN2. Comparison between treatments shows that fenced treatments have the highest mean chl $a(0.6379 \mathrm{ug} / \mathrm{cm} 2$ $\mathrm{p}<0.05)$ values in all sites. The second week of sampling yielded the highest mean chl $a$ values compared to all other periods of sampling $\left(0.661 \mathrm{ug} / \mathrm{cm}^{2}\right)$.

Table 3. Comparison using 3-way ANOVA of Chlorophyll $a$ on 4 sites (Sites CAP1 to STAN2), on five sampling times (dates) during winter 2007. Significant differences are shown in bold. $\mathrm{Si}=$ sites, $\mathrm{Ti}=$ time, $\mathrm{Tr}=$ treatment

\begin{tabular}{|ccccc|}
\hline Source & df & MS & $F$ & $p$ \\
\hline $\mathrm{Si}$ & 3 & 26.107 & 39.444 & $\mathbf{0 . 0 0 0 0}$ \\
$\mathrm{Ti}$ & 5 & 7.570 & 11.436 & $\mathbf{0 . 0 0 0 0}$ \\
$\mathrm{Tr}$ & 2 & 14.674 & 22.170 & $\mathbf{0 . 0 0 0 0}$ \\
Error & 320 & 0.662 & & \\
Total & 330 & & & \\
\hline
\end{tabular}

Cochran's C test $=0.1998, \mathrm{p}>0.05$

Graphical presentation of chl $a$ results shows increasing values or rising curve for the fenced treatment in CAP1 and CAP2. In contrast, a rapid increase and decrease punctuates the graphical charts of STAN1 and STAN2 (Fig. 5.). This rapid decline of chl $a$ in the two Stanley sites could be due to two factors (1) physical factors i.e. effects of heat and desiccation during low tide or (2) biological factors i.e. grazing or relatively low recruitment. If this is due to physical factors such as heat stress or exposure to high temperatures, examination of relationships between the physical factors such as temperature and total bright sunshine hours and microalgal abundances should show at least a significant negative correlation even just at one point in the time of sampling. And if this is due to a biological factor such as the effect of grazing, this low density of chl $a$ would be reflected in rock chip 
algal cover as well as treatment plot cover. Furthermore, if this is due to low recruitment of algae, the open treatments and general observations in the shore should show that virtually, no turfs or foliose algae should be recruiting. This third reason was discounted as even before the set-up, green algal turfs in nearby areas can be observed growing in patches. The first and second arguments for explanation of the variable microalgal density in the two Stanley sites will be further explored using the results from grazer pressure within fenced treatments and within transects as well as the treatment plot covers. Each of these results would provide evidence for the second argument or nullify it.

\section{Cape d' Aguilar site 1}

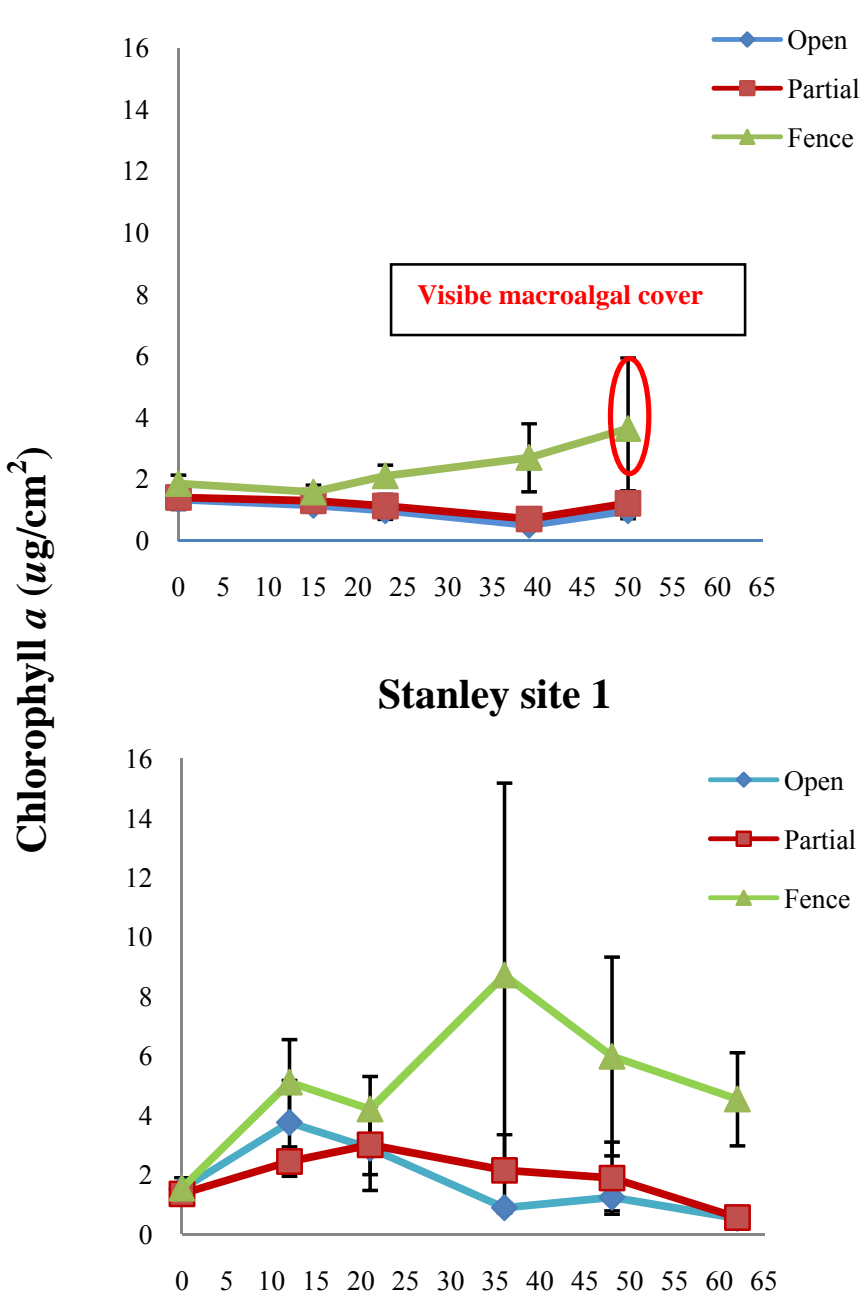

\section{Cape d' Aguilar site 2}

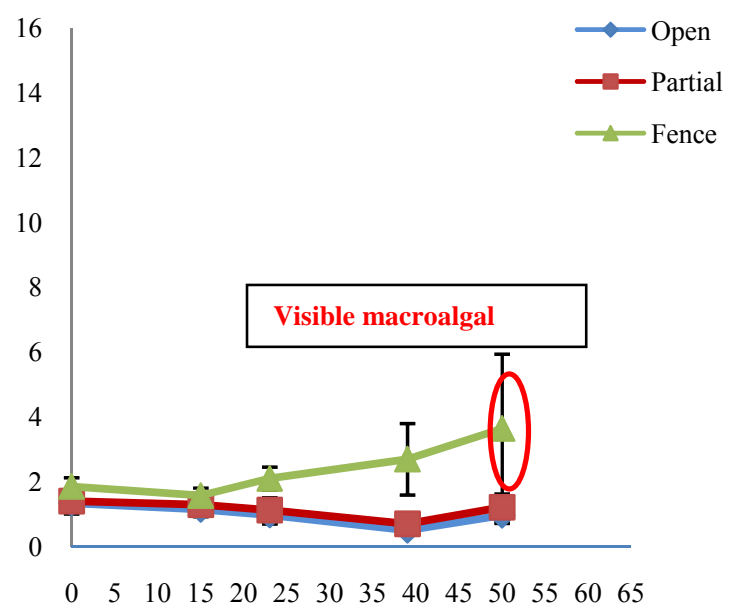

Stanley site 2

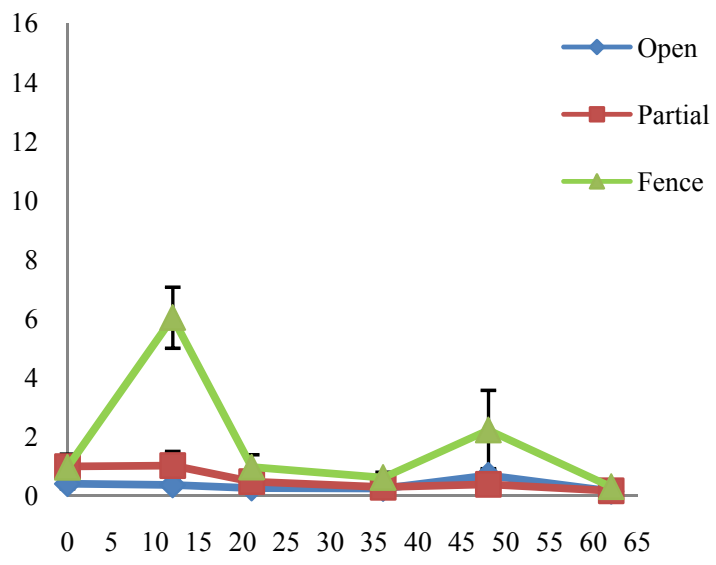

Time (Days)

Fig.5. Microalgal abundance in the four study sites as measured using chl $a$. (Error bars represent \pm SE). Rise and fall of fence treatment values reflect the effect of grazing intruders in the two sites of Stanley site 1 and site 2 (see discussion for further explanation). Note the differing initial values showing the relative abundance of biofilm in each site at the beginning of set-up. 
Our results showed that microalgal standing stock is primarily determined by grazing in these shores and sites (Fig. 5 and 6; Tables 3 and 4). Although shore differences were not significant, site, time and treatment differences were all significant. Site differences may mainly come from differences between the two Stanley sites and the two Cape sites i.e. higher chl $a$ concentration found in the two Cape sites compared to the two Stanley sites. Treatment differences can be attributed to sudden release of grazer pressure in fenced treatments causing an immediate change and increasing the number of sporelings that survived. The open and control treatments showed no statistical difference between each other which means that there was no cage effect in our treatments to influence algal recruitment or to dampen water flow inside our fences. It is presumed that the wire barrier protected algal sporelings from being eaten by limpets and other grazers.

\subsection{Effects of fishes and crabs on microalgal abundance}

Table 4. Comparison using 2-factorial ANOVA of Chlorophyll $a$ among seven treatments to separate the effects of fish and crabs on microalgae during winter 2007. Significant differences are shown in bold. $\mathrm{Ti}=$ time, $\mathrm{Tr}=$ treatment

\begin{tabular}{|ccccc|}
\hline Source & df & MS & $F$ & $p$ \\
\hline $\mathrm{Ti}$ & 4 & 1.576 & 4.841 & $\mathbf{0 . 0 0 1 1}$ \\
$\mathrm{Tr}$ & 6 & 1.907 & 5.857 & $\mathbf{0 . 0 0 0 0}$ \\
$\mathrm{Tix} \mathrm{Tr}$ & 24 & 0.482 & 1.480 & 0.0837 \\
Error & 140 & 0.326 & & \\
Total & 174 & & & \\
\hline
\end{tabular}

Cochran's C test $0.1005, \mathrm{p}>0.05$

A two-factor ANOVA model separating the effects of different consumer groups such as fishes and crabs on microalgae showed highly significant differences of microalgal abundance across time and treatments $(p=0.0011, p=0000$; Table 4$)$ but not the interaction of time and treatment. SNK tests showed that significant time differences were due to increased microalgal abundance since the initial set-up. SNK tests of significant differences in treatments showed three overlapping groups, cage $\geq$ fence $\geq$ roof $=$ open $=$ control treatments. The cage treatment has the highest overall microalgal abundance followed by the fence treatment $\left(1.48 \mathrm{ug} / \mathrm{cm}^{2}\right.$ and $\left.1.28 \mathrm{ug} / \mathrm{cm}^{2}, \mathrm{p}<0.05\right)$ while all the other treatments fall into the range of $0.069-1.062 \mathrm{ug} / \mathrm{cm}^{2}$. The cage control and the open treatments registered the least among all treatments $\left(0.069\right.$ and $0.818 \mathrm{ug} / \mathrm{cm}^{2}$ at $\left.\mathrm{p}<0.05\right)$. Although cage and fenced 
treatments overlap as a group, the cage treatment (Fig. 6) showed a consistent trend of increasing value compared to all the other treatments. Field observations also confirmed that cage treatments have the highest algal cover compared to all the other treatments and reached to more than 50\% algal cover before the fence treatments did (refer to Fig.15 and 16). The succeeding results of rock chip algal cover should confirm this. Shading effects due to artifacts were not considered here since control treatments for cage and roof treatments have the same or similarly the same values of chl $a$. This would mean that differences in microalgal abundance between the fenced treatments and that of the cage treatments would be interpreted alone as due to effects of grazers on algal sporelings that can dislodge and bulldoze such microalgae growing on the rock surface.

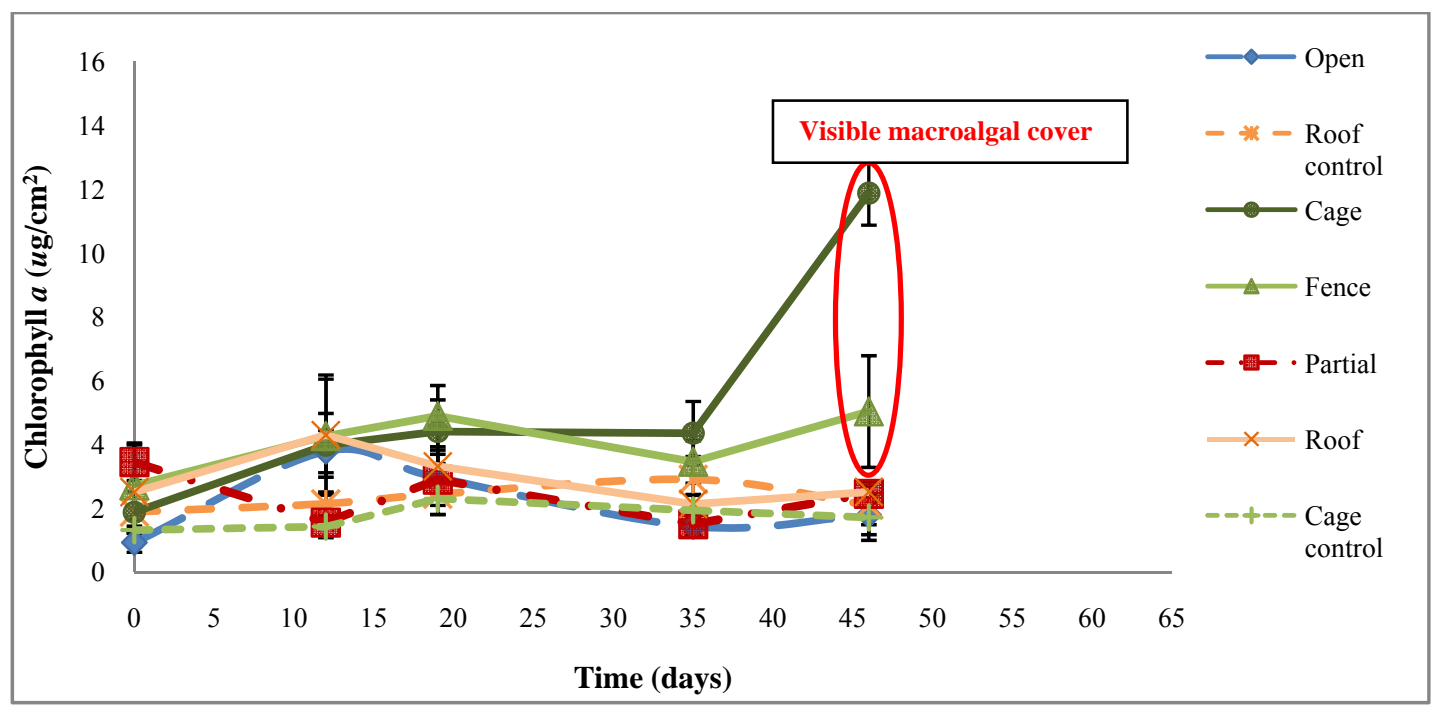

Fig.6. Mean chlorophyll $a$ concentration $( \pm \mathrm{SE})$ for the seven treatments in the first two months of study to estimate the biofilm standing stock

\subsection{Physical variables}

Although environmental factors were not being investigated directly, some available data on temperature, total bright sunshine hours and total evaporation and amount of cloud cover were gathered. The examination of relationship between microalgal abundance and the physical environment was needed in order to determine other probable physical factors which can significantly affect the microalgal standing stock in site. A Pearson correlation was therefore carried out between chlorophyll $a$ levels of all three treatments and air temperature, total bright sunshine hours and total evaporation. Results of Pearson's correlation coefficients for comparisons between microalgal abundances and the physical variables yielded negative 
correlations. Although there were negative correlations in all three factors examined, none were significant (Table 5). Physical factors are known to structure the algal assemblage especially during the summer season in Hong Kong shores (Williams 1993a; Kaehler and Williams 1996) the non-significance of correlations between physical factors and treatments confirm the reduced heat stress that so negatively affects the intertidal shores of Hong Kong during the summer. This is also reflected in the decreasing trend of air temperature and sunshine hours as well as increasing cloud cover from the beginning of set-ups on October 2007 until March 2008 (Fig. 7). Decreased temperature would translate to favorable conditions for algal growth as well as increased recruitment of these organisms as a direct result of such conditions in all shores.

Table 5. Pearson's correlation coefficients for comparisons between measures of microalgal abundance (chl $a$ concentration) and various physical variables at the four study sites.

\begin{tabular}{|cccc|}
\hline Treatments & Air Temperature & Sunshine hours & Total Evaporation \\
\hline Open & 0.24 & -0.08 & -0.02 \\
Partial & 0.16 & -0.13 & -0.01 \\
Fence & -0.19 & -0.06 & 0.12 \\
\hline
\end{tabular}



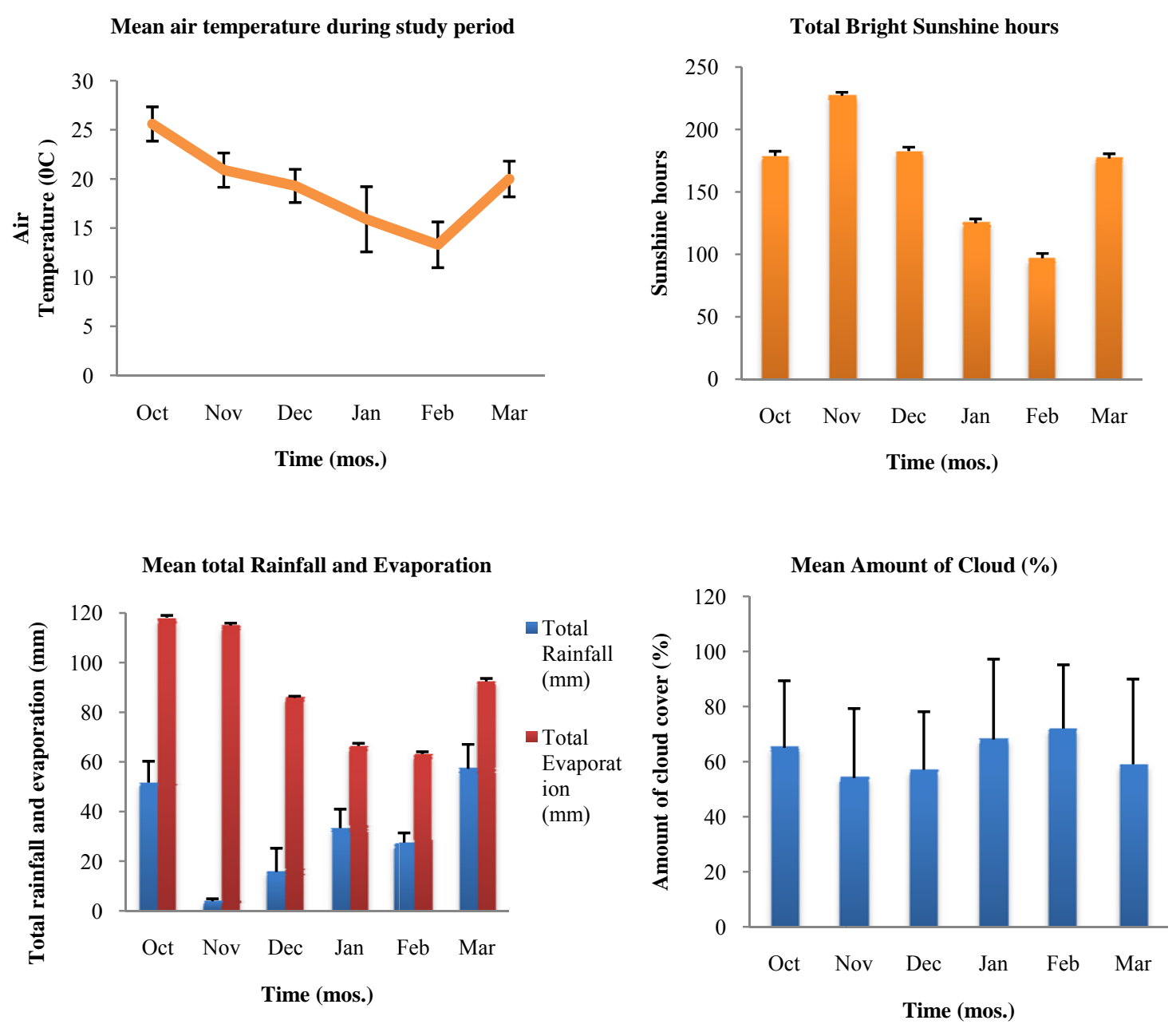

Fig. 7. Selected physical factors recorded during the field experiments that can potentially affect sites and treatments at Cape d' Aguilar and Stanley rocky shores, Hong Kong Island (courtesy of Hong Kong Observatory).

Water and nutrient parameters data were taken from the Hong Kong Environmental Protection Department (EPD). Graphs below (Fig. 8) show the average patterns of nutrients and water parameters for the two shores. Although nutrient data were not statistically tested with the current data chlorophyll $a$ and percentage cover of macroalgae, Stanley shows a higher concentration of nutrient data compared to Cape d' Aguilar and this was true for both the 8 year data and the recent 2007 data. Silica remains higher in Stanley for the winter 2007 and other nutrient parameter appears to be unchanged except for the orthophosphate which were both higher in the winter 2007 than the 8 year average. There was however higher turbidity during winter 2007 and slightly lower surface water temperature than the 8 year average. 

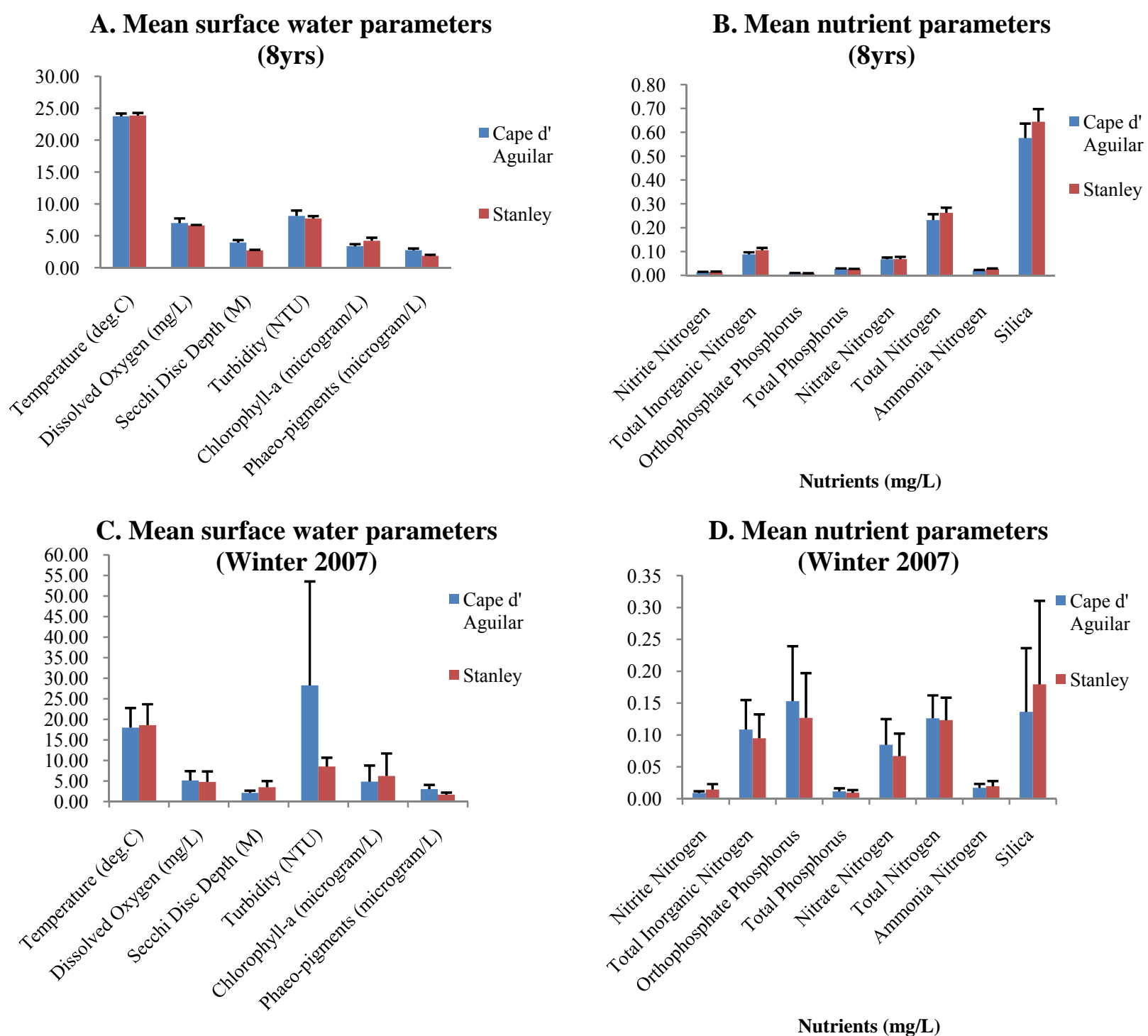

Fig. 8. Comparison of water and nutrient parameters data between the two shores of Stanley and Cape' d Aguilar collected from 1998-2006 ( $1{ }^{\text {st }}$ row, charts A and B above) and during the winter 2007 experiment $\left(2^{\text {nd }}\right.$ row, charts $C$ and $D$; note the change in scale). Bar on top represents mean of total counts, + SE. (Courtesy Hong Kong Environmental Protection Department).

Nonetheless, when the number of recorded grazer intruders in the fenced treatments in the Stanley sites was analyzed, the total number of grazers and the coiled gastropods were statistically significant by site; only the coiled gastropods were significant through time. The site differences were attributed to higher number of intruders in STAN1 than in STAN2 and this was also reflected in the temporal differences. This means that there were far more grazers recorded during the third week of visitation than during any other sampling dates.

When further explored through Pearson correlation, no relationship were found between chl $a$ and rock chip cover to that of grazer pressure (Table 9). 


\subsection{Grazer pressure in the study sites}

Table 6. Comparison using 2-way ANOVA for grazer abundance in the four study sites (Site) on different sampling dates (Time) during winter 2007. Significant differences are shown in bold.

\begin{tabular}{|lrccccccccc|}
\hline Source & df & \multicolumn{2}{c}{ Total limpets } & \multicolumn{4}{c|}{ Total coiled gastropods } & \multicolumn{3}{c|}{ Total grazers } \\
& & MS & $F$ & $\mathrm{p}$ & MS & $F$ & $\mathrm{p}$ & MS & $F$ & $\mathrm{p}$ \\
\hline Site & 3 & 54.871 & 11.563 & $\mathbf{0 . 0 0 0 1}$ & 17.896 & 3.731 & $\mathbf{0 . 0 2 8 0}$ & 51.460 & 20.422 & $\mathbf{0 . 0 0 0 0}$ \\
Time & 8 & 6.682 & 1.408 & 0.2528 & 1.175 & 0.245 & 0.9765 & 2.808 & 1.114 & 0.3950 \\
Error & 20 & 4.745 & & & 4.796 & & & 2.520 & & \\
Total & 31 & & & & & & & & & \\
\hline
\end{tabular}

Cochran's C test: 0.191 (limpets), 0.266(coiled gastropod), 0.248 (totgrazers), $\mathrm{p}>0.05$

Results showed that total grazers and limpets were both significantly higher $(p=0.0000$ and $\mathrm{p}=0.0001$; see Table 6) across all sites but not with time. SNK tests of sites revealed that CAP2 has the least count of total grazers $(5.02, \mathrm{p}<0.05)$ and STAN1 has the highest count $(11.24, \mathrm{p}<0.05)$ of total grazers. Limpet counts are highest at STAN2 $(8.15, \mathrm{p}<0.05)$ and least at CAP2 (2.61, $\mathrm{p}<0.05)$. Coiled gastropods did not differ significantly across all sites although CAP2 had the highest mean count at 4.01 followed by STAN1 at 3.9. Results also show that across all sampling dates (Time), grazer counts were not significantly different in all sites. Various grazer species were located at each site and Table 7 below summarizes the presence or absence of species in each site. STAN1 and STAN2 have more species present when compared to either CAP1 or CAP2. It also shows that CAP2 has the least number of species of grazers present. These differences would play a critical role in understanding the grazer pressure found in each site as the number of grazers and the species are also critical as this can dictate what will be the impact of the animals to the community (Hawkins and Hartknoll 1983; Vadas 1985). 
Table 7. List of species of grazers, presence/absence in the four study sites

\begin{tabular}{|c|c|c|c|c|c|}
\hline & Group/Species & CAP1 & CAP2 & STAN1 & STAN2 \\
\hline & Chiton & & & & \\
\hline \multirow[t]{2}{*}{1} & $\begin{array}{l}\text { Acanthupleura } \\
\text { japonica }\end{array}$ & $\sqrt{ }$ & $\sqrt{ }$ & $\sqrt{ }$ & $\sqrt{ }$ \\
\hline & Limpets & & & & \\
\hline 2 & Cellana toreuma & $\sqrt{ }$ & $\sqrt{ }$ & $\sqrt{ }$ & $\sqrt{ }$ \\
\hline 3 & Cellana grata & & & $\sqrt{ }$ & \\
\hline 4 & Siphonaria laciniosa & $\sqrt{ }$ & & $\sqrt{ }$ & $\sqrt{ }$ \\
\hline 5 & Siphonaria japonica & $\sqrt{ }$ & $\sqrt{ }$ & $\sqrt{ }$ & $\sqrt{ }$ \\
\hline 6 & Patelloida pygmea & & & $\sqrt{ }$ & $\sqrt{ }$ \\
\hline \multirow[t]{2}{*}{7} & Patelloida saccharina & $\sqrt{ }$ & & $\sqrt{ }$ & $\sqrt{ }$ \\
\hline & Coiled gastropods & & & & \\
\hline 8 & Lunella coronata & $\sqrt{ }$ & $\sqrt{ }$ & $\sqrt{ }$ & $\sqrt{ }$ \\
\hline 9 & $\begin{array}{l}\text { Chlorostoma } \\
\text { argyrostoma }\end{array}$ & $\sqrt{ }$ & & $\sqrt{ }$ & $\sqrt{ }$ \\
\hline 10 & Monodonta labio & & $\sqrt{ }$ & $\sqrt{ }$ & $\sqrt{ }$ \\
\hline 11 & Monodonta neritoides & & & & $\sqrt{ }$ \\
\hline 12 & Nerita albicila & $\sqrt{ }$ & & $\sqrt{ }$ & \\
\hline \multirow[t]{2}{*}{13} & Planaxis sulcatus & $\sqrt{ }$ & & $\sqrt{ }$ & $\sqrt{ }$ \\
\hline & Littorinids & & & & \\
\hline 14 & $\begin{array}{l}\text { Echinolittorina } \\
\text { radiata }\end{array}$ & $\sqrt{ }$ & & $\sqrt{ }$ & \\
\hline 15 & $\begin{array}{l}\text { Echinolittorina } \\
\text { trochoides }\end{array}$ & & & $\sqrt{ }$ & \\
\hline 16 & Echinolittorina vidua & & & $\sqrt{ }$ & $\sqrt{ }$ \\
\hline
\end{tabular}

Note: these grazers are the species encountered during quadrat counts near the set-ups. 


\section{CAP1}

CAP2

\section{October}

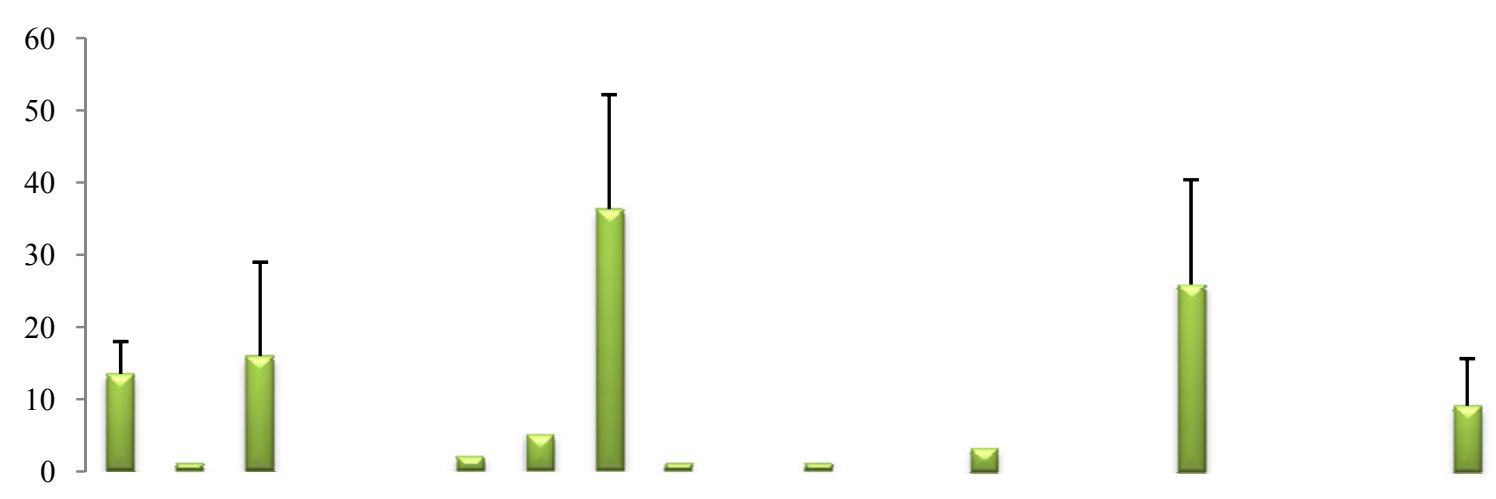

\section{November}

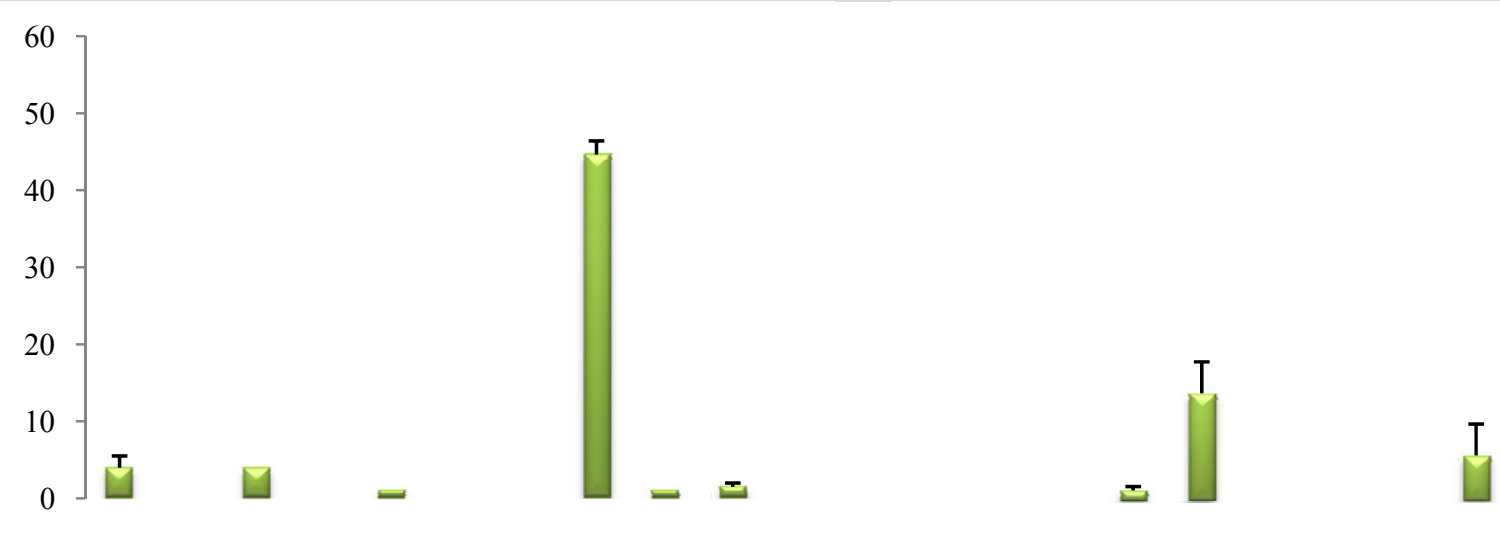

\section{December}
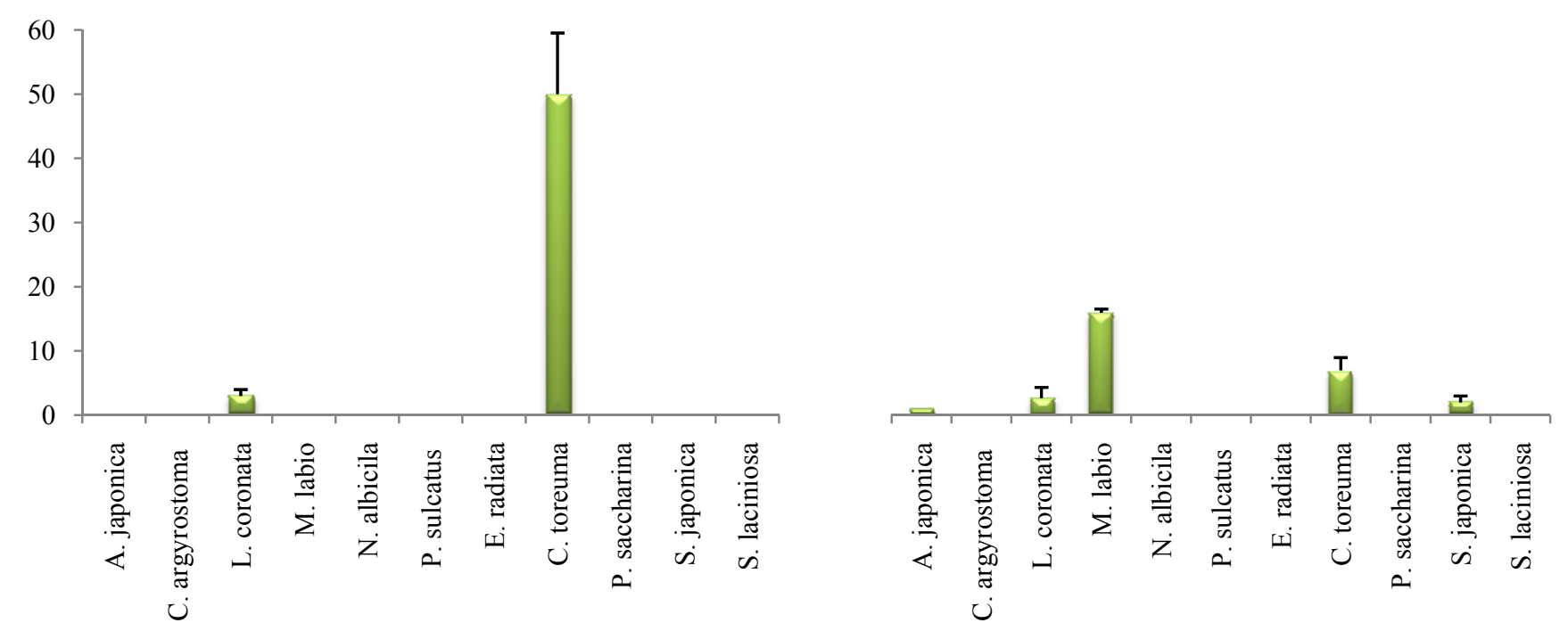

\section{Grazers}

Fig. 9. Different grazer species and abundance found in Cape d' Aguilar sites 1 and 2 (CAP1 and CAP2). In each site, two different grazers dominate with the limpet C. toreuma in CAP1, and the snail $M$. labio in CAP2. Bar on top represents mean of total counts (+SE) of molluscan grazers. 


\section{October}

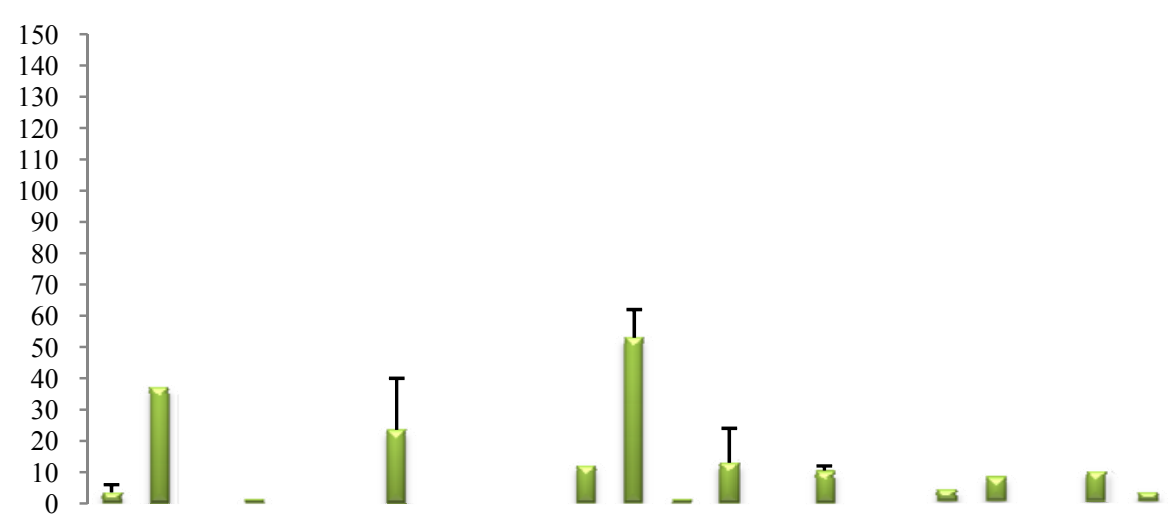

\section{November}
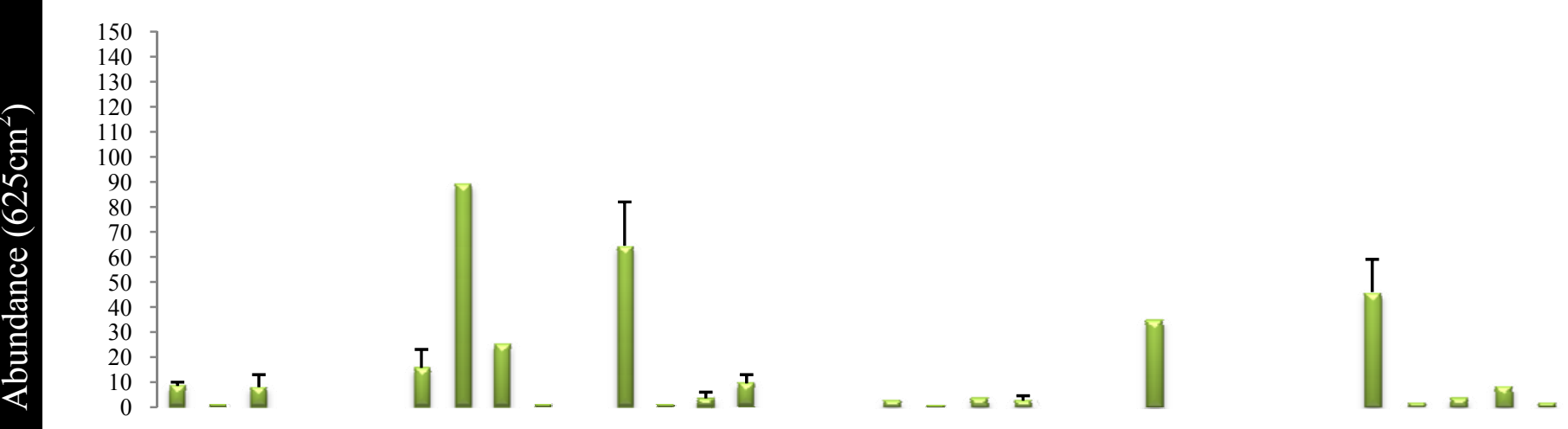

December
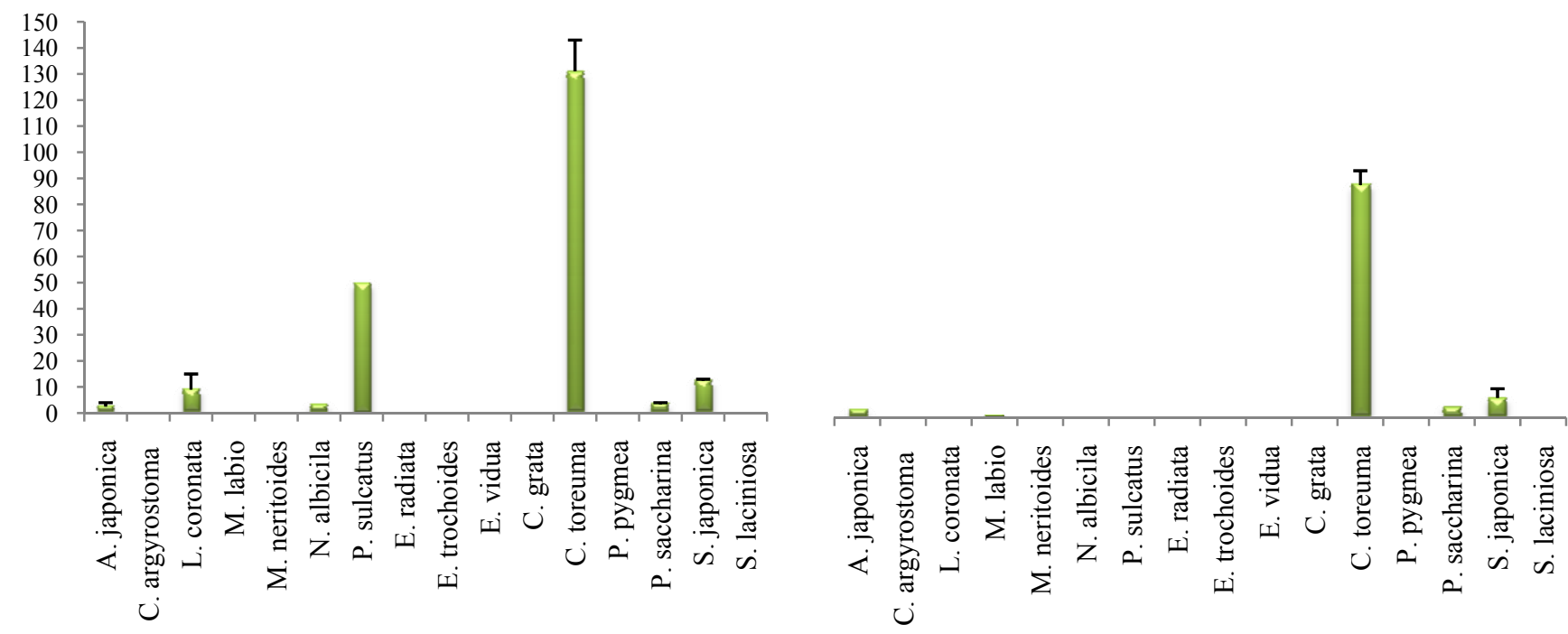

\section{Grazers}

Fig.10. Different grazer species and abundance found in Stanley sites 1 and 2 (STAN1 and STAN2). In both sites, the limpet $C$. toreuma dominates while two other small snails $P$. sulcatus and E. radiata follows closely. Bar on top represents mean of total counts $(+\mathrm{SE})$ of molluscan grazers. 
CAP1

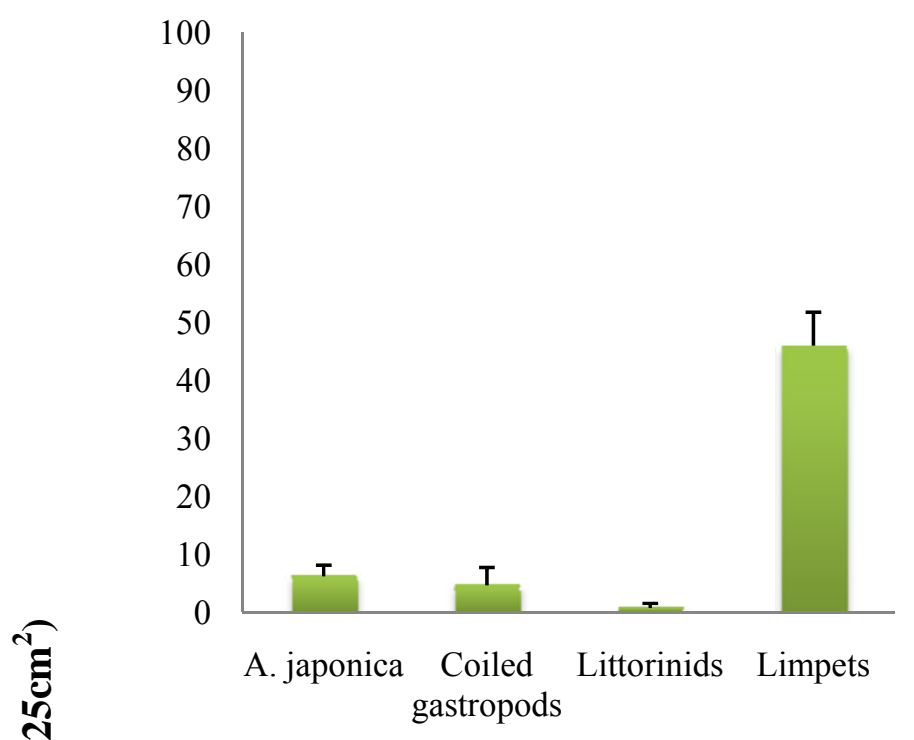

\section{STAN 1}

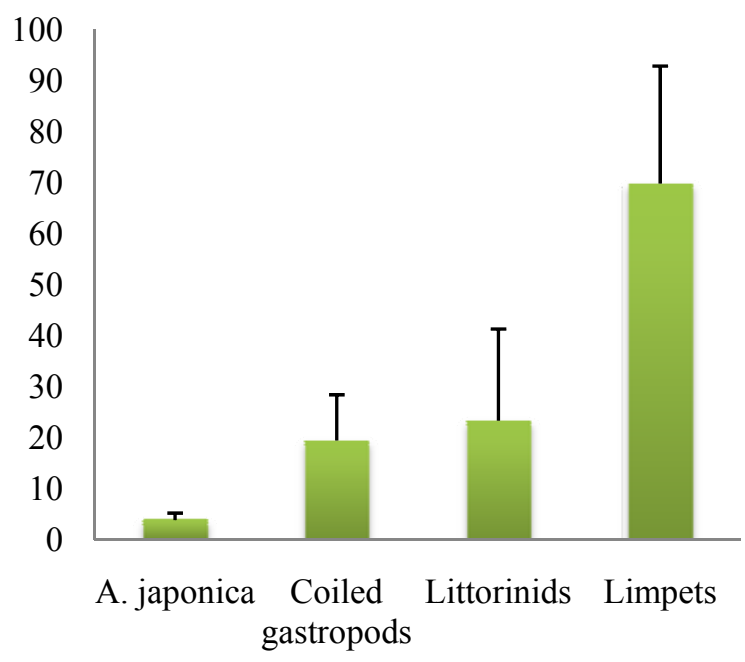

CAP2

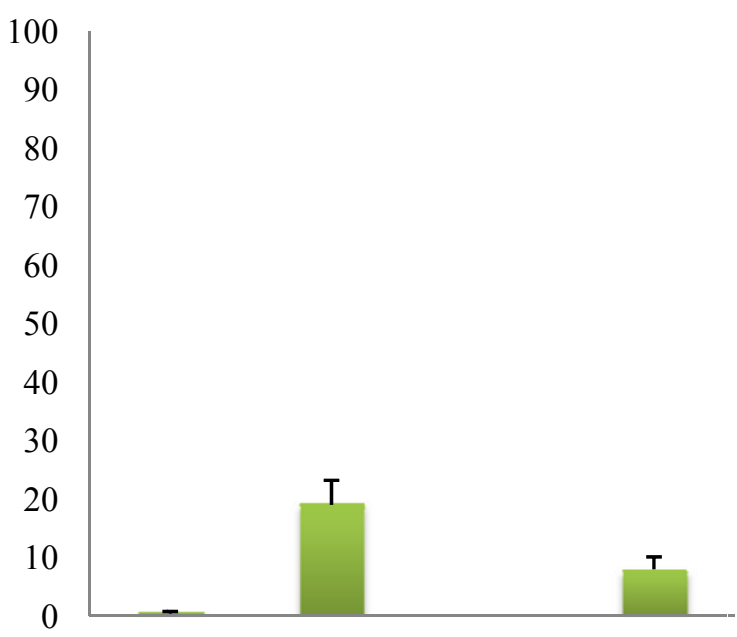

A. japonica Coiled Littorinids Limpets gastropods

STAN2

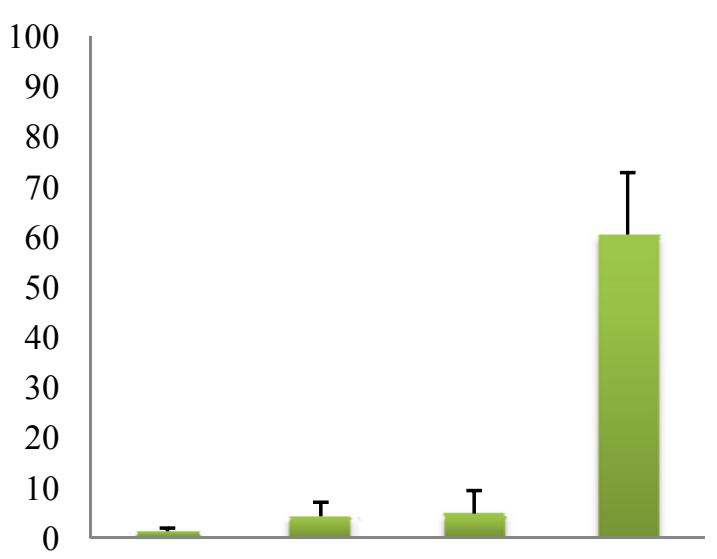

A. Coiled Littorinids Limpets japonica gastropods

\section{Groups of molluscan grazers}

Fig.11. Mean grazer abundance classified into different functional groups of grazers showing from October to December 2007 in the four study sites (CAP1 to STAN2). Bar on top shows mean abundance + SE.

The pattern of grazer abundance from Figs. $\mathbf{9}$ and $\mathbf{1 0}$ show that in each study site, the limpet

C. toreuma is the most abundant among all molluscan grazers except in CAP2 where the snail

M. labio dominates. This pattern is again reflected when all the other species are grouped together according to functional groups (Steneck and Watling 1982; Steneck and Diether 
1994) based on morphology and food resources as well as feeding apparatuses (Fig. 11). In the analysis, only limpets and total grazers were significantly different compared to coiled gastropods. The abundance of limpets compared to all the other molluscan groups would appear to indicate the higher grazing pressure arising from this group.

\subsection{Grazer intruders in fenced treatments}

As mentioned earlier, grazers which were able to move inside fenced treatments especially in the two Stanley sites were recorded to account for grazing pressure found inside fenced plots and to find if there were relationships between microalgal abundance ( $\operatorname{chl} a$ ) and grazing pressure. For the two Stanley sites, STAN 1 and STAN 2, either limpets or coiled gastropods dominate the composition of grazers found in these sites (see Fig.10). Fenced treatments found in these sites have the most number of recorded grazers during any sampling visit. The counts shown below (Fig. 12) were pooled from each fenced treatment found in each site as opposed to individually putting the different grazer species. Another reason is that counts inside fenced plots were patchy and variable; one species can be found during a date and on the next sampling date it is gone. To avoid this, all limpet species were pooled together as one group and other gastropod grazers were either placed under littorinids or as coiled gastropods. The most abundant species found inside fences is $P$. sulcatus followed by the limpet,C. toreuma, and the gastropod, M. labio.

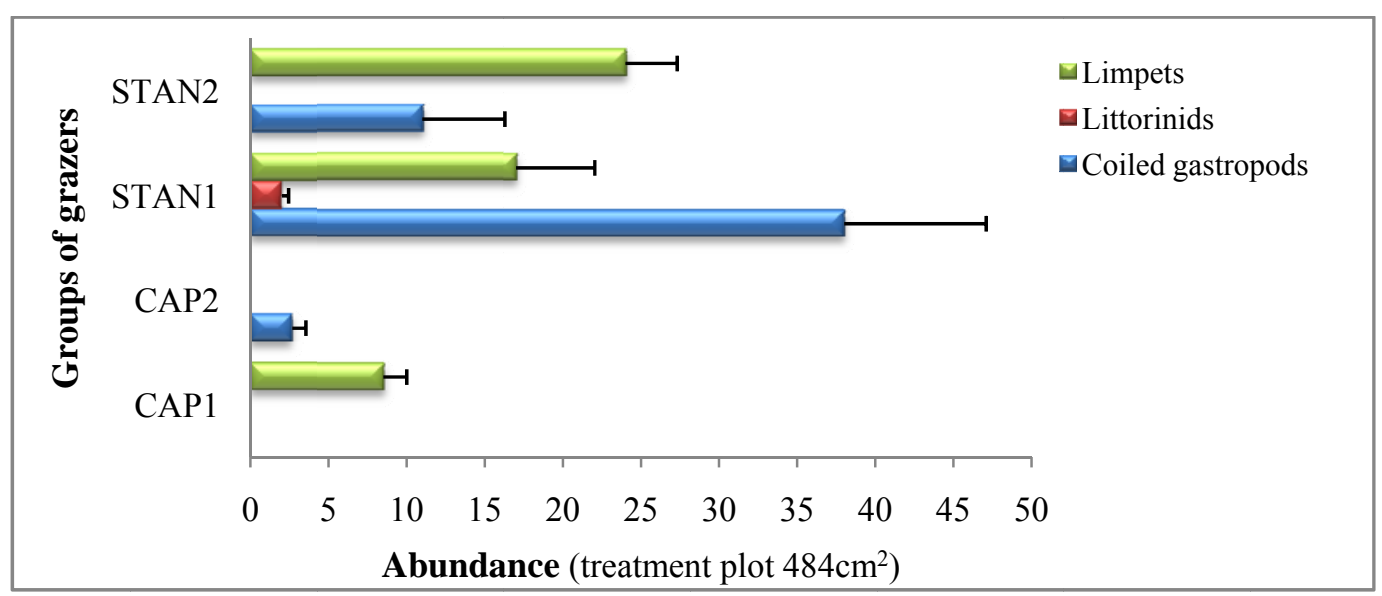

Fig. 12. Total mean abundance of grazers found inside fence treatments during the whole duration of experiment in each study site. Bar on top shows mean abundance $+\mathrm{SE}$. 
Although there were no previous studies in the Stanley sites for grazer recruitment, it is probable that at this time of the year, beginning October until the end of the winter season, this is the season for recruitment for most limpets and gastropods in the area due to the number of these organisms found settling inside the fenced treatments (pers. obs.). The sizes of most of these tiny grazers fall in the range of between 3 to $5 \mathrm{~mm}$ or about the same size as our mesh size of $5 \times 5 \mathrm{~mm}$. Beginning from the third visit (after three weeks), complete exclusion of most of these baby grazers (C.toreuma, $P$. sulcatus) was proving to be impossible. For one month after ending the set-ups in Cape d' Aguilar, foams were fixed underneath the exclusion treatments (fences) to exclude the grazers but apparently, grazers were still able to settle inside the fences. Thus, complete removal was impossible and this was reflected in the pattern of decline of chl $a$ values at the two Stanley sites (Fig.5) and lower rock chip and treatment plot algal cover (Fig.14, 18 and 19) throughout the duration of the experiment compared to the other two sites at Cape d' Aguilar (Fig. 13, 16 and 17).

Table 8. Comparison using 2-way ANOVA for grazer counts inside fenced treatments in two sites (STAN1 and STAN1) on different sampling dates (Time) during winter 2007 through January 2008. Significant differences are shown in bold.

\begin{tabular}{|c|c|c|c|c|c|c|c|c|c|c|}
\hline \multirow[t]{2}{*}{ Source } & \multirow[t]{2}{*}{ df } & \multicolumn{2}{|c|}{ Total limpets } & \multicolumn{4}{|c|}{ Total coiled gastropods } & \multicolumn{2}{|c|}{ Total grazers } & \multirow[b]{2}{*}{$p$} \\
\hline & & MS & $F$ & $\mathrm{p}$ & MS & $F$ & $\mathrm{p}$ & MS & $F$ & \\
\hline Site & 1 & 4.376 & 4.059 & 0.0906 & 30.284 & 30.628 & 0.0015 & 6.692 & 18.282 & 0.0052 \\
\hline Time & 6 & 3.161 & 2.932 & 0.1081 & 5.899 & 5.966 & 0.0236 & 1.323 & 3.615 & 0.0715 \\
\hline Error & 6 & 1.078 & & & 0.989 & & & 0.366 & & \\
\hline Total & 13 & & & & & & & & & \\
\hline
\end{tabular}

Cochran's C test: 0.693 (limpets), 0.290 (coiled gastropod), $0.323, \mathrm{p}>0.05$

ANOVA results for grazer counts inside fenced treatments showed that total grazers and coiled gastropods were significantly different $(p=0.0052, p=0.0015$; Table 8) in the two Stanley sites. Temporal differences of abundance counts in the two sites were recorded only for the groups of coiled gastropods $(\mathrm{p}=0.0236)$ but not limpets or total grazers. SNK tests show that coiled gastropods and total grazers were both more abundant in STAN1 site than in STAN2 site (5.86 vs 2.89, $\mathrm{p}<0.05 ; 7.62$ vs.6.24, $\mathrm{p}<0.05)$. SNK tests of significant differences in time show that there were more coiled gastropods recorded inside fenced treatments during the second and fourth week of sampling $(7.78,5.46 \mathrm{p}<0.05)$ than on any other weeks of sampling. A Pearson correlation matrix (Table 9) shows that grazer abundance (limpets, 
littorinids and coiled gastropods) were negatively correlated with chl $a$ values and rock chip algal cover (SEM) for the fenced treatments in the two sites but not to total grazers. This correlation though was not significant and this undermines directly pointing that the main cause of decreased microalgal density and growth were indeed due to grazers. Other evidences are needed to support this proposition that grazers reduced the microalgal abundances of the two sites.

Table 9. Pearson's correlation coefficients for comparisons between measures of microalgal abundance (chlorophyll a concentration), rock chip algal cover and various groups of grazers found inside fence treatments at the two Stanley sites. COILEDG: Coiled gastropods, TOTG: Total grazers

\begin{tabular}{|ccc|}
\hline Grazers & Chlorophyll $a$ & rock chip cover \\
\hline LIMPET & -0.149 & -0.029 \\
LITTORINID & 0.411 & 0.375 \\
COILEDG & 0.442 & -0.041 \\
TOTG & 0.306 & 0.035 \\
\hline
\end{tabular}

\subsection{Direct assessment of spatial variation in microalgal cover using Scanning Electron Microscope}

After examination of physical factors and grazer density within fenced plots showed weak to insignificant relationship to grazing and chlorophyll $a$, a more direct method to assess grazer effects on microalgal abundance was needed. The use of microscope to assess grazer effects was meant to ascertain the main cause of decreased algal abundance in the two Stanley sites.

Table 10. Summary of comparisons using nested ANOVA for various functional groups of microalgae in experimental treatments (Tr) at 4 sites (Si), on 2 shores (Sh) and on 5 sampling dates (Ti) within winter 2007. Significant differences are shown in bold.

\begin{tabular}{|c|c|c|c|c|c|c|c|c|c|c|c|c|c|}
\hline Source & $\mathrm{df}$ & $\begin{array}{l}\text { Cyano- } \\
\text { bacteria }\end{array}$ & & & Diatom & & & $\begin{array}{c}\text { Total } \\
\text { encrusting } \\
\text { algae }\end{array}$ & & & $\begin{array}{l}\text { Total } \\
\text { erect } \\
\text { algae }\end{array}$ & & \\
\hline & & MS & $F$ & $\mathrm{p}$ & MS & $F$ & $\mathrm{p}$ & MS & $F$ & $\mathrm{p}$ & MS & $F$ & $\mathrm{p}$ \\
\hline Sh & 2 & 14846.16 & 43.53 & 0.0000 & 3554.35 & 24.32 & 0.0000 & 183109.54 & 271.63 & 0.0000 & 12080.26 & 42.52 & 0.0000 \\
\hline $\mathrm{Si}(\mathrm{Sh})$ & 2 & 310.19 & 0.91 & 0.4055 & 129.68 & 0.89 & 0.4145 & 6381.10 & 9.47 & 0.0002 & 850.53 & 2.99 & 0.0539 \\
\hline $\begin{array}{l}\text { Ti (Sh x } \\
\text { Si) }\end{array}$ & 16 & 301.16 & 0.88 & 0.5898 & 257.01 & 1.76 & 0.0449 & 889.44 & 1.32 & 0.1964 & 744.44 & 2.62 & 0.0015 \\
\hline $\begin{array}{l}\text { Tr (Tix } \\
\text { Sh x Si) }\end{array}$ & 40 & 366.59 & 1.07 & 0.3732 & 196.24 & 1.34 & 0.1138 & 669.02 & 0.99 & 0.4945 & 488.93 & 1.72 & 0.0130 \\
\hline Error & 120 & 341.05 & & & 146.17 & & & 674.12 & & & 284.11 & & \\
\hline Total & 180 & & & & & & & & & & & & \\
\hline
\end{tabular}


Univariate results show highly significant differences between different microalgal covers in the two shores $(p=0.0000$, Table 10). There were also significant differences in the interactions between sites and shores for the erect and encrusting algae but not for cyanobacteria and diatoms. Significant differences through interactions between time and site $\mathrm{x}$ shores were recorded only for diatoms and erect algae. Moreover, only the erect algal cover was significantly different for all the interactions of experimental treatments and time $\mathrm{x}$ shores $\mathrm{x}$ sites.

SNK tests show that at the shore level, cyanobacteria and diatoms were more abundant at Stanley than at Cape d' Aguilar. In contrast, there were more abundant encrusting algal cover at Cape d' Aguilar than at Stanley and there were no significant differences between the two shores for erect algal cover. Erect and encrusting algal cover also differed significantly with sites nested to shores. This indicates that these algae were variable not just at the scale of tens to hundreds of meters but to even thousands of meters. CAP1 has the largest erect algal cover $(16.95 \%, \mathrm{p}<0.05)$ compared to all the other sites while STAN2 has the least erect algal cover at $6.30 \%(\mathrm{p}<0.05)$. In terms of diatom abundance, CAP2 has the least and the two Stanley sites have the highest count $(\mathrm{STAN} 1=8.26 \%$, STAN2 $=9.22 \%, \mathrm{p}<0.05)$ which probably was a reflection of the silica content (Fig.8) in this shore compared to that of the Cape sites. Temporal differences in diatom abundance was significant in only one site (CAP1) and this was during the second week of sampling which was also the highest count $(4.27 \%, \mathrm{p}<0.05)$ measured.

SNK tests of total encrusting algae showed that Cape d' Aguilar has higher encrusting algal cover than Stanley $(49.72 \%$ vs $39.96 \%, \mathrm{p}<0.05)$ with CAP2 having the most cover $(59.35 \%$, $\mathrm{p}<0.05)$ followed by CAP1 and STAN1 $(40.09 \%, 46.97 \%, \mathrm{p}<0.05)$. STAN2 had the least cover of encrusting and erect algae. SNK tests of total erect algae did not show significant differences between the two shores but it did show significant differences between sites. CAP1 for examples has the most cover followed by STAN1 and CAP2 (16.94\%, 11.91\%, $10.30 \%$ at $\mathrm{p}<0.05)$ and STAN2 last $(6.30 \%, \mathrm{p}<0.05)$.

Effects of experimental treatments on microalgal cover showed that only the erect algae $(p=0.013)$ was significantly different in all treatments. SNK tests showed that fenced treatments have the highest cover followed by the control and the open treatments $(19.78 \%$ vs. $5.54 \%$ and $8.76 \%, \mathrm{p}<0.05)$. The overall pattern suggest that fenced treatments were 
successful in excluding grazers even at the level of hundreds of microns so that erect algae were able to recruit successfully in each fence plots. It is known from previous works (Denley and Underwood 1979; Underwood 1980; Underwood et al. 1983) that grazers can easily bulldoze algal sporelings especially erect algae so that the growth of these algae are aborted if not relegated to cryptic habitats such as cracks, crevices and heterogeneous substrates. Below, Figs. 13 and 14 show the early evidence of the effect of grazers which was to undermine the growth or recruitment of erect algae but allows the growth of a competitively inferior encrusting algae. There was significantly higher cover of erect algae in exclusion treatments in all sites. With this growth comes higher canopy of turf forming and foliose algae which appear to decrease if not smother the growth of encrusting algae in fenced plots (pers. obs.). But encrusting algal cover dominates in both the control and the open treatments with only some scattered growth or cover of erect algae showing sporadic appearance as observed in the field and depicted in the graphs.

Our control and open treatments was not statistically different from each other in terms of erect algal cover. This shows that our fenced set-ups do not have any artifacts or cage effects which usually affect caging experiments. Cyanobacteria and diatom abundance were rarely found in the three treatments at Cape d' Aguilar but can be found in all three treatments at the Stanley shores. The graphical comparison of the two shores below also show that the two Stanley sites have smaller erect algal covers compared to the two Cape sites in exclusion treatments. As noted earlier when comparing the microalgal abundance of the four sites measured using chl $a$ (Fig. 5), it was postulated that if this rapid decline is mainly due to grazers, a direct assessment of grazer effects using the rock chips taken from the same plots where chl $a$ samples were also taken should reflect the same effect. Interestingly our SEM results parallels that of the chl $a$ data shown earlier, a variable chl $a$ levels during the sampling periods beginning the third week of sampling; our SEM data shows high variability of the erect algal cover in all the four sites. Moreover, this variability is reflected at the scales of tens of centimeters to thousands of meters. It appears that, the rapid decline of $\operatorname{chl} a$ and the variable erect algal cover in the exclusion treatments of the two Stanley sites (Figs.14, 18 and 19) seem to point to the effect of grazers rather than physical factors. 


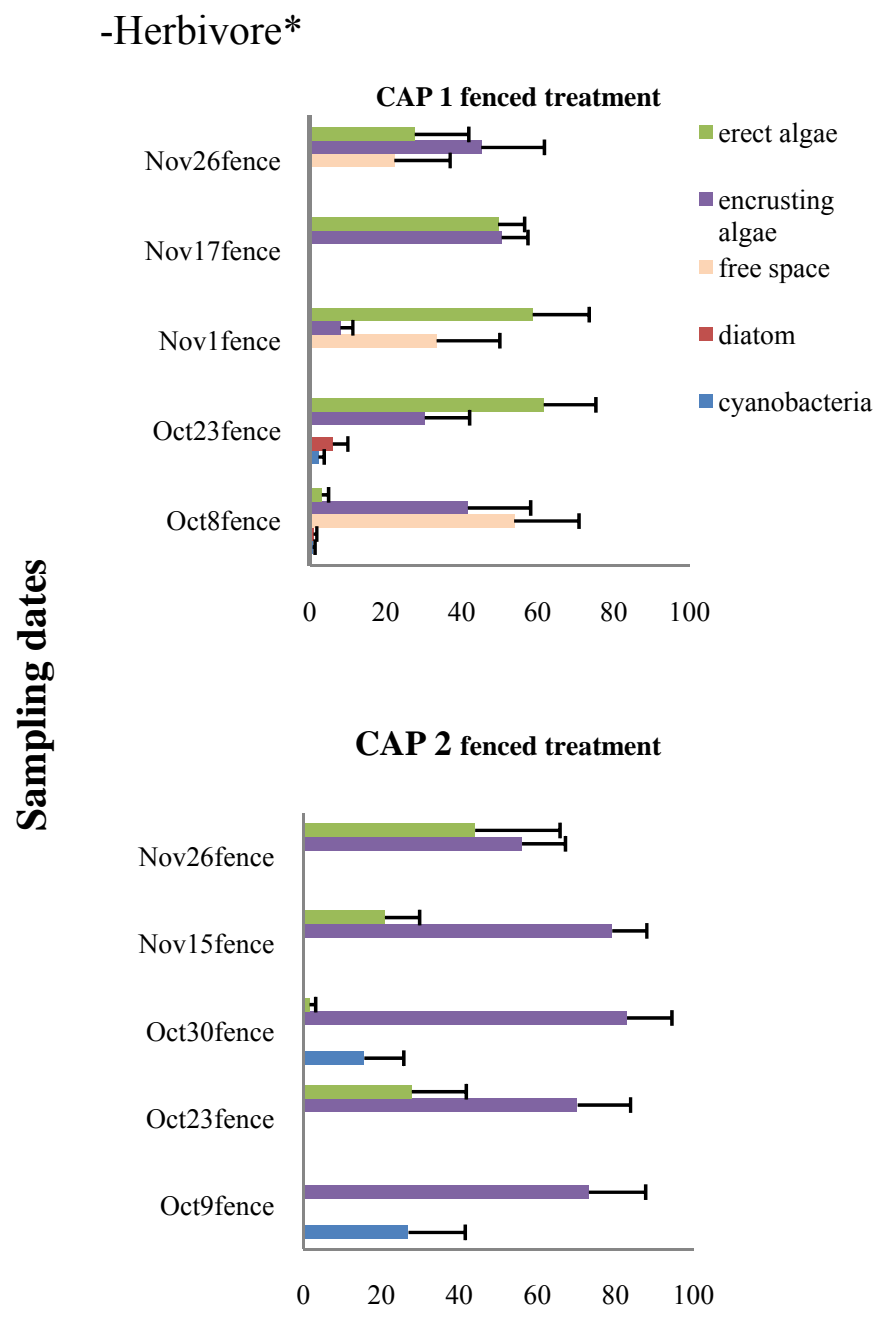

\section{Control}

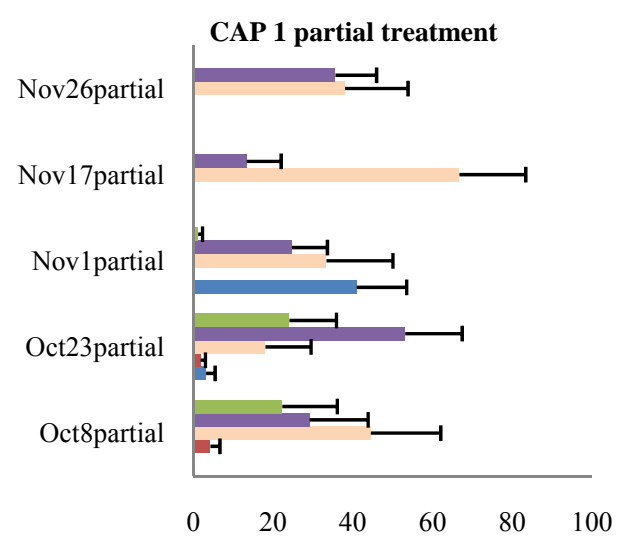

CAP 2 partial treatment

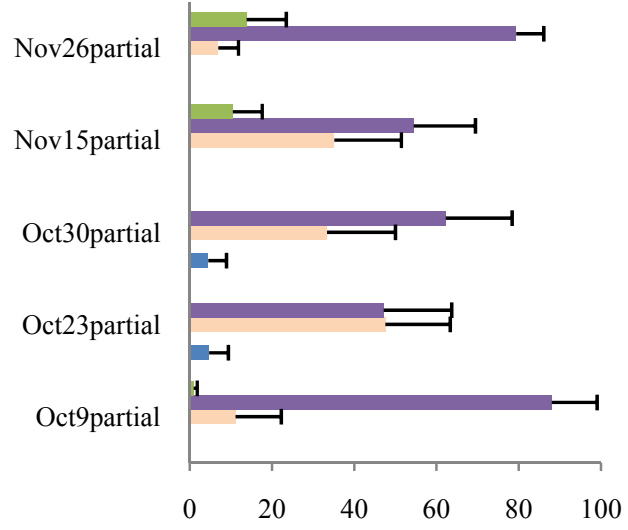

+ Herbivore

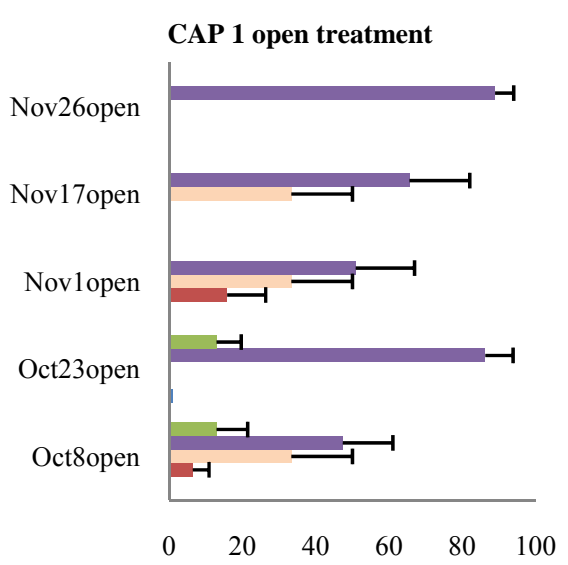

CAP 2 open treatment

Nov26open

Nov15open

Oct30open

Oct23open

Oct9open

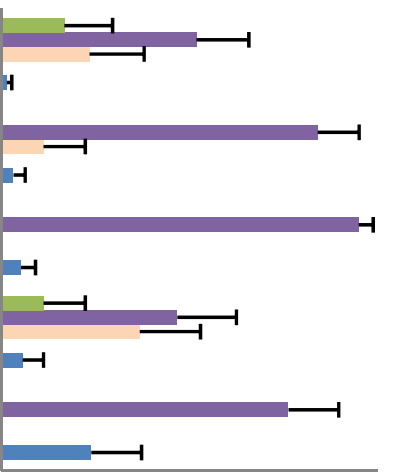

$\begin{array}{llllll}0 & 20 & 40 & 60 & 80 & 100\end{array}$

Algal cover (\%)

Fig. 13. Results of rock chip algal cover in Cape d' Aguilar study sites 1 and 2 (CAP1 \& CAP2). Experimental treatment effects were significantly different between the three treatments with the fence treatment having the most abundant erect algal cover in both sites. (*Herbivore legend is common to all charts). 
-Herbivore*

STAN1 fenced treatment

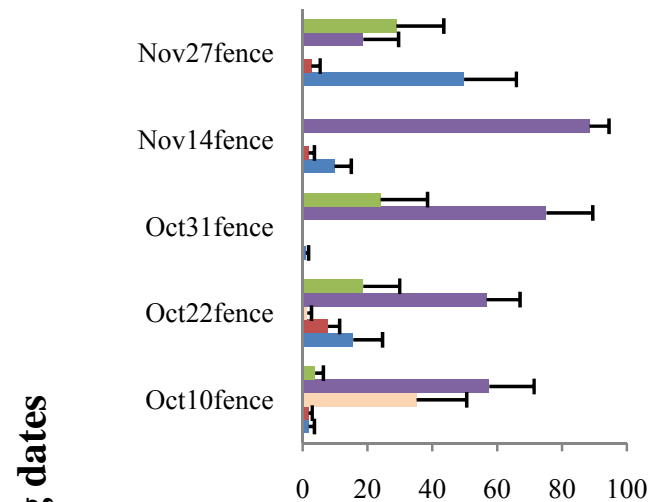

STAN 2 fenced treatment

Nov27fence

Nov14fence

Oct31fence

Oct22fence

Oct10fence

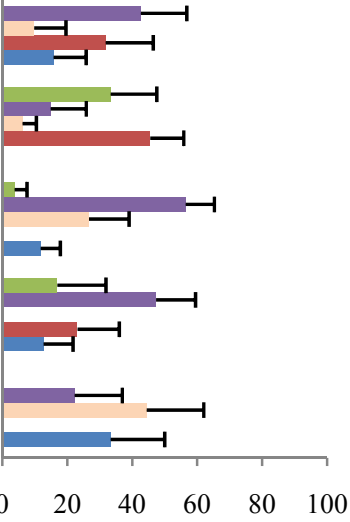

Control

STAN 1 partial treatment

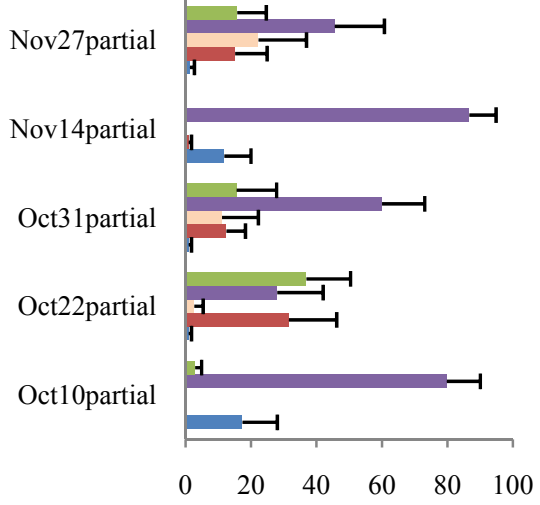

STAN 2 partial treatment

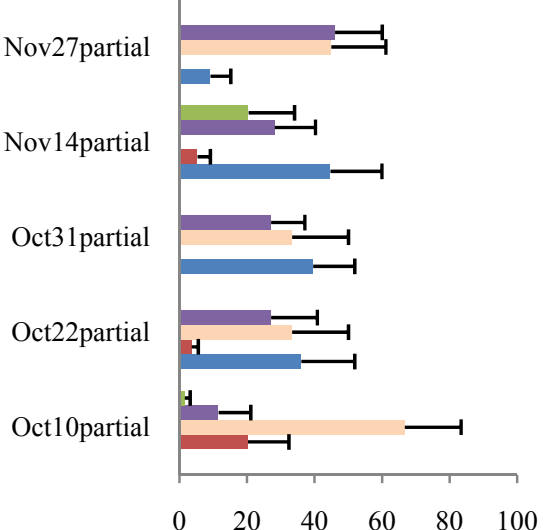

Algal cover (\%)
+Herbivore

STAN 1 open treatment

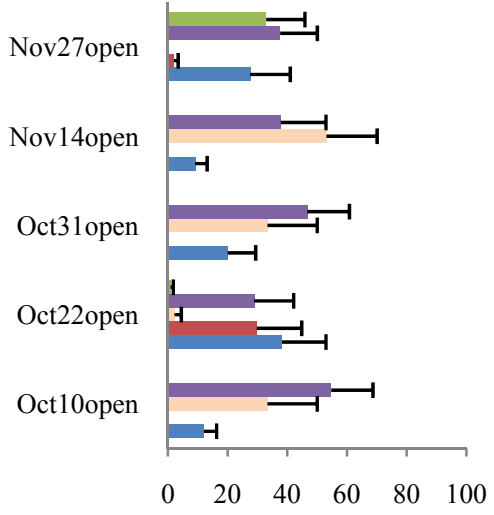

STAN 2 open treatment

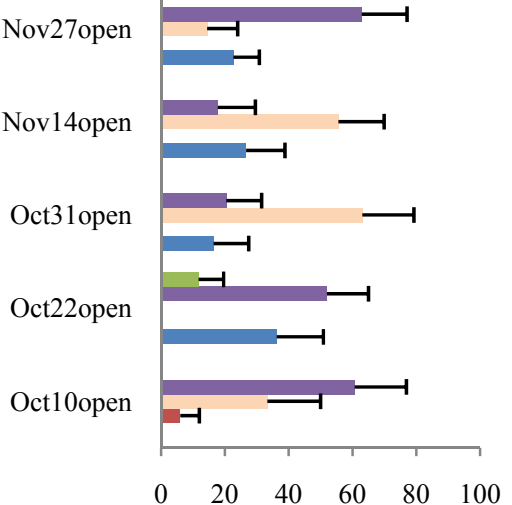

Fig.14. Results of rock chip algal cover in Stanley study sites 1 and 2 (STAN1 \& STAN2). Experimental treatment effects were significantly different between the three treatments with the fenced treatment having the most abundant erect algal cover in both sites. (*Herbivore legend is common to all charts). 


\subsection{Variable consumer effects in microalgal cover of rock chips}

Univariate results for effects of different consumers on the functional groups of algae (SEM data) showed that only cyanobacteria and erect algae were significantly different in time $(p=0.0037, p=0.0059$; Table 11) but were not significantly different in treatments. Further analysis of this difference with SNK tests showed that cyanobacteria had the highest cover in the beginning of the experiment $(18.68 \%, \mathrm{p}<0.05)$ and erect algal cover increased successively through time and by the end of the rock chip sampling period on the last week of November it gained the highest cover $(27.39 \%, \mathrm{p}<0.05)$. Diatoms and encrusting algae were not significantly different in terms of temporal variation of recruitment of algal covers. The effects of different exclusion treatments such as those excluding molluscs (fenced), fishes (roof), crabs, fishes and molluscs (cage) show no significant differences for the erect algal cover. The interaction between time and treatment also showed no significant effects on cyanobacteria, diatoms as well as total encrusting and erect algae. Over all, cyanobacteria, diatom, erect and encrusting algal covers were not significantly different in all exclusion treatments although the cage and fenced treatments have the largest mean cover (23.65\% and $18.98 \%$; Fig. 15).

Table 11. Summary comparisons of ANOVA for various algal covers in separating the effects of different consumers. Significant differences are shown in bold. Ti:time; Tr: treatment

\begin{tabular}{|c|c|c|c|c|c|c|c|c|c|c|c|c|c|}
\hline Source & df & Cyanobacteria & & & Diatom & & & $\begin{array}{c}\text { Total } \\
\text { encrusting } \\
\text { algae }\end{array}$ & & & $\begin{array}{l}\text { Total } \\
\text { erect } \\
\text { algae }\end{array}$ & & \\
\hline & & MS & $F$ & $\mathrm{p}$ & MS & $F$ & $\mathrm{p}$ & MS & $F$ & $\mathrm{p}$ & MS & $F$ & $\mathrm{p}$ \\
\hline $\mathrm{Ti}$ & 4 & 1165.19 & 4.29 & 0.0037 & 68.94 & 1.47 & 0.2195 & 1859.55 & 0.36 & 0.8365 & 2188.51 & 3.96 & 0.0059 \\
\hline $\operatorname{Tr}$ & 6 & 283.34 & 1.04 & 0.4056 & 87.53 & 1.87 & 0.0979 & 332.57 & 0.06 & 0.9989 & 664.74 & 1.20 & 0.3153 \\
\hline $\operatorname{Tix} \operatorname{Tr}$ & 24 & 161.23 & 0.59 & 0.9237 & 24.72 & 0.53 & 0.9591 & 944.73 & 0.18 & 1.0000 & 321.16 & 0.58 & 0.9314 \\
\hline Error & 71 & 271.87 & & & 46.80 & & & 5170.65 & & & 552.91 & & \\
\hline Total & 105 & & & & & & & & & & & & \\
\hline
\end{tabular}

Cochran's test $\mathrm{C}=0.220$ (cyanobacteria), $\mathrm{C}=0.635$ (diatom, $\mathrm{C}=0.123$ (encrusting algae), $\mathrm{C}=0.200$ (erect algae), $\mathrm{p}>0.05$ 

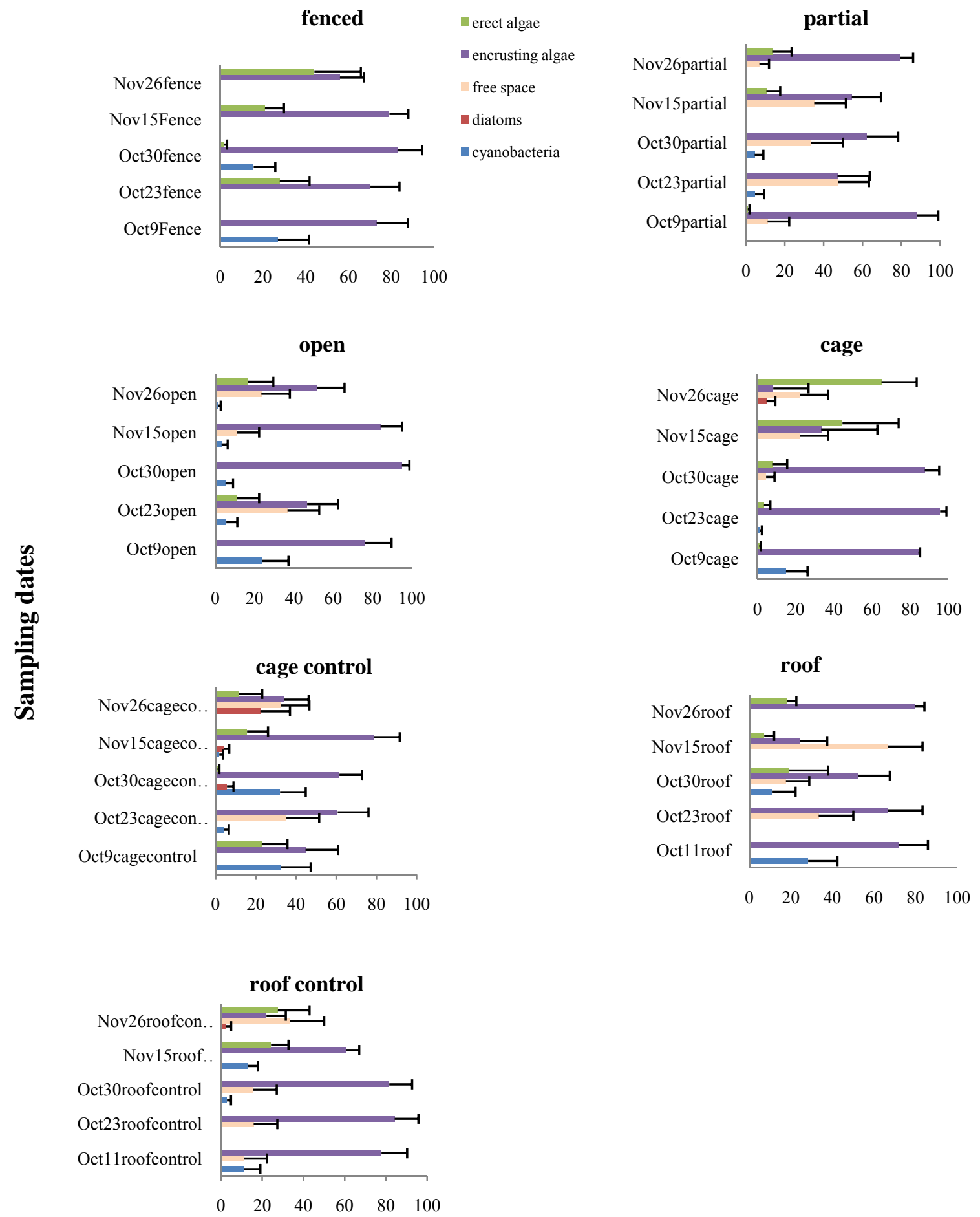

Algal cover (\%)

Fig.15. Results from rock chip algal cover for separating the effects of different consumers. Cage and fenced treatments were not significantly different from each other although the cage treatment has larger erect algal cover than the fenced treatment. Both treatments have the largest erect algal cover compared to all the other treatments. 


\subsection{Percentage cover in treatment plots}

Univariate results of algal cover for treatment plots showed highly significant differences of total encrusting and total erect algae at all spatial scales. SNK tests of this significance on shores and sites reveal that in terms of encrusting algal cover of shores, the Stanley and Cape d' Aguilar rocky shores were not significantly different but Cape d' Aguilar has a distinctly greater erect algal cover in total compared to Stanley ( $15.44 \%$ vs $9.81 \%, \mathrm{P}<0.05$; Table 12). Comparison between the four different sites showed that, STAN1 and CAP1 have both greater encrusting algal cover than either CAP2 or STAN2 $(73.81 \% \& 75.96 \%$ vs. $65.35 \% \& 67.56 \%, \mathrm{P}<0.05)$. Comparison between the four different sites showed that CAP2 has the largest total erect algal cover $(20.93 \%, \mathrm{P}<0.05)$ followed by STAN1 and CAP1 (13.53\% and 9.94\%) and then STAN2 $(6.09 \%)$. SNK tests showed the following rank order: CAP2 $>$ STAN1 \& CAP1 $>$ CAP1 and STAN2, with STAN1>CAP1 and CAP1>STAN2. Recruitment of erect algae across sites first began to appear in exclusion treatments of CAP1 as leathery mats of green turfs mixed with Hildenbrandia after 2 weeks (Fig 16). This was followed by the arrival of brown turfs of Hinksia mitchelliae and coralline crusts after 5 weeks. Barnacle spats started recruiting inside the treatment plots although moderately by the beginning of December.

The early recruits of Ulva began to appear by the beginning of December and covered most of the fenced treatments by February. In contrasts, no barnacle spats and coralline crusts however were observed recruiting inside the exclusion treatments of CAP2. Ulva and Porphyra covered most exclusion treatments by late December. Recruitment of the encrusting cyanobacteria Kyrtuthrix maculans was also more pronounced in CAP2 compared to CAP1 which had a relatively less or almost no cover represented in most of the treatment plots examined. In the two Stanley sites, Ulva recruited early in site 1 but only later in site 2 by early January. Porphyra was not observed in any plots found in the two Stanley sites but a consistent dark brown film that covered the fenced and open plots during late November and up to early January was observed in site 2. Moreover, Hildenbrandia was only observed in site 1 of Stanley but not in site 2. In contrast to more species of algae flourishing in CAP1 and CAP2, the Stanley sites seem bare in comparison. 
The green turfing algae and Ulva cover were both significantly different for the interaction of time (shores $\mathrm{x}$ sites) and of treatment (time $\mathrm{x}$ shores $\mathrm{x}$ sites). These temporal variations are mainly due to fluctuations in the abundance of green turfs and Ulva (right column Figs. 16-19) as well as time of arrival or recruitment. The interaction treatment (time $\mathrm{x}$ shores $\mathrm{x}$ sites) for Ulva and green turfs resulted from significant increases of abundance of these algae in the fenced treatments found in each sites. This shows the presence of spatial and temporal variation among algae recruiting into these plots and sites.

Multivariate analyses of various algal cover also showed that variation occurred at all spatial scales from tens of centimeters (plots) to thousands of meters (shores); see in Table 12. Patterns of significant differences like this would lend support to spatial and temporal variation occurring from plots to sites or from small (plots) to medium (shores) scale of spatial variation. In addition, a T-test was used to compare the two sites in each shore to analyze and compare any differences of algal assemblage found within sites. T- tests between groups for site comparison between CAP1 and CAP2 reveals that CAP2 has significantly higher algal cover in terms of green turfs $(11.36 \%$ vs $5 \%, \mathrm{p}=0.007)$ and erect algae $(20.9 \%$ vs $9.94 \% \mathrm{P}=0.000)$ and lower encrusting algae ( $65.35 \%$ vs $75.96 \%, p=0.002)$. Ulva cover was not significantly different between each site. It also showed that total encrusting algae was highest in control treatments $(80.65 \%, \mathrm{p}=0.000)$, followed by open treatments $(76.81 \%, \mathrm{p}=0.000)$. Ulva and turf forming algae had a mean cover of $8.10 \%(\mathrm{p}=0.002)$ and $21.71 \%(\mathrm{p}=0.000)$ in fenced treatments.

T- tests for STAN1 and STAN2 showed no significant differences in terms of total encrusting algae and Ulva covers $(73.80 \%, \mathrm{p}=0.06,2.19 \%, \mathrm{p}=0.93)$. But green turfs and total erect algal covers have both highly significant differences $(11.33 \%, \mathrm{p}=0.000 ; 13.53 \%, \mathrm{p}=0.001)$ in the two sites. Green turfs and Ulva were found highest in fenced treatments $(13.94 \%, \mathrm{p}=0.000,5.17 \%$, $\mathrm{p}=0.004$ ) while total encrusting algae formed the largest cover in open treatments at $76.42 \%$ $(\mathrm{p}=0.001)$. It is apparent that although erect algal cover dominates in fenced treatments, the persistence of encrusting algae in the control and open treatments in all sites show that grazers limit the abundance and growth of erect algae in these shores during the winter season. It is interesting to note that if any competition occurs between the two groups, the erect algae is superior to encrusting algae as demonstrated in exclusion plots. 
Table 12. Summary of comparisons using nested ANOVA for various algal covers in experimental treatments (Tr) at 4 sites ( $\mathrm{Si}$ ) and on 2 shores (Sh), on 9 sampling dates (Ti) within winter 2007. Significant differences are shown in bold.

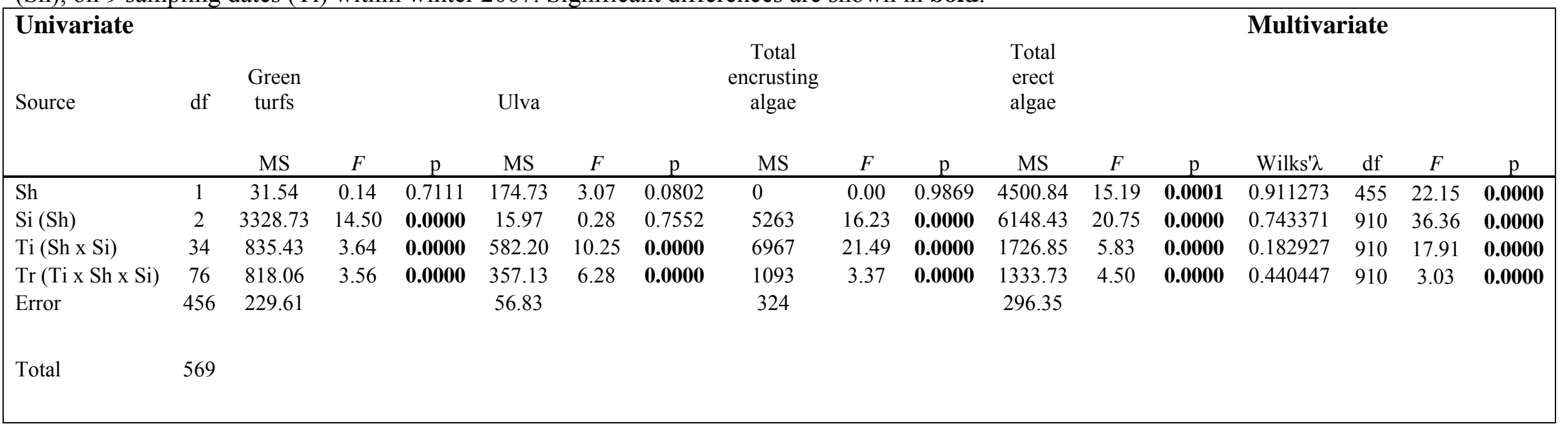

Cochran's test $\mathrm{C}=0.054$ (Green turfs), $\mathrm{C}=0.223$ (Ulva), $\mathrm{C}=0.049$ (encrusting algae), $\mathrm{C}=0.045$ (erect algae),

$\mathrm{p}>0.05$ 


\section{Percentage cover of macroalgal assemblage across the four study sites Cape D’ Aguilar site 1 (CAP1) \\ -Herbivore}

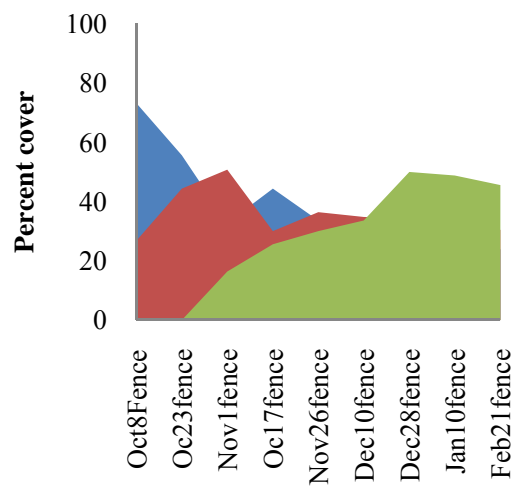

Sampling dates

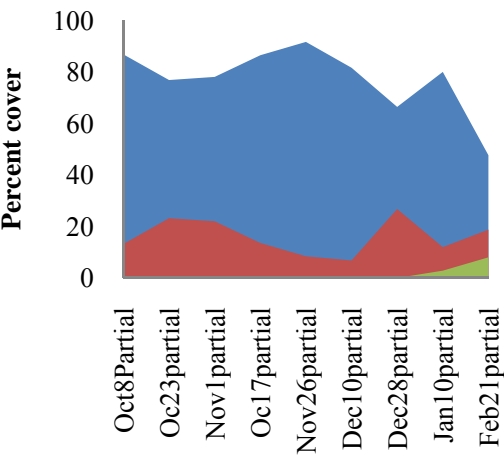

Sampling dates

- free space

mencrusting algae

werect algae

- encrusting algae

- erect algae

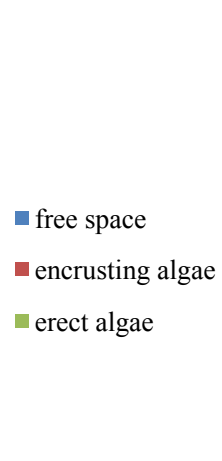

\section{Control}

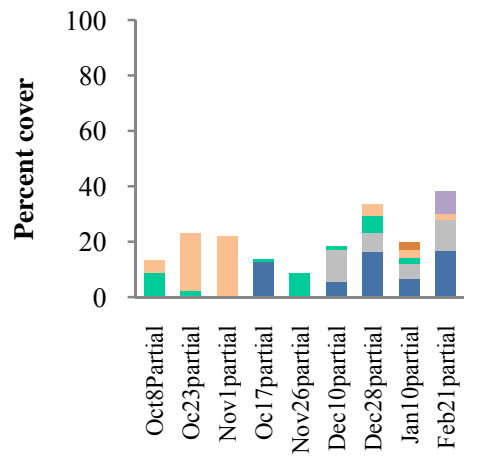

+Herbivore

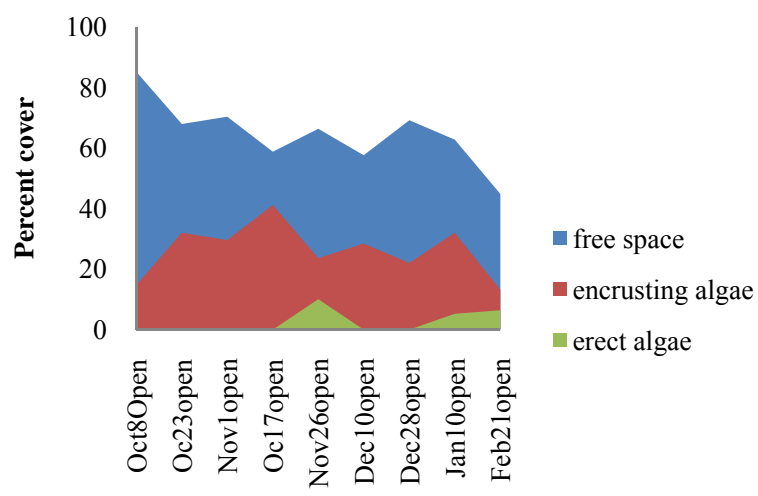

Sampling dates

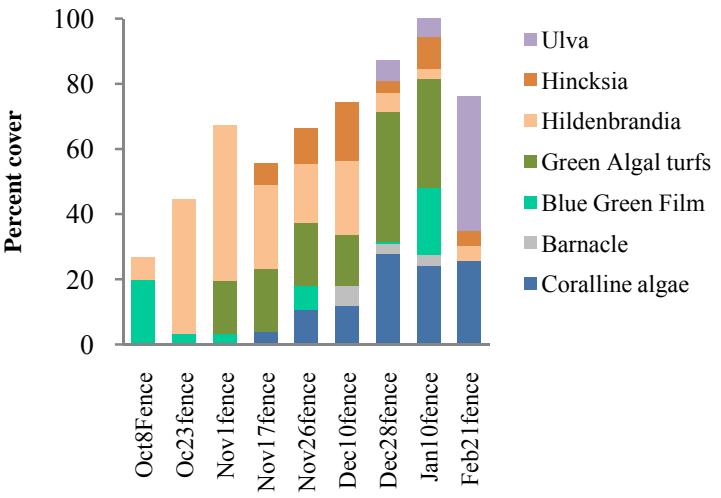

Sampling dates
Sampling dates

Ulva

- Hincksia

Hildenbrandia

- Green Algal Turfs

- Blue Green Film

Barnacle

- Coralline algae

- Ulva

- Hincksia

Hildenbrandia

- Green Algal Turfs

- Blue Green Film

Barnacle

- Coralline algae

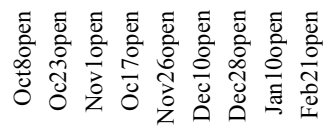

Sampling dates

Fig.16. The left column depicts the percent change of area colonized by erect and encrusting algae in each treatment through time while the right column shows changes of algal composition in these treatments through time. (CAP1: total erect algal cover $=9.94 \%$ and total encrusting $=75.96 \%$ algal cover, $\mathrm{p}<0.05$; Fence $>$ Control $=$ Open $p<0.05$ ) 


\section{Cape D’ Aguilar site 2 (CAP2) \\ -Herbivore}
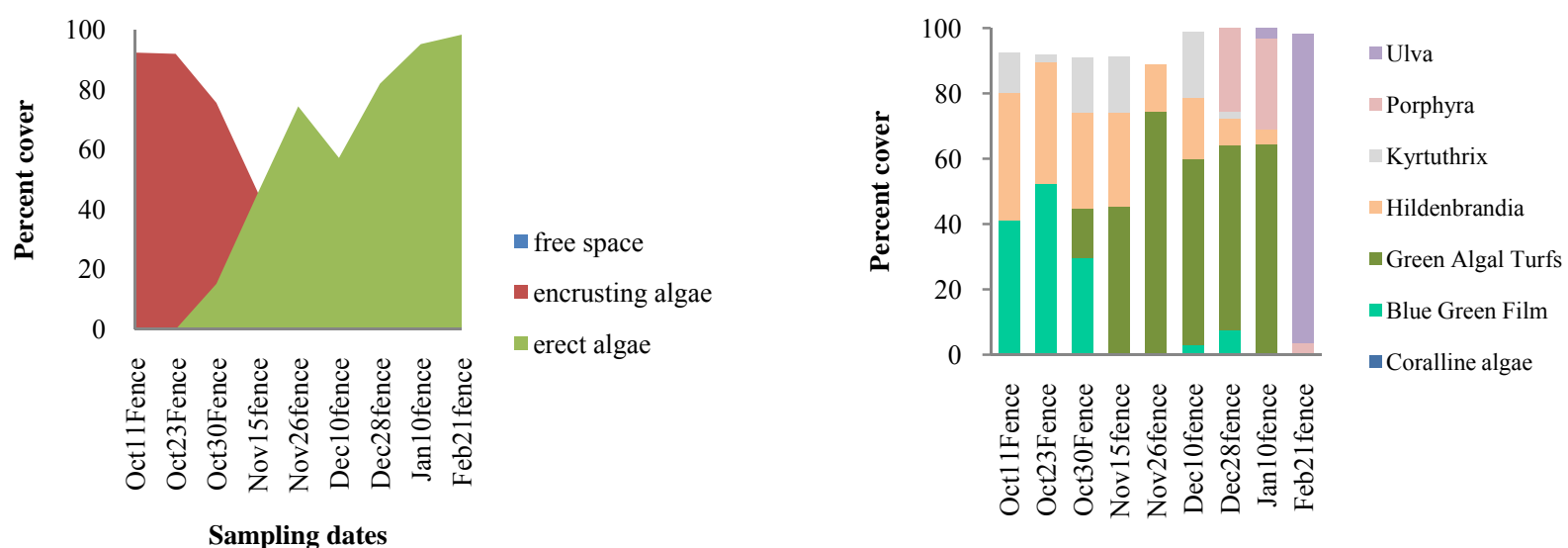

\section{Control}

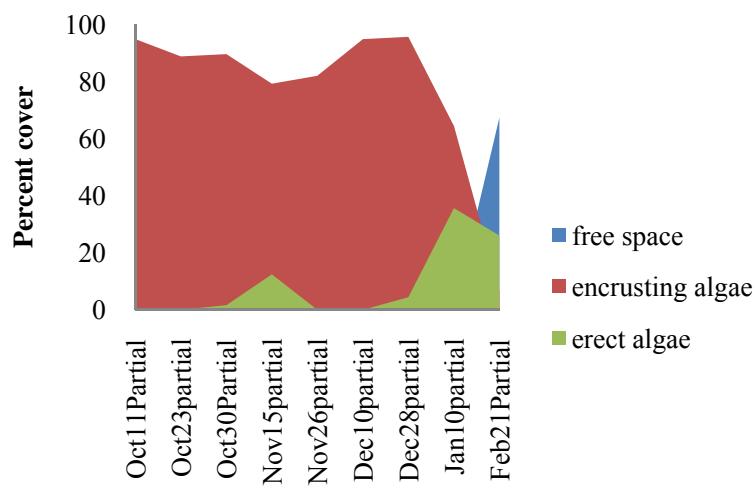

Sampling dates

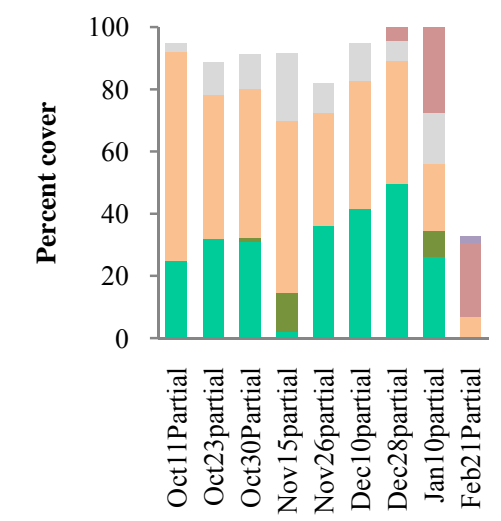

Ulva

Porphyra

Kyrtuthrix

Hildenbrandia

- Green Algal

Turfs

Blue Green Film

Coralline algae

Sampling dates

\section{+Herbivore}

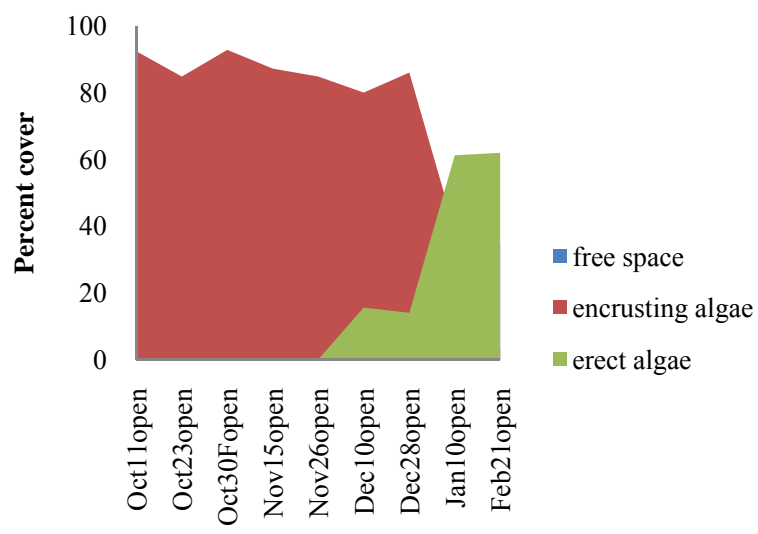

Sampling dates

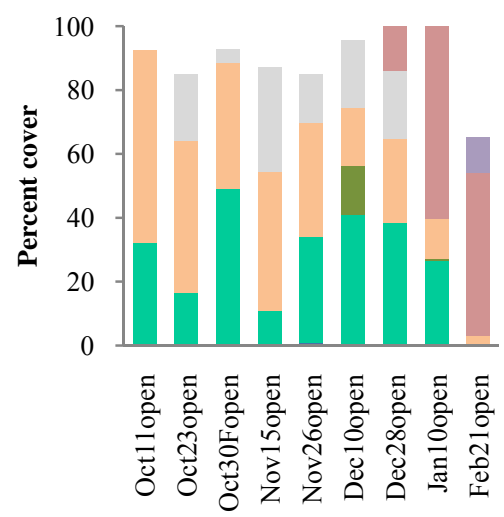

Sampling dates

Fig.17. The left column depicts the percent change of area colonized by erect and encrusting algae in each treatment through time while the right column shows changes of algal composition in these treatments through time. (CAP2: total erect algal cover $=20.93 \%$ and total encrusting $=65.35 \%$ algal cover, $\mathrm{p}<0.05 ;$ Fence $>$ Control $=$ Open $p<0.05$ ) 


\section{Stanley site 1 (STAN1)}

-Herbivore

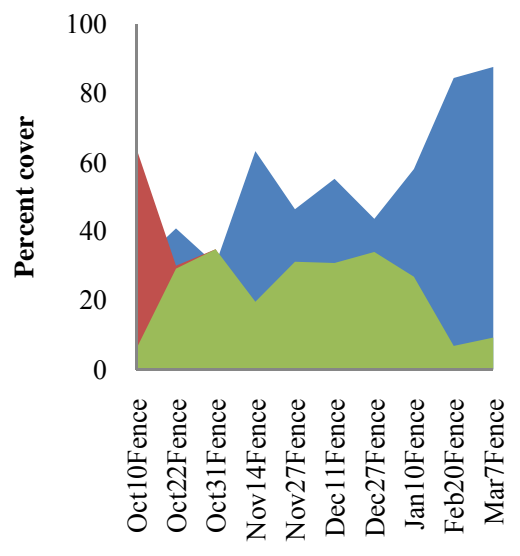

Sampling dates

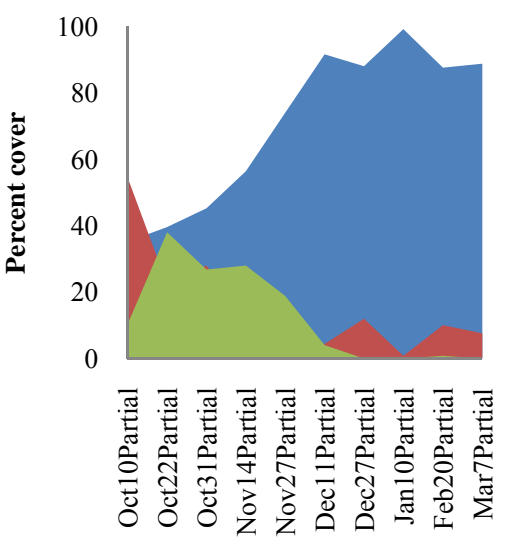

Sampling dates
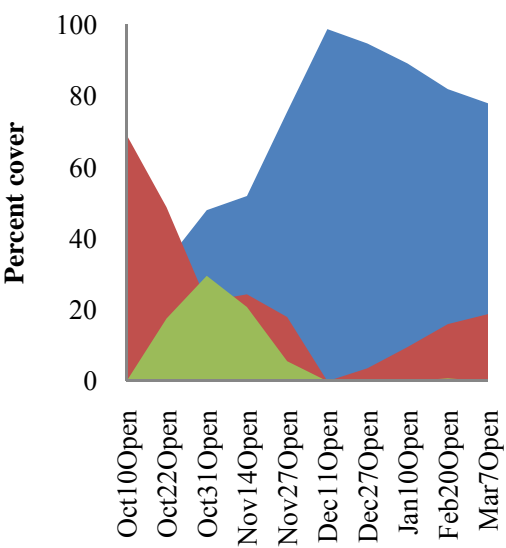

Sampling dates
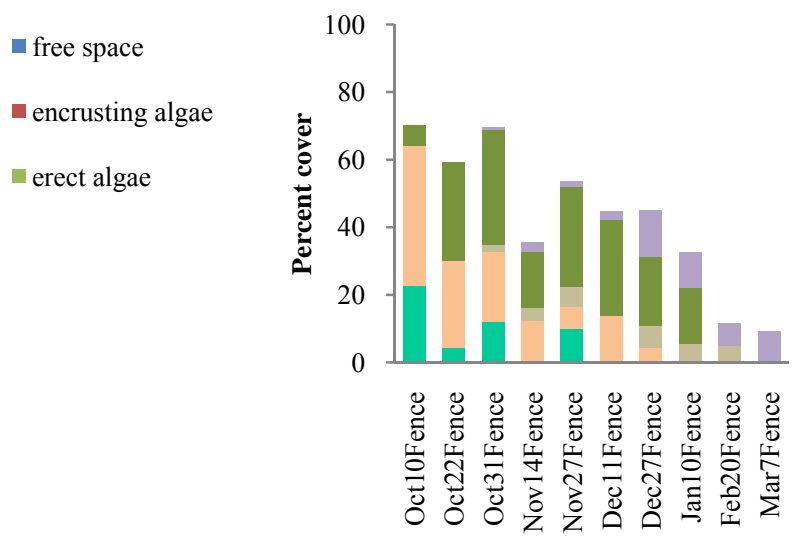

- Ulva

- Green algal turfs

- Ralfsia

$\square$ Hildenbrandia

- Blue Green Film

\section{Control}

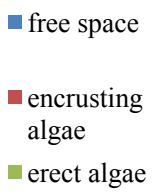

merect algae

+Herbivore
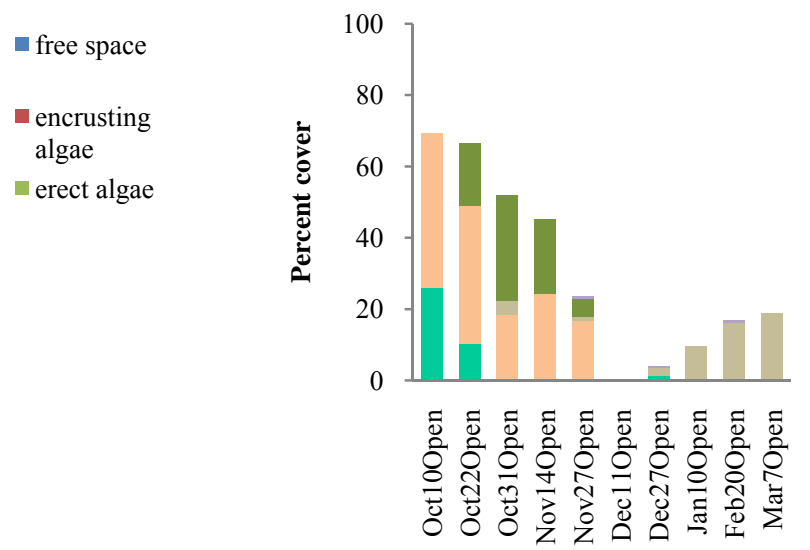

Ulva

- Green algal turfs

Ralfsia

Hildenbrandia

Blue Green Film

Fig.18. The left column depicts the percent change of area colonized by erect and encrusting algae in each treatment through time while the right column shows changes of algal composition in these treatments through time. (STAN1: total erect algal cover $=13.53 \%, \mathrm{p}<0.05$ and total encrusting $=73.81 \%$, ns; Fence $>$ Control $=$ Open $\mathrm{p}<0.05$ ) 


\section{Stanley site 2 (STAN2)}

\section{-Herbivore}

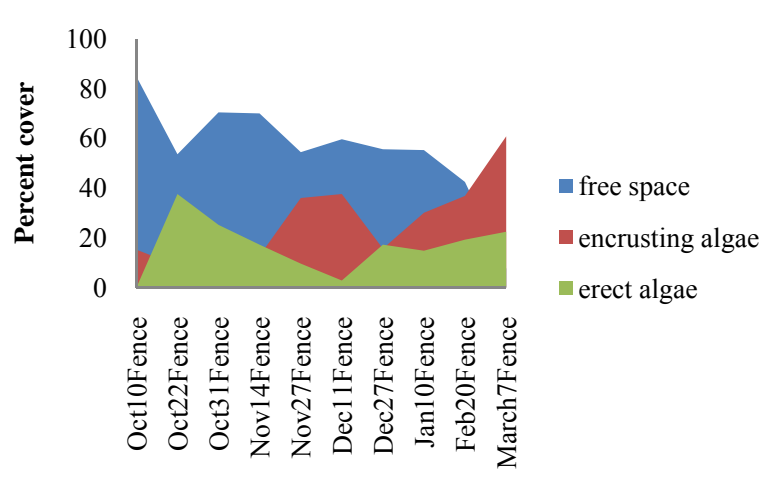

Sampling dates

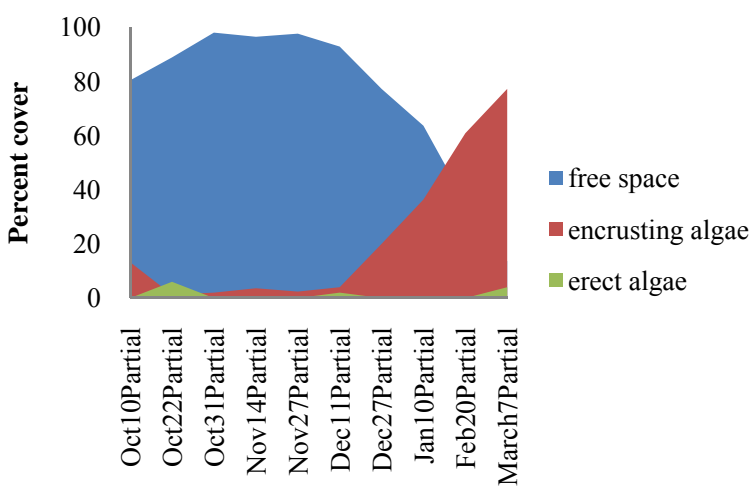

sampling dates

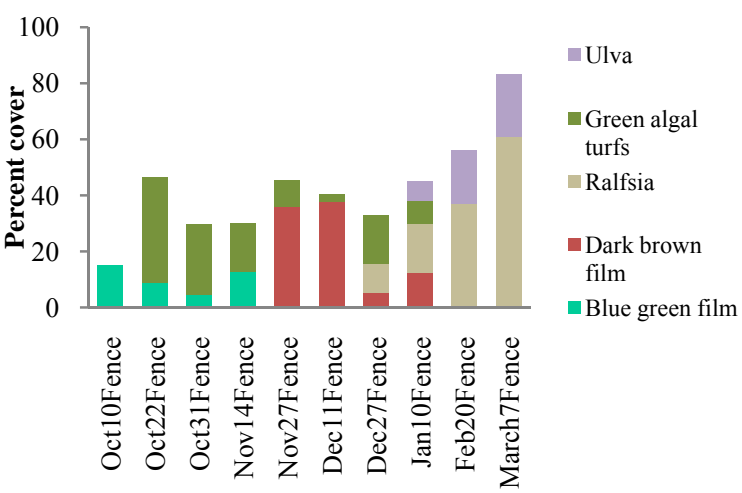

Sampling dates

\section{Control}

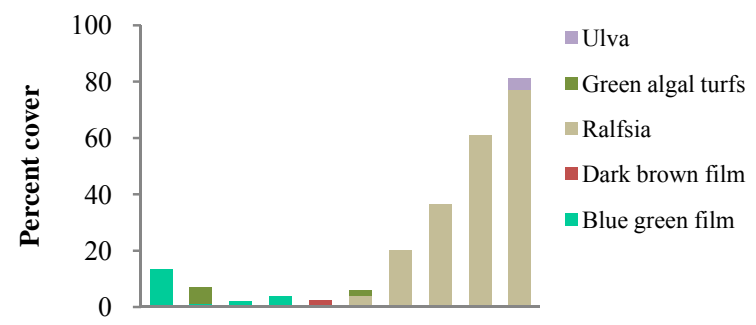

+Herbivore
Sampling dates

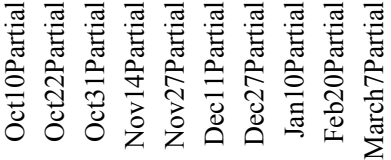

therbivore

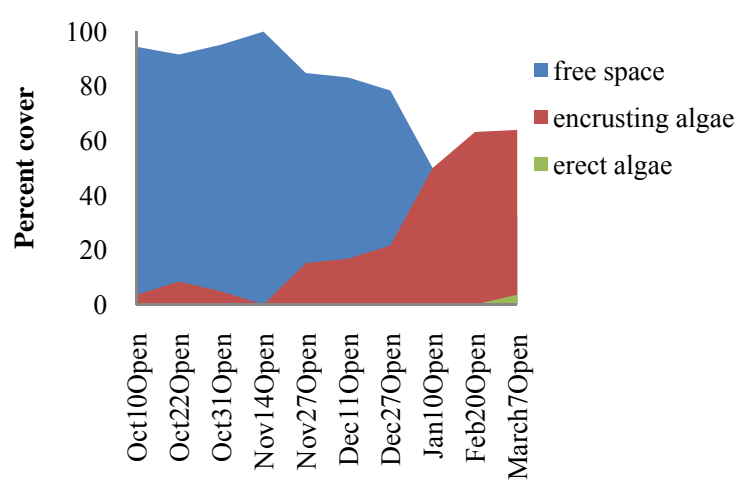

Sampling dates

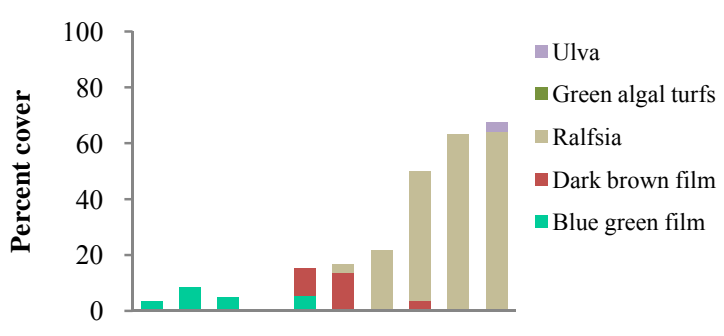

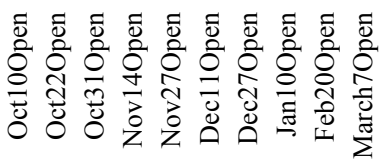

Sampling dates

Fig.19. The left column depicts the percent change of area colonized by erect and encrusting algae in each treatment through time while the right column shows changes of algal composition in these treatments through time. (STAN2: total erect algal cover $=6.09 \%, \mathrm{p}<0.05$ and total encrusting $=67.56 \%$ ns; Fence $>$ Control $=$ Open $p<0.05$ ) 


\subsection{Multivariate analyses}
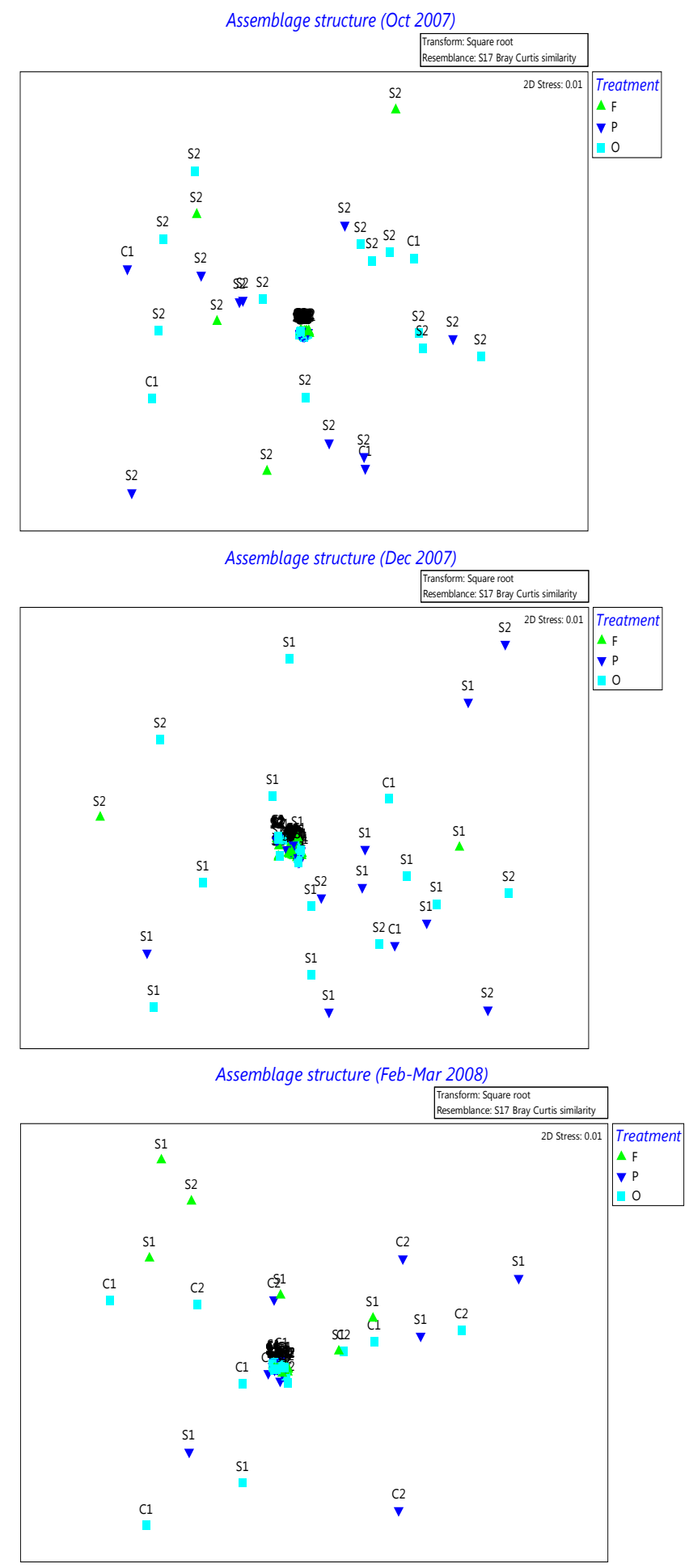

Fig.20. nMDS plots of similarities in algal recruitment for Cape d' Aguilar sites (C1 and C2) and Stanley sites (S1 and S2). Data represent spatial variation between treatment groups, fenced (F), partial fence $(\mathrm{P})$, open $(\mathrm{O})(\mathrm{n}=5)$.
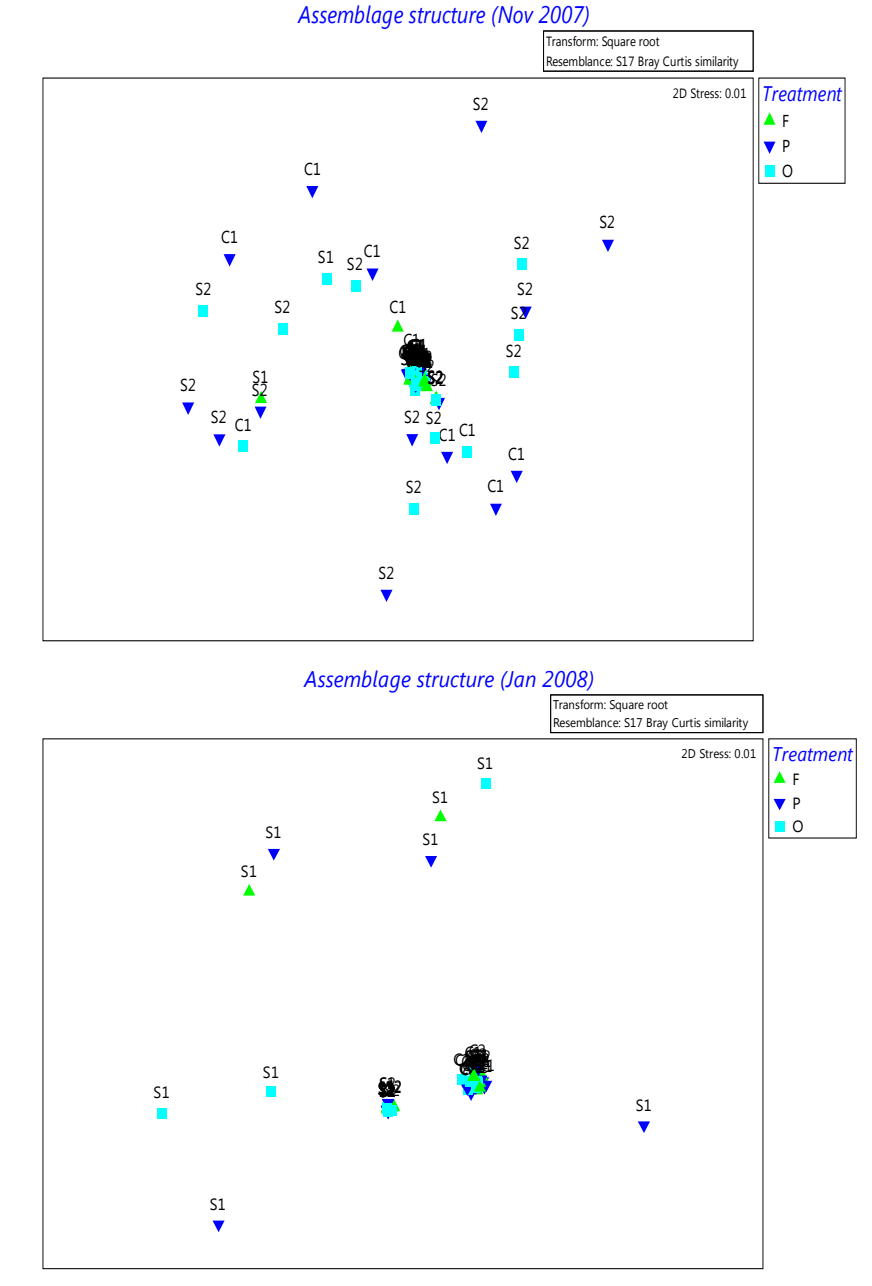
The nMDS ordinations comparing recruitment of various algal species in each treatment plots separated assemblages found in each sites (Fig. 20) for the months of sampling. Fenced plots are mostly cramped together beginning November while the control and open treatments cleanly segregate from each cluster. Stress values were always 0.01 in all months of sampling giving it a highly interpretable result (Field et al. 1982; Clarke 1993). The nMDS plots also show that the partial and open treatments are much closer with each other in all months except that during the last period of sampling in February and March, the fenced treatments also show a close value with the other two treatments. CAP2 (C2) showed a clump clustering of treatments in almost all the months of sampling.

Distinct clusters were further analyzed using ANOSIM for each months of sampling. A two factor, crossed ANOSIM was used to reveal differences between sites and treatments in all the months. Results of the ANOSIM showing the global $\mathrm{R}$ values were then tabulated with their significance level indicated by a bold type face (Tables 13 and 14). Further examination of assemblage using ANOSIM showed significant differences between and across treatments and across sites (Table 13). Pairwise comparison of sites show that CAP1 and STAN1 were more similar to each other compared to STAN1 and STAN2 or CAP2 and CAP1; the rankings were as follows CAP2 $>$ CAP1 $=$ STAN1 $>$ STAN2 across all assemblage covers. This seeming paradox may have arisen as a result of greater fluctuation of abundance of erect algal cover in CAP1 compared to CAP2. Nevertheless these rankings also reflect the effect of grazer pressure found inside fenced plots in each site (Fig. 12). Pairwise tests of treatments using ANOSIM also revealed that fenced treatments were significantly greater than partial or open treatments $(\mathrm{F}>\mathrm{P}=\mathrm{O}, \mathrm{p}<0.05)$ during all the months of sampling (except during the month of set-up) and this was true to all sites. 


\subsection{ANOSIM (Analysis of similarities) of assemblage cover}

Monthly variation in Global $R$ values across sites and treatments from a 2 factor crossed ANOSIM and from a One way ANOSIM of treatments (values in bold are significant at $p<0.05$ )

Table 13. Summary table of Global $R$ values from different species assemblage in all sites

\begin{tabular}{|c|c|c|c|}
\hline Month & $\begin{array}{c}\text { Differences across } \\
\text { sites (Global } \boldsymbol{R} \text { ) }\end{array}$ & $\begin{array}{c}\text { Differences across } \\
\text { treatments (Global } \\
\boldsymbol{R} \text { ) }\end{array}$ & $\begin{array}{c}\text { Treatment (One } \\
\text { way ANOSIM) }\end{array}$ \\
\hline Oct-07 & $\mathbf{0 . 2 8 1}$ & 0.004 & 0.005 \\
\hline Nov-07 & $\mathbf{0 . 2 2 5}$ & $\mathbf{0 . 1 2 8}$ & $\mathbf{0 . 0 5}$ \\
\hline Dec-07 & $\mathbf{0 . 3 6}$ & $\mathbf{0 . 1 6 9}$ & $\mathbf{0 . 0 7 2}$ \\
\hline Jan-08 & $\mathbf{0 . 4 6 8}$ & $\mathbf{0 . 1 0 7}$ & $\mathbf{0 . 0 4 6}$ \\
\hline Feb-Mar & $\mathbf{0 . 4 3 2}$ & $\mathbf{0 . 1 1 8}$ & $\mathbf{0 . 0 7 3}$ \\
\hline 2008 & & & \\
\hline
\end{tabular}

Table 14. Summary table of $\mathbf{R}$ values from pairwise tests between sites $(\mathrm{C} 1=\mathrm{CAP} 1, \mathrm{C} 2=\mathrm{CAP} 2$, $\mathrm{S} 1=\mathrm{STAN} 1, \mathrm{~S} 2=\mathrm{STAN} 2)$ and between treatments $(\mathrm{F}=$ fence, $\mathrm{P}=$ partial fence, $\mathrm{O}=$ open $)$.

Significantly different comparisons are in bold $(\mathrm{p}<0.05)$

\begin{tabular}{|c|c|c|c|c|c|c|c|c|c|}
\hline \multicolumn{5}{|c|}{ Sites } & \multicolumn{5}{|c|}{ Treatments } \\
\hline Month & $\begin{array}{c}\text { C1 vs } \\
\text { C2 }\end{array}$ & $\begin{array}{c}\text { C1 vs } \\
\text { S1 }\end{array}$ & $\begin{array}{c}\text { C1 vs } \\
\text { S2 }\end{array}$ & $\begin{array}{c}\text { C2 vs } \\
\text { S1 }\end{array}$ & $\begin{array}{c}\mathrm{C} 2 \text { vs } \\
\text { S2 }\end{array}$ & $\begin{array}{c}\text { S1 vs } \\
\text { S2 }\end{array}$ & $\mathrm{F}$ vs $\mathrm{P}$ & $\mathrm{F}$ vs $\mathrm{O}$ & $\mathrm{P}$ vs $\mathrm{O}$ \\
\hline Oct-07 & 0.338 & 0.149 & 0.099 & 0.202 & 0.517 & 0.313 & 0.004 & 0.016 & -0.015 \\
\hline Nov-07 & 0.131 & 0.143 & 0.233 & 0.263 & 0.532 & 0.225 & 0.179 & 0.189 & -0.009 \\
\hline Dec-07 & 0.348 & 0.16 & 0.355 & 0.423 & 0.621 & 0.211 & 0.262 & 0.266 & -0.021 \\
\hline Jan-08 & 0.313 & 0.222 & 0.623 & 0.472 & 0.813 & 0.314 & 0.098 & 0.236 & -0.02 \\
\hline $\begin{array}{l}\text { Feb-Mar } \\
2008\end{array}$ & 0.26 & 0.349 & 0.676 & 0.353 & 0.638 & 0.361 & 0.1 & 0.228 & 0.024 \\
\hline
\end{tabular}

\subsection{Percentage cover in treatment plots (consumer effects study)}

Results for the various experimental treatments to separate the effects of different herbivores showed that various algal covers, Hildenbrandia, Porphyra, Kyrtuthrix, green algal turfs and total encrusting and total erect algae differed significantly across time and treatments (Table 15). Ulva differed significantly across time but not across all treatment groups. The interaction time $\mathrm{x}$ treatment produced however a slightly different result with the following algal covers significantly 
different $(\mathrm{p}<0.05)$ from the others: Porphyra, green algal turfs, total encrusting algae and total erect algae. Tukey tests reveal this significant differences for Porphyra cover across all treatments; the fenced treatments have the highest cover with $29.42 \%, \mathrm{p}<0.05$, followed by the cage treatments with $21.49 \%, \mathrm{p}<0.05$ and all the other control and roof treatments did not differ significantly.

Recruitment of green algal turfs in fenced and cage treatments reveal significant differences between the two. Green turfs formed significantly higher cover inside cage treatments $(24.84 \%$, $\mathrm{p}<0.05)$ compared to the fenced treatments $(9.85 \%, \mathrm{p}<0.05)$ in total. Comparison between all the control and the roof treatments showed no significant differences in recruitment of green turfs. For the covers of total encrusting algae and total erect algae, the fenced and cage treatments did not differ significantly. Cage treatments have the highest erect algal cover (48.58\%) followed by fenced treatments (44.5\%). Rank orders from Tukey tests for total erect algae showed the following order: cage $=$ fenced $>$ roof control $=$ open $=$ partial $=$ cage control $=$ roof $(p<0.05)$. In terms of total encrusting algae this order was reversed with cage and fenced treatments having the least encrusting algal cover $($ cage $=$ fenced $<$ open $=$ roof control $=$ partial $=$ roof $=$ cage control, $p<0.05)$. Multivariate statistical analysis also support the result that time, treatment and the interaction of time $\mathrm{x}$ treatment were all variable; this is probably rooted on the natural fluctuations of the abundance of erect algae such as green turfs and the foliose algae Porphyra and Ulva.

Table 15. Univariate and multivariate summary of comparisons using a two factorial ANOVA for various algal covers to determine effects of various experimental treatments (Tr) sampled on 9 sampling dates (Ti) within winter 2007. Significant differences are shown in bold. Hil.:Hildenbrandia, Kyr: Kyrtuthrix, Por: Porphyra

\begin{tabular}{|c|c|c|c|c|c|c|c|c|c|c|c|c|c|c|}
\hline $\begin{array}{l}\text { Univariate } \\
\text { Source }\end{array}$ & $\mathrm{df}$ & $\begin{array}{l}\text { Hil. } \\
\text { MS }\end{array}$ & $F$ & $\mathrm{p}$ & $\begin{array}{l}\text { Kyr. } \\
\text { MS }\end{array}$ & $F$ & $\mathrm{p}$ & $\begin{array}{l}\text { Por. } \\
\text { MS }\end{array}$ & $F$ & $\mathrm{p}$ & $\begin{array}{l}\text { Ulva } \\
\text { MS }\end{array}$ & $F$ & $\mathrm{p}$ & \\
\hline $\mathrm{Ti}$ & 8 & 5794.49 & 25.08 & 0.0000 & 638.27 & 3.42 & 0.0009 & 2054.50 & 19.28 & 0.00 & 2939.43 & 19.28 & 0.0000 & \\
\hline $\operatorname{Tr}$ & 6 & 2142.05 & 9.27 & 0.0000 & 873.34 & 4.68 & 0.0002 & 6217.93 & 58.35 & 0.00 & 124.71 & 0.82 & 0.5568 & \\
\hline $\operatorname{Ti} \mathrm{X} \operatorname{Tr}$ & 48 & 305.61 & 1.32 & 0.0897 & 139.63 & 0.75 & 0.8862 & 753.56 & 7.07 & 0.00 & 214.40 & 1.41 & 0.0508 & \\
\hline Error & 252 & 231.08 & & & 186.63 & & & 106.56 & & & 152.46 & & & \\
\hline Total & 314 & & & & & & & & & & & & & \\
\hline $\begin{array}{l}\text { Uni- } \\
\text { variate }\end{array}$ & & & & & & & & & & & $\begin{array}{l}\text { Multi- } \\
\text { variate }\end{array}$ & & & \\
\hline Source & $\mathrm{df}$ & $\begin{array}{l}\text { Green } \\
\text { Turfs }\end{array}$ & & & $\begin{array}{l}\text { Tot } \\
\text { encr }\end{array}$ & & & $\begin{array}{l}\text { Tot } \\
\text { erect }\end{array}$ & & & & & & \\
\hline & & MS & $F$ & $\mathrm{p}$ & MS & $F$ & $\mathrm{p}$ & MS & $F$ & $\mathrm{p}$ & Wilks' $\lambda$ & $\mathrm{df}$ & $F$ & $\mathrm{p}$ \\
\hline $\mathrm{Ti}$ & 8 & 2260.25 & 47.71 & 0.00 & 17142 & 55.41 & 0.0000 & 9389.07 & 34.5581 & 0.0000 & 0.0652 & 1330.06 & 15.67 & 0.00 \\
\hline $\operatorname{Tr}$ & 6 & 3861.23 & 81.51 & 0.00 & 13801 & 44.61 & 0.0000 & 16223.34 & 59.7128 & 0.0000 & 0.1102 & 1157.29 & 16.54 & 0.00 \\
\hline $\operatorname{Ti} X \operatorname{Tr}$ & 48 & 925.41 & 19.54 & 0.00 & 1180 & 3.82 & 0.0000 & 1145.87 & 4.2176 & 0.0000 & 0.0313 & 1719.04 & 3.32 & 0.00 \\
\hline Error & 252 & 47.37 & & & 309 & & & 271.69 & & & & & & \\
\hline Total & 314 & & & & & & & & & & & & & \\
\hline
\end{tabular}




\section{Comparison of percentage cover of macroalgal assemblage across the seven} treatments

\section{Cape D’ Aguilar site 2 \\ -Herbivore (Fenced treatment)}

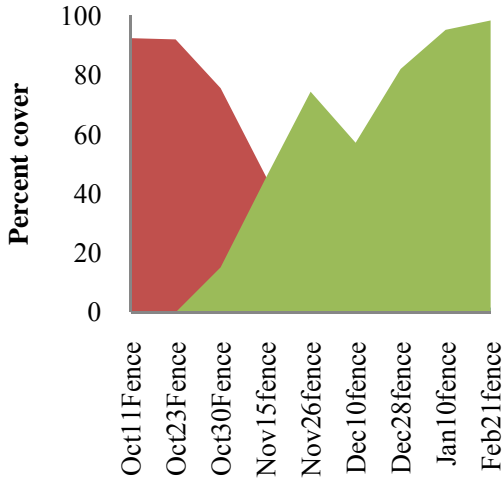

Sampling dates
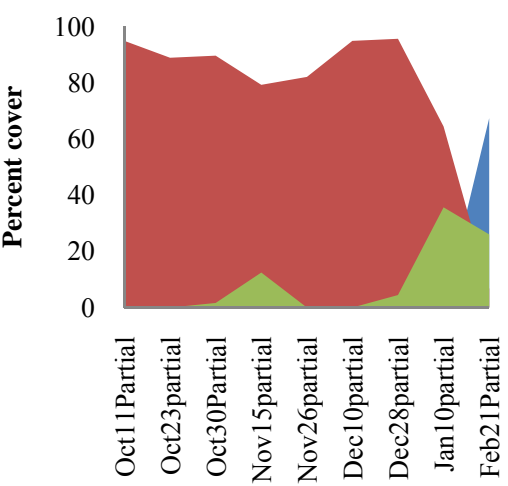

Sampling dates

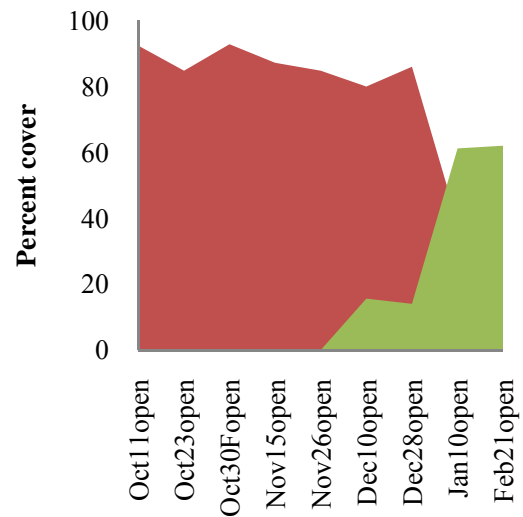

Sampling dates
- free space

- encrusting algae

verect algae

\section{Partial fence (control)}
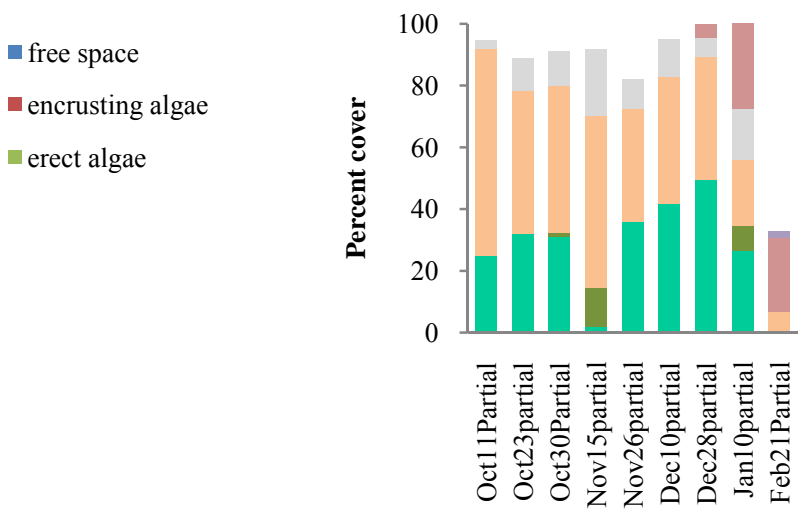

Open control

m free space

- encrusting algae

- erect algae

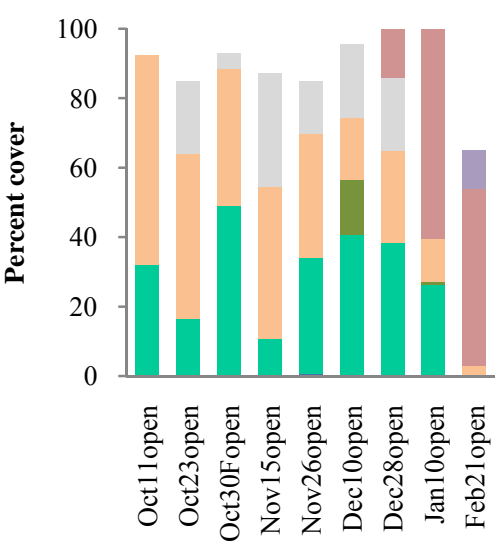

Sampling dates
Sampling dates

- Ulva

- Porphyra

Kyrtuthrix

- Hildenbrandia

- Green Algal Turfs

- Blue Green Film

- Coralline algae

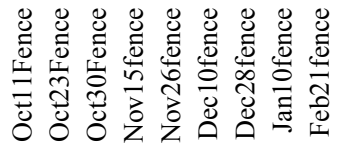

Sampling dates

- Ulva

- Porphyra

Kyrtuthrix

- Hildenbrandia

- Green Algal

- Turfs

- Coralline algae

-Ulva

- Porphyra

Kyrtuthrix

Hildenbrandia

- Green Algal Turfs

- Blue Green Film

- Coralline algae 


\section{Cape D’ Aguilar site 2}

\section{Cage}

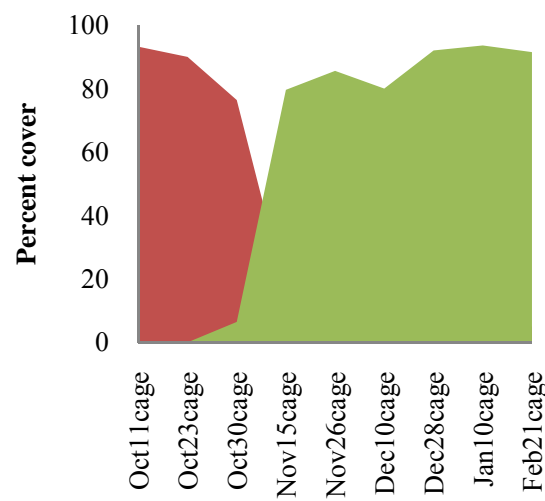

Sampling dates

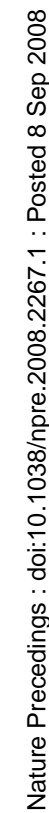

- free space

- encrusting algae

ఐ erect algae

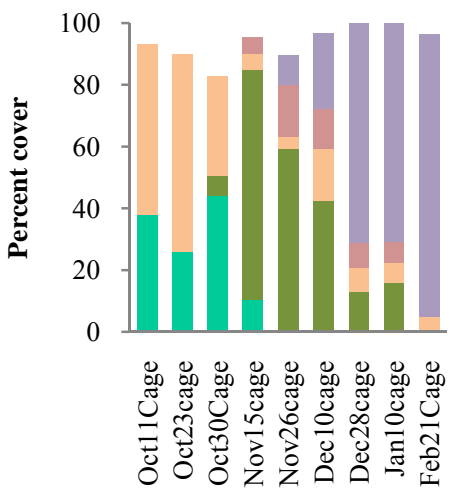

Sampling dates

\section{Cage control}

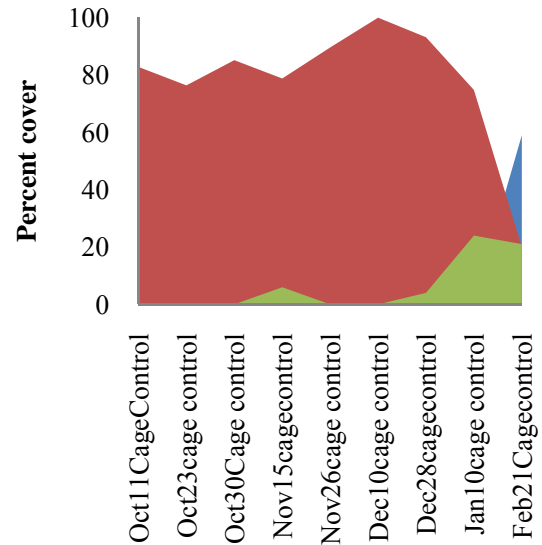

Sampling dates

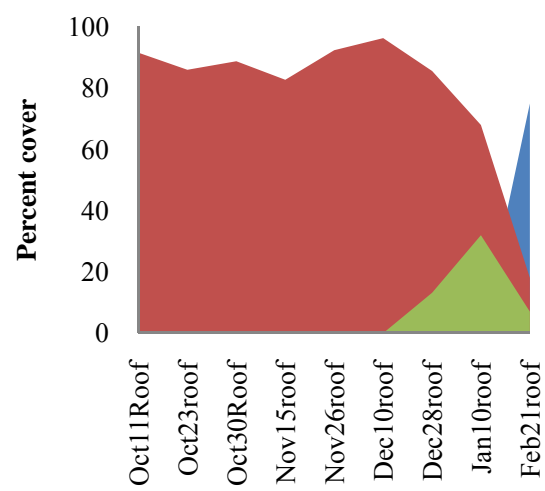

Sampling dates
- free space

- encrusting algae

verect algae

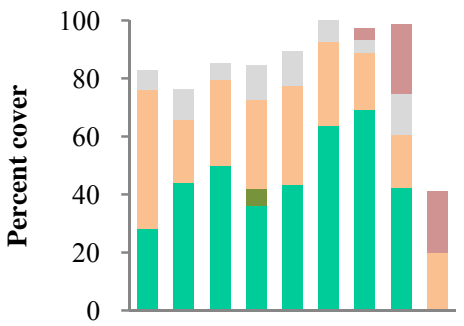

- Ulva

- Porphyra

Kyrtuthrix

- Hildenbrandia

- Green algal turfs

- Blue Green Film

- Coralline algae

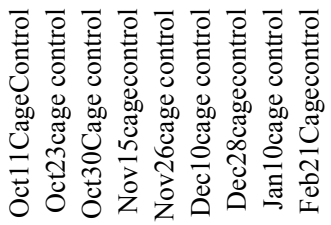

Sampling dates

Roof

free space

- encrusting algae

- erect algae

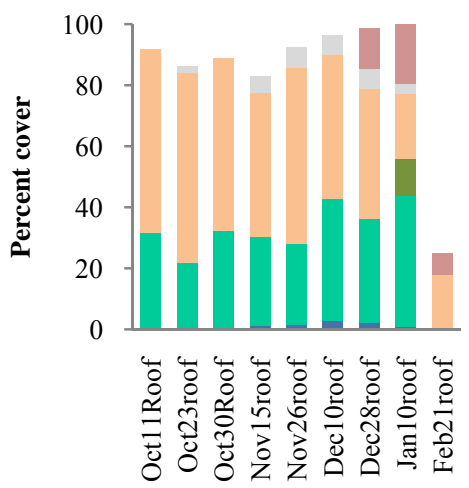

- Ulva

" Porphyra

Kyrtuthrix

Hildenbrandia

- Green Algal

Turfs
Blue Green Film

Sampling dates 


\section{Roof control}

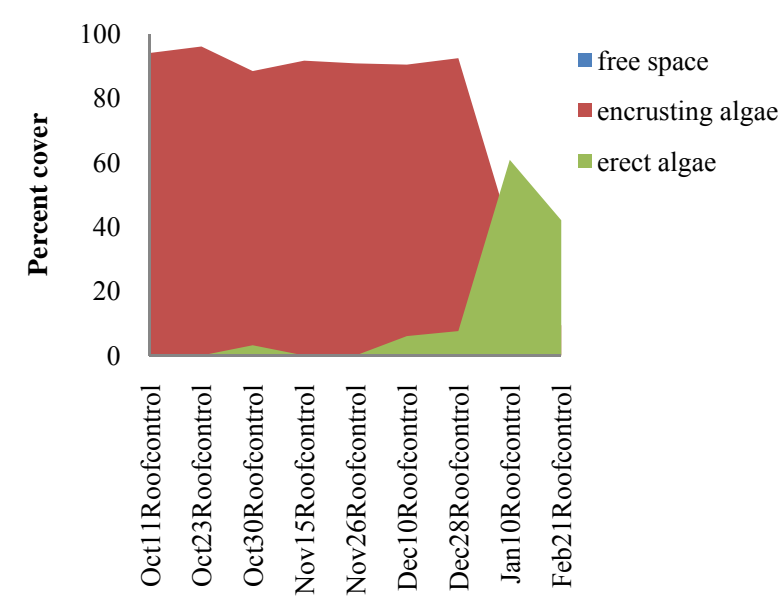

Sampling dates
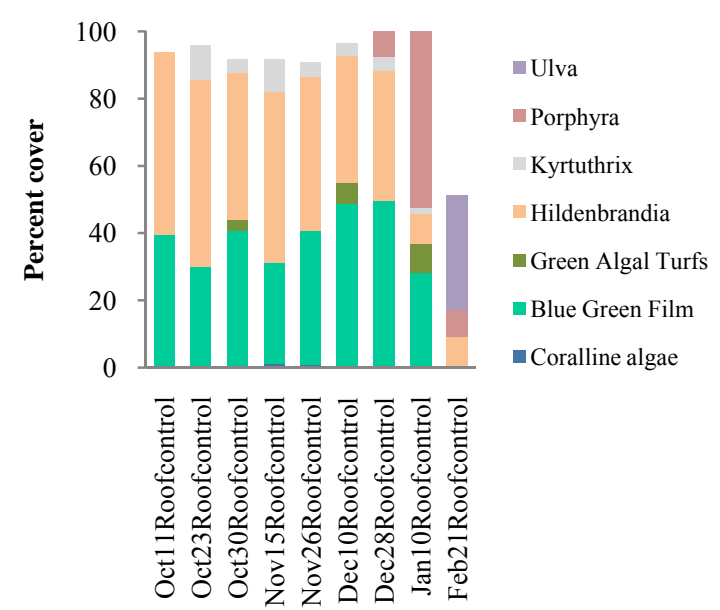

Sampling dates

Fig.21. The left column shows the change in area of total erect and encrusting algae in the seven treatments used to separate the effects of different herbivores in Cape d' Aguilar shore. It shows that cage and fenced treatments were not statistically significant in algal cover; it also shows that the encrusting algal cover and free space dominates in all the control and roof treatments. The right column depicts colonization of various groups of algae in each treatment plots. Turfing algae arrives first followed by foliose algae such as Ulva and Porphyra. In terms of green turf cover, cage and fence treatments were statistically different from each other.

Colonization of different treatment plots show that blue green films and encrusting algal cover were the primary cover of substratum before any erect or foliose algae comes to colonize a 'bare' substratum (right column Fig. 21). Turf forming algae first recruits into the encrusting or bare substratum and this is followed by Ulva and Porphyra. The arrival of Ulva precedes the arrival of Porphyra in cage treatments although Porphyra cover became dense during early January up to late February even in the open and various control treatments. The proportion of encrusting algae and the blue green film that covers most of the open and control treatments show stable cover compared to the fluctuating abundance of erect algal cover. The presence of erect algal cover that includes filamentous, turf forming and foliose algae during the winter in most Hong Kong shores ensures that the crab G. albolineatus in these shores are well fed with the more nutritious filamentous and turf forming algae compared to the encrusting algae (Kennish 1996; Kennish et al. 1996; Kennish 1997). 


\subsection{Multivariate analyses (consumer effects study)}

The following nMDS ordinations of species assemblage in all treatments show distinct identifiable clusters in each month of sampling (Fig. 22). These clusters were then further analysed using ANOSIM in each month of sampling. A one way ANOSIM was used to examine differences among treatments (Table 16) and a pairwise tests of all treatments were tabulated (Table 17). The results show a clustering of all treatments into one group during the first set-up (October 2007) and a separation of the cage and fenced treatments beginning November 2007 until January 2008. All the other treatment groups such as roof, open and the control treatments were closer to each other than to either fenced or cage set-ups.

The ANOSIM pairwise tests also show that between fenced and cage treatments, there was a significant difference except during the near end of sampling which was February 2008. Since our interest lies with the question whether fishes has no effect or has an effect on the algal assemblage, the $R$ value which shows variation between treatments or groups as to whether accept the null hypothesis or reject it (Clarke 1993) shows an increasing significant value starting from October 2007 until January 2008. In this analysis, ANOSIM shows a significant difference between the two treatments across all sampling periods (except during the beginning of set-up and the ending). The Tukey test conducted earlier showed that this difference between the two treatments was mainly due to the greater abundance of green turfs found in the cage treatment compared to the fenced treatment (Table 15). The biological meaning would not be further, the fenced treatments can exclude molluscs but not fishes or crabs. Previous observations and sightings confirm that these crabs can actually enter and feed on turfing algae inside fenced treatments (Hutchinson and Williams 2001; Gray Williams pers. comm.). If this is the case, then it is possible that the lesser abundance of green turfs found inside fenced treatments were either due to crabs or fishes. In terms of total erect algal cover, the fenced and cage treatments were grouped together as one despite a higher means for the cage treatments $(48.58 \%$ vs. $44.5 \%, \mathrm{p}<0.05)$. The findings here showed that high spatial variation occurring in plots of the same treatment can have a magnified effect on other treatments by increasing variability (Coleman 2002). Spatial variation between treatment plots do occur as a result of fluctuating recruitment patterns of different algal assemblage. 

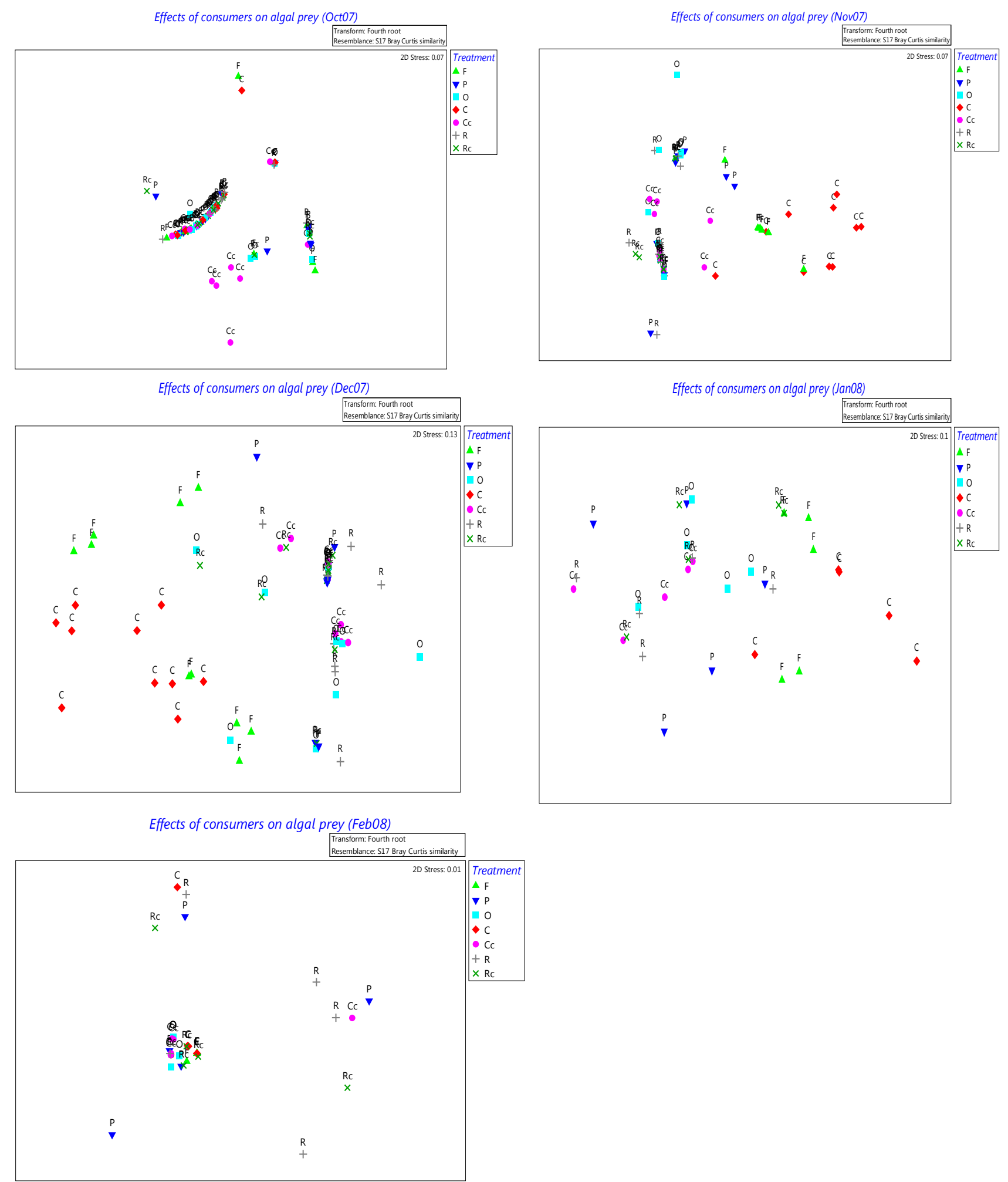

Fig. 22. nMDS plots of similarities in algal recruitement for consumer effects study in Cape d' Aguilar site. Data represent spatial variation between treatment groups, fenced (F), partial fence $(\mathrm{P})$, open $(\mathrm{O})$, full cage $(\mathrm{C})$, cage control $(\mathrm{Cc})$, roof $(\mathrm{R})$ and roof control $(\mathrm{Rc})(\mathrm{n}=5)$. 


\section{ANOSIM of algal assemblage cover on the effects of different fast moving and slow moving consumers}

Table 16. Monthly variation in global $R$ values for treatments from a One way ANOSIM of treatments (values in bold are significant at $\mathrm{p}<0.05)$

\begin{tabular}{|l|c|}
\hline Month & Treatment (One way ANOSIM) \\
\hline Oct-07 & 0.008 \\
\hline Nov-07 & $\mathbf{0 . 4 0 2}$ \\
\hline Dec-07 & $\mathbf{0 . 3 9 5}$ \\
\hline Jan-08 & $\mathbf{0 . 3 2}$ \\
\hline Feb-08 & $\mathbf{0 . 2 9 7}$ \\
\hline
\end{tabular}

Table 17. Summary table of $R$ values from pairwise tests between treatment groups, fenced $(F)$, partial fence $(P)$, open $(\mathrm{O})$, full cage $(\mathrm{C})$, cage control $(\mathrm{Cc})$, roof $(\mathrm{R})$ and roof control $(\mathrm{Rc})$.

\section{Treatments}

\begin{tabular}{|c|c|c|c|c|c|c|c|c|c|c|c|c|c|c|c|c|c|c|c|c|c|}
\hline Month & $\begin{array}{c}\mathrm{F} \text { vs } \\
\mathrm{P}\end{array}$ & $\begin{array}{c}\text { F vs } \\
\mathrm{O}\end{array}$ & $\begin{array}{c}\text { F vs } \\
\text { C }\end{array}$ & $\begin{array}{c}\mathrm{F} \text { vs } \\
\mathrm{Cc}\end{array}$ & $\begin{array}{c}\mathrm{F} \text { vs } \\
\mathrm{R}\end{array}$ & $\begin{array}{c}\text { F vs } \\
\text { Rc }\end{array}$ & $\begin{array}{c}\text { P vs } \\
\mathrm{O}\end{array}$ & $\begin{array}{c}\mathrm{P} \text { vs } \\
\mathrm{C}\end{array}$ & $\begin{array}{l}\mathrm{P} \text { vs } \\
\mathrm{Cc}\end{array}$ & $\begin{array}{c}\mathrm{P} \text { vs } \\
\mathrm{R}\end{array}$ & $\begin{array}{c}\text { P vs } \\
\text { Rc }\end{array}$ & $\begin{array}{c}\mathrm{O} \text { vs } \\
\mathrm{C}\end{array}$ & $\begin{array}{c}\mathrm{O} \text { vs } \\
\mathrm{Cc}\end{array}$ & $\begin{array}{c}\text { O vs } \\
\mathrm{R}\end{array}$ & $\begin{array}{c}\mathrm{O} \text { vs } \\
\mathrm{Rc}\end{array}$ & $\begin{array}{c}\mathrm{C} \text { vs } \\
\mathrm{Cc}\end{array}$ & $\begin{array}{c}\mathrm{C} \text { vs } \\
\mathrm{R}\end{array}$ & $\begin{array}{c}\mathrm{C} \text { vs } \\
\mathrm{Rc}\end{array}$ & $\begin{array}{c}\mathrm{Cc} \\
\text { vs R }\end{array}$ & $\begin{array}{l}\mathrm{Cc} \\
\mathrm{vs} \\
\mathrm{Rc}\end{array}$ & $\begin{array}{c}\mathrm{R} \text { vs } \\
\mathrm{Rc}\end{array}$ \\
\hline Oct-07 & 0.00 & -0.02 & 0.01 & -0.03 & 0.08 & -0.01 & -0.03 & 0.04 & 0.02 & 0.05 & -0.02 & 0.00 & -0.02 & 0.02 & -0.05 & 0.05 & -0.01 & -0.01 & 0.11 & 0.01 & 0.00 \\
\hline Nov-07 & 0.44 & 0.68 & 0.34 & 0.84 & 0.75 & 0.81 & -0.05 & 0.77 & 0.21 & 0.02 & 0.06 & 0.88 & 0.11 & 0.01 & 0.03 & 0.88 & 0.88 & 0.92 & 0.07 & 0.03 & -0.07 \\
\hline Dec-07 & 0.66 & 0.49 & 0.45 & 0.84 & 0.78 & 0.69 & 0.03 & 0.88 & 0.09 & -0.01 & -0.04 & 0.82 & 0.09 & 0.06 & 0.05 & 0.97 & 0.95 & 0.89 & 0.06 & 0.00 & -0.01 \\
\hline Jan- 08 & 0.36 & 0.64 & 0.46 & 0.95 & 0.53 & 0.39 & -0.04 & 0.57 & -0.04 & -0.12 & -0.11 & 0.86 & 0.01 & 0.00 & -0.11 & 0.91 & 0.75 & 0.63 & -0.11 & 0.08 & -0.03 \\
\hline Feb-08 & 0.52 & 0.73 & 0.05 & 0.78 & 0.70 & 0.26 & 0.16 & 0.23 & 0.12 & -0.08 & -0.01 & 0.38 & -0.05 & 0.29 & 0.24 & 0.47 & 0.37 & 0.00 & 0.20 & 0.26 & 0.12 \\
\hline
\end{tabular}




\subsection{Effects of grazing on algal prey diversity}

In addition to assessment of algal cover reduction due to grazing, biodiversity indices were calculated in each site to test the hypothesis that grazing does not only reduce abundance cover but at the same time indirectly affects and reduces diversity of affected plots, sites and shores. Results of the calculation of Shannon and Simpson diversity indices were tabulated in Table 18. This table shows reduced abundance begets reduced diversity; grazing effects were inversely proportional to diversity with the control and open treatments showing a much reduced algal diversity compared to the fenced treatments (FENCE $>$ PARTIAL $=$ OPEN at 0.4338 vs $0.3223 \&$ $0.3204)$. This is true not only for treatments but also for sites (CAP2 $>$ CAP $1=$ STAN $1>$ STAN 2 at 0.7025 vs 0.3176 and $0.2766>0.0894$ ) and for shores (Cape d' Aguilar $>$ Stanley at 0.5178 vs 0.1882 ). The rankings in terms of higher grazing pressure and algal diversity showed inversely proportional relationship. This implies that grazing pressure does not only reduce algal abundance and affect distribution but also indirectly reduces algal diversity of rocky shores into simplistic communities such as cyanobacteria and encrusting macroalgae.

Table 18. Summary comparison of ANOVA tests for the two diversity indices for various algal covers in separating the effects of different consumers. Significant differences are shown in bold.

\begin{tabular}{|lrcrcccc|}
\hline Source & $\mathrm{df}$ & \multicolumn{2}{c}{ Shannon } & \multicolumn{3}{c|}{ Simpson } \\
& & MS & \multicolumn{1}{c|}{$F$} & $\mathrm{p}$ & MS & \multicolumn{1}{c|}{} & $\mathrm{p}$ \\
\hline Site & 3 & 8.100 & 78.54 & $\mathbf{0 . 0 0 0 0}$ & 5.453 & 75.94 & $\mathbf{0 . 0 0 0 0}$ \\
Treatment & 2 & 0.999 & 9.69 & $\mathbf{0 . 0 0 0 1}$ & 0.656 & 9.13 & $\mathbf{0 . 0 0 0 1}$ \\
Error & 460 & 0.103 & & & 0.072 & & \\
Total & 465 & & & & & & \\
\hline
\end{tabular}




\subsection{Discussion}

In this section, the discussion is mainly divided into two main topics, the effects of molluscan grazers and the effects of other consumers on the algal community. Discussion of the effects of molluscan grazers is divided into effects on microalgal abundance and the spatial variability that it exhibits. Then top-down control mechanism will be discussed in the light of the findings of this study and then the problems encountered in manipulation of the grazers in Stanley. Consumer effects will be further discussed such as on other tropical rocky shore experiments and the effect of physical factors and finally a last look into the effects of consumers on algal abundance and distribution. Conclusions are then drawn from these discussions and some recommendations are also given.

\subsection{Grazing and microalgal abundance}

Earlier, the question, "are patterns found in previous studies (Williams 1993a, 1993b) in the area reflected in the present larger scale grazer-alga study?" Comparison between the mid shore treatments of Williams 1993b and this study showed inconsistent results; whereas his study did not produce differential impacts of grazing in the mid shore, this study recorded differential impacts of grazing in the four study sites. Microalgal abundances measured using chl $a$ concentration represents the microalgal standing stock (Nicotri 1977; Nagarkar and Williams 1997; Jenkins et al. 2001). This is primarily represented in the epilithic algal biofilm that covers most rock surfaces in temperate and tropical rocky shores. The biofilm therefore represents a major part in the energy base of food web in marine benthic intertidal shores. This primary production driven by the biofilm nourishes most of the grazers living in the shores such as limpets and other gastropods. Previous investigations in temperate (Underwood 1981; MacLulich 1987) and tropical (Williams 1993b; Nagarkar 1996; Nagarkar and Williams1997) shores show that chl $a$ is highly variable in space and time. Measurements of microalgal standing stock are very important as it represents the amount of algal sporelings, new recruits and settled algae (Underwood 1984). This would follow that the concentration of chl $a$ measured from herbivore exclusion treatments represent the microalgal standing stock minus grazer effect. 
This study showed high variation between treatments (refer to Table 4), within treatments (Fig. 5 and 6) as well as sites. Microalgae (diatoms, cyanobacteria, algal sporelings) are food sources for gastropods which can affect their population dynamics and distribution (Underwood 1984). Previous investigations of epilithic microalgae and the effects of grazing in Hong Kong shores show that grazers can limit the abundance of this food supply (Nagarkar 1996). Another investigation (Williams et al. 2000) showed that bare rock surfaces are colonized by microalgae (diatoms, cyanobactera) and succeeded by ephemeral macroalgae (Enteromorpha spp, Porphyra suborbiculata) in herbivore exclusions.

Although microalgal standing stock can be influenced by several factors such as exposure to heat and desiccation, relative humidity, total evaporation, seasonality and grazing (Castenholz 1961, 1963;MacLulich 1987; Jenkins et al. 2001), this study showed no relationship between physical factors and microalgal standing stock including rock chip algal (SEM) cover (see Table 5). In another comparison (Table 9) using Pearson's correlation no significant relationship between the amount of chl $a$ present, algal cover and the number of grazers found inside fenced treatments were detected in the two Stanley sites. It is interesting to note that although there is no significant relationship between the measured chl $a$ concentration in herbivore exclusions to that of grazer numbers found inside fenced treatments, the fluctuating abundance of measured chl $a$ were reflected in rock chip (SEM) algal cover. One reason why the correlation test was not sensitive to the effect of grazers on reduced chl $a$ values could be the low values of chl $a$. So although a single grazer can have a disproportionate effect of clearing a plot of microalgae present, this cannot be detected by correlation tests effectively. Thus, although we have correctly measured the values of chl $a$ present in exclusion plots, the number of grazers recorded in plots may not be enough to be detected as significant. For instance the significant factor (refer to Table 8) coiled grazers, have a mean number of only 6 and 3 in STAN1 and STAN2, which implies that although this number is small and does not reach into fifties or hundreds, per plot $\left(484 \mathrm{~cm}^{2}\right)$ can already affect the outcome of measured chl $a$ values in exclusion plots (pers. obs.).

Evidence that supports this observation includes treatment plot covers from SEM examinations and plot covers of macroalgae. A more direct examination of grazing effects other than chl $a$ (Nicotri 1977; Underwood 1984; Williams 1993b) and wax discs (Thompson et al 1997; Hutchinson and Williams 2003) can be done by microscope examinations using dissecting 
scopes or SEM (Nagarkar 1996; Nagarkar and Williams 1997; Williams et al 2000; Jenkins et al. 2001) although this can be more labor intensive. Results from this study (Table 10 and Figs. 13 and 14) suggest that grazers prevent space colonization by new algal recruits and sporelings by bulldozing and feeding on these. This preemption of space by grazers has been reported in many temperate rocky shores such as in New South Wales (Underwood 1980; Underwood and Jernakoff 1981; Underwood et al. 1983), in New England (Lubchenco and Menge 1978), as well as in Oregon coasts (Freidenburg et al. 2007). This preemption of space occurs when grazers like limpets and coiled gastropods feed on microalgae by scraping the rocky substratum with their radulae (Steneck and Watling 1982; Hawkins et al. 1989; Williams 1994; Wai and Williams 2006). Nicotri (1977) demonstrated that grazers can affect the abundance and density of microflora by reducing the amount of chl $a$ content on rock surface investigated. Her investigations on diatoms showed a patchy distribution of these organisms as well as evidence for selective grazing by littorinids. This selectivity of different kinds of grazers is well establish in the literature (Bovbjerg 1965, Callow 1970, 1973; Cates 1975, Cates and Orians 1975; Menge 1977; Patrick 1972) and is thought to be mainly a function of their feeding apparatuses as shown by anatomical examinations of these grazers including food choice experiments (Steneck 1982; Steneck and Watling 1982; Kennish 1996; Kennish et al. 1996; Nakai et al. 2006).

In our investigations clear differences between shores are not significant and probably this was caused by the rapid decline of chlorophyll $a$ in fenced treatments in the two Stanley sites. This is also possible when factors that drive the spatial variability occurring at lower scales are not effective at higher spatial scales (Archambault and Bourget 1996; Underwood and Chapman 2000; Coleman 2002). Previous investigations (Williams 1993a, 1993b, and 1994) also show seasonal variation mainly affecting the abundance and distribution of micro- and macroalgae in the cooler months of December until February. Temporal differences were however not explored in this study so direct comparisons cannot be made with these studies. The main focus of this study, which is grazing during winter, show that grazing becomes more conspicuous in these shores during the winter given favorable conditions of reduced heat stress and desiccation affecting the whole rocky shore community. During this cool period, herbivore exclusion treatments are covered with erect algae and biofilm cover is much reduced in general (Williams 1993a and 1994; Kaehler and Williams 1997, 1998). 


\subsection{Grazing from micro to macro spatial scales of variability}

Grazing and many other ecological processes are said to be context dependent and scale dependent in many rocky shore communities found at different geographical areas (Dayton and Tegner 1984, Levin 1992, Benedetti-Cecchi et al 2000; Underwood and Chapman 2000). In the following paragraphs, the effects of grazing on different scales of spatial variability will be discussed including possible explanations of the occurrence of these variations at a given scale.

This study demonstrates that grazing is highly variable in space and time from micro to medium scales of spatial variability. As discussed above, microscopic examinations of algal cover from rock chips contain a much more informative and direct assessment of grazing (Jenkins et al. 2001). The use of SEM can help pinpoint exactly which specific algal functional groups are affected by grazing in different treatments, sites and shores. Although chlorophyll $a$ can be used for microalgal assessment of abundance and biomass, results of direct assessment of algal cover from SEM quantifications can show a more direct link between grazing and the reduction of algal cover for each treatment. Using SEM this study was able to investigate the effects of grazing on different functional groups of microalgae and show the extent of micro-spatial variation in algal cover for the different treatments, sites and shores.

Our results indicate that fluctuations in the abundance of erect algal cover (composed of turf forming algae such as green turfs, brown turfs and foliose algae) were mainly causing the differences between treatments as its abundance is mainly controlled by grazers. Observed variations between sites and shores are mainly from fluctuations of abundance of encrusting and erect algae throughout the sampling period. It is generally held that once an algal sporeling finds refuge, this would eventually grow and mature (Underwood 1980, Underwood et al. 1983; Menge et al. 1986a). This study suggests that simple escapes and recruitment differences of microalgae and macroalgae in each treatment plots would later drive the large scale patterns observed as differences between sites and shores. Other studies (Underwood and Petraitis 1993; Archaumbault and Bourget 1996; Coleman 2002) also show that observed events that work at micro or small spatial scales can actually drive observed patterns that occur in larger spatial scales. An examples of this pattern is recruitment where dispersed sessile algal propagules and juveniles of sessile invertebrates can travel in very far areas as carried by ocean currents 
(Deysher and Norton 1982; Hoffman and Ugarte 1985). There are however cases when this pattern appears secondary to another much stronger controlling factor such as seasonal and oceanographic differences (Williams 1993a; Vinueza et al. 2006 ), supply of recruits and temperature (Hutchinson and Williams 2001). When local processes such as grazing controls the assemblage in the winter, this control is released and becomes secondary when a large swamp of algal recruits occur in the shore or when the summer heat bakes the rocks freeing it from algal patches. Although this study showed the importance of grazing in controlling the assemblage from micro to medium spatial scales, observed variations are not completely due to grazing alone since other physical factors such as heat, desiccation and temperature and the number of recruits can also affect the algal assemblage as a whole (Lubchenco and Menge 1978; Underwood 1980; Garrity 1984; Williams 1993; Kaehler and Williams 1996). Algal succession that occurs in the herbivore exclusions is therefore a direct result of a combination of release from grazers and availability of recruits during that specific period of time.

Further, our results suggest that although winter is a favorable condition for both grazers and macroalgae, the release from the control of heat and desiccation for the plants would mean extended survival once it attains escape from herbivores. For herbivores, this would mean greater food availability and this in turn could support more grazers. The fluctuations of abundance of algae in the fenced treatments in the two Stanley sites could only mean two things; first, there is low number of algal recruits reaching into the shores or second, grazers are feeding on the microalgae found in the fenced treatments. The first reason is untrue as there are erect algae that can be found all over the area, in rock pools and on top of scattered rocks near the sites. The second explanation is the most plausible given significant variation in grazer pressure between sites (Tables 6 and 8). The observed patterns from this study show that in general, variation between shores are greater $(91.24 \%)$ compared to sites $(89.62 \%)$ and treatments $(87.85 \%)$; variability increases from micro (tens to hundreds of microns), small (tens of centimeters to tens of meters) and to medium (hundreds of meters to kilometers) scales.

Study of spatial variation in Hong Kong rocky shores have been conducted for several years already (Williams 1993a and 1994, Hutchinson and Williams 2001, 2003) and it appears that observations remain consistent between the earlier findings of Williams 1993a, 1993b and 1994 wherein erect macroalgal species find refuge from grazing within the exclusion plots. General 
patterns of mollusc exclusion studies reveal that fenced treatments are generally a biological refugia for most of these algal species turning succession into a mature plant community of green foliose algae before finally being wiped-out by the summer heat (Williams 1993a, 1994; Wai and Williams 2003). In Williams study (1993a, 1993b, 1994), spatial differences were from meters (low-shore vs. mid-shore) to hundreds of meters (sites) but not from kilometers. Clear differences between treatments emerge in the low shore set-ups but not in the mid-shore. In this study colonization of space starts from bare rock surface of encrusting algae followed by biofilms, green turfs, brown turfs and then Ulva and Porphyra or foliose algae. Microscopic examinations show that during succession from a bare space to colonization of a foliose algae, a coat of protein polysaccharides cover the surfaces of bare patches which prepares it to be colonized by various microalgae and then turfing algae (Nagarkar and Williams 1997; Williams et al. 2000). This predictable pattern of biofilm to macroalgal succession is an evidence of reduced stress from grazers as well as from other physical factors (Underwood 1980; Kaehler and Williams 1998; Freidenburg et al. 2007). Grazing can thus affect the structure of a community from increasingly small (microns) to increasingly large (hundreds of meters to kilometers) with variable effects at each level.

\subsection{Top-down control and shifts in Assemblage}

In this section, the question on what type of control occurs in these rocky shores will be explained briefly and related to previous studies in the area as well as similar studies. Our experiment demonstrates that removal of grazers in exclusion treatments shifts the overall assemblage from a barren encrusting cover to erect and foliose algal cover. Williams (1993b) attributed these changes to many factors such as the cold current that comes from China (Kurish current) during the winter months and the relatively lower heat stress and temperature during the cool winter season in Hong Kong. This is however simplistic and it is apparent from this study that mid-shore set-ups such as the open and the control set-ups were not covered by macroalgae as much as the fenced or the cage treatments were throughout the time of the experiment (October 2007 to March 2008). 
This can mean that during the cool season although favorable conditions exist generally in the shores, grazers exploit this to actually control the abundance of macroalgae. Although this study did not last for years, the short period of examination does allow us to speculate that biologically, the algal assemblages in these shores are controlled by grazing during the winter. Processes that work at large spatial scales such as recruitment and seasonal variations (Hutchinson and Williams 2001) are factors that can determine the community structure at such scales but at smaller scales the effects of these factors maybe secondary to predation and grazing (Hawkins and Hartknoll 1983; Menge and Olson 1990). The timing of recruitment as well as the amount of these recruits found in the water column can also affect the community structure (Sousa 1984; Hoffman and Ugarte 1985) as it can swamp grazers (Underwood 1980) thereby covering the rocky shore.

In this study, there is a clear variation of algal recruitment in different sites and between treatments. The most conspicuous effect of grazing can be found in the two Stanley sites whose microalgal values are reflected clearly on lower rock chip algal cover as well as lower treatment plot algal cover. Kaehler and Williams (1997) also used exclusion treatments in combination with recruitment tiles to determine the effect of grazers on algal recruits; their study showed that there are variations in the recruitment patterns of two encrusting algal species Ralfsia expansa and Hapalospongidion gelatinosum but rarely did they encounter erect algal cover throughout the period of their examinations. They attributed this low recruitment of erect algal covers to predation of turfing algae by echinoid and molluscan herbivory. In contrast the results of this study, SEM observations of erect algal cover show clearly that during the sampling periods of October and November, as early as two weeks, erect algal turfs can be observed recruiting into our 'natural recruitment plates' of rock chips. This can mean that either roughened PVC plates is not a good design for settlement plates with erect algae, or that the lack of observation for the several period of months of examination a mere reflection of lack of algal recruits.

In addition this contrasted with another exclusion study (Hutchinson and Williams 2001) of similar time frame (monthly examinations) but without the inclination effect in the same area to study the recruitment of algae and to determine grazer effects on different functional groups for a period of more than one year. Their results show that the erect algae recruited abundantly including the encrusting algae which was similar to what this study found. Given this similar 
results of erect algal cover recruiting into plots cleared (Hutchinson and Williams 2001) or uncleared (this study) on a basis of monthly examination for more than a year and for six months at a period of every 15 days examination of algal settlers, this may suggest that roughened PVC pipes may not be the proper media for erect algal settlers in these shores. Similarly, the results of exclusion treatments in the three studies including this one, suggests that herbivory of algal recruits are indeed a constant feature in these shores; this can be by urchins, fishes, crabs or molluscs.

The shift from a predominantly encrusting algal cover to erect algae in these shores evidently show the major influence of grazers after the hot months (May to September) and during the cool season (December to February); both grazers and algae interact together, with grazers ultimately determining which assemblage forms in the area. In Menge and Sutherland's model (Menge and Sutherland 1976, 1987) with environmental stress affecting the structure of a community to change, they proposed that under benign conditions, the effects of predation on a community structure are stronger and the shorter the food chain, the stronger this effect. Seasonal tropical rocky shores such as the Hong Kong rocky shores lend support to this model under certain conditions such as during the cool season and low on the shore during the summer season (Williams 1993a, 1994). Under reduced stress such as the reduced effect of heat and desiccation during the cooler months, grazing plays an important role in these shores .The observed patchy distribution of macroalgae in the open and control treatments in all four sites show the strong effect of grazing. Some though attain escapes such as on heterogeneous substrata and in cracks and crevices as well as pools; Ulva and other several foliose species were seen growing luxuriantly in pools and low on the shore as the season changes into cooler months. And although summer die offs occur in these shores (Williams 1993a; Kaehler and William 1996; Wai and Williams 2006) especially for sessile invertebrates and foliose macroalgae, the observed barrenness and patchy distribution of erect algae in the open and control treatments supports our hypothesis that grazers are the major causes of low recruitment of erect algal cover. This 'topdown effect' have been observed in many rocky shores such as in earlier studies (Connell 1961; Paine 1966; Castenholz 1961; Menge 1977) while bottom up regulation developed mainly from plant ecologists (Fretwell 1977, 1987; Grime 1977; Oksanen et al. 1981) who sees plants as the main provider of food and nutrient sources for organisms thereby controlling the food chain; this study however did not find any bottom up effect probably as this was conducted on protected 
shores. There are cases however when community regulation may not fit strictly on either one such as on a case where limpets occupy the rocky shores and no attached macroalgae can be visibly seen in these shores but the dense limpet aggregates would mean these grazers are taking food sources other than scraping from a limited ground area (Bustamante et al. 1995; Menge et al. 1999). Results from our study however clearly show a strong classical top-down effect of grazers with little or no subsidy of nutrients to effect strong primary production in algae (Fig. 8 chart D).

This study showed that local processes such as grazing that occurs at spatial scales of tens of centimeters are reflected downwards (micro spatial scales of variation-hundreds of microns) and upwards (macrospatial scales-tens of centimeters to hundreds and thousands of meters). Such variation which is driven by a local process demonstrates that 'noise effects' seen in lower spatial scales can actually be clear variations driven by the processes studied when properly replicated and manipulated; explanation of variations that occur in different communities and spatial scales are key tasks for ecologists (Benedetti-Cecchi 2000; Coleman et al 2006 ). Proper site and treatment replications would ensure that microscale variations are not merely noises but shows explainable variations with biological meanings (Menge and Olson 1990; Underwood 1993; Underwood and Petraitis 1993; Underwood 2000; Underwood and Chapman 2000; Coleman 2002). When local scale processes such as the interaction between grazers and algae can drive up large scale patterns or events, this has obviously an important role (Wooton 2001) such as on predicting regional scale patterning and possible effects on algal recruitment at a much larger scale. This may seem impossible even to predict such scales of studies but enough site and single species studies or interaction studies can however be modeled and used to draw up predictions of large scale patterns given what we observe today (Wooton 2001).

\subsection{Effects of limpets and coiled gastropods in fence treatments}

The effects of limpets and coiled gastropods have been generally discussed in the above preceding parts; in here, the mechanism involved will be tackled more. Although the main reason for decreased algal cover in the two Stanley sites has been proposed earlier as due to grazing pressure, there is a mechanism involved why grazers such as limpets and coiled gastropods 
should be suspects and not the physical factors of temperature and bright sunshine hours. Physical factors are important in rocky shores such as in the windswept shores of Patagonia (Bazterrica et al. 2007) and in seasonal shores during the summer such as in Hong Kong (Williams 1993a and 1993b, 1994) and in wave exposed shores (Dayton 1971; Lubchenco and Menge 1978) but its effects in creating new spaces which are paramount to all organism in the rocky shores can be masked or simply become secondary to biological factors (Benedetti-Cecchi et al. 2001) or another physical factor (Vinueza et al 2006). During the early phase of this experiment, fenced treatments in the two Stanley sites were not as efficient in excluding grazers as expected. The number of grazers found inside the fenced treatments were therefore recorded and taken into account because even a tiny single grazer can have a disproportionate effect to microalgal measurements and eventually on the algal cover. Over several periods of sampling, it is apparent that we were not successfully removing them all. The most abundant of these grazers are the newly recruiting juvenile limpets (C. toreuma) and some coiled gastropods $(P$. sulcatus, M. labio, $M$. neritoides); these tiny grazers with a size range of 0.3 to $0.5 \mathrm{~mm}$ can enter the small mesh size of $5 \times 5 \mathrm{~mm}$ in exclusion treatments.

One highlight of this is that grazing can indeed affect the algal assemblage but the number and species of grazers present are also important in determining the relative effects of grazing in the shore. For example when the number of grazing molluscs are mainly made of Monodonta labio, and few limpets, grazing pressure was lesser compared when there are more species of grazers present and far more limpets (refer to Figs.11 and 12; Tables 6 and 7). Thus, it is reasonable that the main cause of higher recruitment of erect algae in Cape 2 is the relatively smaller number of species and lower grazer pressure found in this area compared to the two Stanley sites and the other Cape site; there are also far fewer juvenile limpets encountered in this area compared to the other three sites during transect counts and during inspection of cages. Although the mobile top shell M. labio are more abundant in this site than on any other site, their feeding apparatus is fit for removing ephemeral and smaller algae (Steneck and Watling 1982) but once the algae has attained into an escape size such as small turfs, this may be too large for the snail to handle. Limpets on the other hand can excavate filamentous algae including microalgae but are also poor on removing erect algae once these has attained a large size (Steneck and Watling 1982). 
It is also interesting to note here that although Cape 1 and 2 sites are only separated by tens of meters, the variation between the two in terms of the presence of grazers seem to drive the effect of lower turf and foliose algal cover found in Cape 1. This can be the main reason why in the SNK tests, Cape 1 has greater similarity to STAN 1 than to Cape 2. It seems a paradox that although both sites can be found in one shore, the variable effect of grazers can actually make it look more like the community assemblage from another shore despite the distance of hundreds to thousands of meters. The similarity of total algal cover found in Cape 1 to that of STAN 1 shows that relatively the proportion of grazers found in STAN 1 can be the same to that found in Cape 1 (refer to results Fig.11). Another striking similarity is that all limpet grazers found in the three sites (STAN1 and 2; Cape 1) are more abundant compared to Cape 2. In essence, this study shows that the relative grazing effect in these shores can be controlled directly by limpets. Although chitons are implicated to be dominant tropical rocky shore grazers (Harper and Williams 2001) with large body mass and a more powerful feeding apparatus (Steneck and Watling 1982) compared to many other molluscan grazers, its patchy distribution during the study could not be accounted for.

When the study was about to end, foams were used to pad and fill the underneath of each fences and control treatments to exclude grazers, but a month of exclusion did not make any differences between treatments. There were no previous grazer assessment data in the two Stanley sites to show that at this period of the year most of these grazers recruit into shores. Our assessment data of the number of grazers show no significant differences in time of the three months of sampling from October to December which seem to suggest that in all sites, recruitment of grazers may happen year round but survival could be higher during the cool period as opposed to the hot summer months which greatly decimates a number of grazers (Williams 1993a, 1993b; Kaehler and Williams 1996; Harper and Williams 2001). Such die backs in seasonal rocky shores may become widespread in the coming years given the scenarios of climate change which can increase heat stress on many rocky shore organisms (Thompson et al 2002; Vinueza et al. 2006).

In Panama, most molluscan grazers hide from predators such as fishes and carnivorous gastropods in cryptic habitats like crevices, cracks, holes and sloping rock surfaces (Garrity and Levings 1981; Garrity1984; Menge et al. 1986). This behavior of escape mechanism can be driven by escape from predator attacks as well as from heat stress (Garrity and Levings 1981; 
Williams 1993a). The lack of abundant carnivorous predators in Hong Kong shores may explain the difference in foraging behavior between gastropods in Panama and in Hong Kong; molluscan grazers in Hong Kong freely forage on their range of habitat without undergoing any defense tactics although the snail M. labio may sometimes exhibit a peculiar dance behavior that seemingly tries to frighten away any nearby aggressor and then moves away changing its trajectory (Gray Williams pers. comm.). A carnivorous red crab (Carcinus maenas) could sometimes be seen on the shore and may eat limpets by crushing their shells using its powerful claws but its rarity may suggest that its impact on the population of limpets is seldom primary. As a result, the summer die backs which are a primary feature of these shores can be seen as a way to recycle accumulated organic biomass in bodies of animals and algae during the winter period.

\subsection{The world is green but also yellow}

In lieu of the above results, in these shores, grazing controls most of the algal assemblages during the after period of mass die offs. Other tropical rocky shores which are not seasonal such as in Panama (Menge et al. 1986a) and in Galapagos (Vinueza et al 2006) experiences mass algal growth in cages following escape from herbivores. These foraging pressures found in Panama, Galapagos and found in Hong Kong are similar in the aspect of growth from predator release be it fishes, molluscs, iguanas, crabs or a combination of these grazers. While another study (Sauer Machado et al. 1996) in Brazillian tropical rocky shores show that this may not be the case in all tropical shores due to a complex interaction of consumers and possibly competition among algal species, these findings, may suggest that many tropical shores are characteristically context dependent. Although similar patterns of shift in assemblage occur during grazer release, shift in assemblage can be accomplish by way of many other kinds of disturbances. Sessile species can be easily dislodged from wave action (Dayton 1971; Menge 1974), storms (Underwood 1999; Hutchinson and Williams 2003b), ice scouring (McQuaid and Dower 1990; McCook and Chapman 1993), heat stress (Williams 1994; Menge and Sutherland 1987) and predation (Paine 1961, 1994). 
Other physical factors such as seasonal changes (Williams 1993a, 1994) and El Nino effects (Vinueza et al. 2006) and a combination of complex consumer interactions can mask these grazer controlled responses when they do occur. Environmental stress models involving tropical rocky shore communities therefore need to be upgraded and redefined such as the model provided by Menge and Sutherland (1976, 1987) and Menge and Olson (1990). Their model predicts that with high stress systems, there are far fewer consumers and few trophic levels; while in benign environments such as low on the shore in tropical areas, it should have many effective consumers and several trophic levels. Furthermore, given a complex food web, predation will be the dominant structuring factor and the algae that escape consumers will be regulated by competition. In this study, the cool period of the winter season provides a blanket of protection against heat stress normally experienced during the summer in all Hong Kong shores, but this does not reduce or increase the trophic level or the interaction in these shores. Although the Hong Kong shores have a diverse array of consumers, the most conspicuous of these are mainly the grazer algae food-chain. In our study, 16 species of grazers were recorded in different sites which show that it is diverse and species rich but all species subsist on algae. The food chain was therefore essentially a two link food chain but rare predators can link on this food chain occasionally like the red carnivorous crab C. maenas which is a top carnivore in these shores may predate on limpets as well as mussels on wave exposed areas. At this point, we did not find any increase of trophic levels or change of trophic levels from summer to winter; herbivory was effective in winter time but its effect during summer can be masked by high mortality arising from heat stress (Williams 1993a, 1994). This study also did not find evidence that grazers compete for the algae found in the shore although the number of grazers are relatively large compared to temperate areas. In addition, basal species such as algae that escaped herbivory do not seem to be affected by competition. It is however clear that in exclusion plots, encrusting algae is inferior to turf or foliose algae in competing for space or in terms of coverage and exploiting opportunities from grazer removal. In general this may suggest that responses of algal assemblages and herbivores may vary not just temporally (seasonal changes) but also spatially (microns, centimeter to hundreds and thousands of meters) under varying stress levels. Our results also suggest that if context dependency is the norm in most grazer studies, creation of models which can incorporate these varying levels of variation would be appropriate. A model can only be worthwhile not because it works fine today but also because it allows us to predict 
responses or assemblage changes in case one dominant organism is removed or in case a climate forcing would be incorporated.

According to Menge and Olson (1990) the most important aspect of these grazer studies would be when and where consumers have their greatest effects on plants and this may depend on stress levels found in the environment and what stress levels the consumers face. Although the statement seems very general and broad, this gives us the starting point not only to evaluate rocky shores in local contexts but even in the larger sense of it. This may be costly but multiple sites of the same study design done on several tropical countries may just be the right thing; results from such studies can be modeled using cellular automata to incorporate disturbance effects as what Wooton (2001) has done on mussel beds. For example, temporal variation in Hong Kong rocky shores are consistent such that every cool season and just after the hot summer, algal growth becomes evident on the shores again specially in the low and mid-shore. Throughout the cool season, foliose macroalgae can be found growing in most rock pools (see Wai and Williams 2006) but evidently this happens only as a result of escape from herbivores because to a wide extent the mid-shore of a semi-exposed site are quite barren from foliose algae except from cryptic habitats such as cracks, crevices and pools. Even in rock pools the most common algae are the crustose coralline forms and green erect foliose cover in the shores. In the Stanley shore large rounded rocks are often covered on the edges just touching the water with green foliose algae and this extends to covering the whole top of the rock surface during the winter. This cover dramatically increases throughout the cool season. But in the summer such covers become dried up and bleached (Kaehler and Williams 1996). In the rock benches where the experiments were conducted, some nearby rock pools have green erect algal cover growing but where the bench is dried up during low tide, no such green algal cover could be found.

In Cape d' Aguilar shore, the two sites look barren at the start of the experiment even the rock pools found nearby but during the transition to the cool season the barrenness changed; more and more Hildenbrandia covered the area; so did other barnacles and turf forming algae. This spatial variation in each sites and in each shores happens during the cool season and in the summer another set of assemblage takes over as the annual mass die off occurs. Such interaction between time and grazers and sites and shores could certainly interplay to affect such assemblages growing in the shore. The findings of this study coupled with several previous ones (Williams 
1993a, 1993b and 1994) allows us to generalize that in these shores, physical factors such as heat and desiccation controls both the plants and the grazers during the hot summer months but during the winter season, grazing primarily affects the algal assemblage found in the rocky shores. This peculiar flexibility of Hong Kong rocky shores are not incorporated in the Menge and Sutherland model $(1976,1987)$ of environmental stress whose time dimension is fixed.

\subsection{Consumer effects on algal abundance and distribution}

Consumers hold the key to elucidating the biotic factors controlling rocky shore assemblage. The quest to understand the food web and the food chain in many rocky shores is a testament to the persistence of ecologists to find meaning in many processes governing the daily interactions occurring in rocky shores. Many previous studies (Williams 1993a, 1993b, 1994; Kaehler and Williams 1996, 1997; Hutchinson and Williams 2001, 2003) involving grazer- alga interaction were already conducted in Hong Kong but no studies on the effects of several consumers using exclusion treatments were previously performed. Studies on crabs were also previously conducted such as on its feeding ecology and its relationships on seasonal variation of relative abundances of algal cover (Kennish et al. 1996, 1997). These studies provide us a snapshot of how consumers impact the algal assemblage in these shores but their interactive effects and what particular guilds of consumers have predictably larger impact on these algal assemblages are still unanswered.

Although this is not a complete food web study but one that generally tries to separate the effects of different consumers on algal abundance and differentiate the impact of one consumer group from the other, complete separation is impossible to achieve as different animal sizes of various consumers can be present at the same time. Nevertheless, this cursory assessment of the consumer structure in Cape d' Aguilar shore can gives us a brief overview of the possible interactive effects of fast moving and slow moving herbivores on algal assemblages. Our results suggest that fish and crabs have indeed an effect on the present algal assemblage particularly on the functional group of green turfs. This differential effect suggests that these fast moving consumers prefer to graze on green turfs than on any other algae as evidenced by reduced turf algal cover in fenced treatments (Fig.21; Tables 15 and 17). The other experimental results 
which show no significant differences between the effects of fishes and crabs compared to that of molluscs i.e. using measured values of chlorophyll $a$ and percentage algal cover in rock chips could be evidence suggesting that these herbivores may not be efficient grazers of microalgal spores and germlings compared to molluscan grazers. The crab, G. albolineatus, for instance has been found to be limited to cropping filamentous and erect algal turfs since the design of its chelipeds prevents it from cropping foliose leaves as efficiently compared to filamentous and turf algae (Kennish et al. 1996). Fishes are known to feed with visual acuity and could recognize food from non-food as early as during its larval stages (Blaxter 1968, 1986; Kolkovski et al 1997). So although by the first month of the set-up there were observable erect algae (as early as 15days), this food resource may not be useful to fishes and crabs simply because of limitation by the design of its feeding apparatus or turf algal growth and recruitment are simply vigorous enough to replace any loss of algae.

Other studies on the feeding characteristics of fish larvae in aquaculture and observations of mature fishes, show that larval acuity is vital not only for orientation and feed recognition but also with color separation from an early stage (Blaxter 1968,1986; Dendrinos et al. 1984). Kolkovski et al. (1997) also demonstrated that fishes are visually stimulated by feed color and movement. Most fishes located in rocky intertidal habitats graze on the rocky substratum during immersion such as rising tides but there are evidences that suggest fishes can graze on subtidal algae located on rocky and coral reefs which can cause a patchy algal distribution in such areas (Randal 1961, 1965, Hay 1984). Garrity et al. (1986) also found that in Panama where fish grazing was examined on its effect on predaceous gastropods and sessile species, the intensity of consumer pressure varies in different scales of localities. Bertness et al. (1981) also compared the effects of shell crushing fishes on littorinid grazing and found that tropical rocky shores have greater incidence of shell crushing by fishes on littorinids than on temperate shores. Such shell crushing behavior of predacious fishes has definitely modified the behavior of predaceous and herbivorous gastropods limiting their foraging habits (Garrity and Levings 1981). This study only examined the effects of fishes and crabs on one locale which makes it limited in generalization but perhaps may represent the shore of Hong Kong. Most herbivorous fishes are limited to shallower depths as a predator avoidance mechanism (Hay 1984) as well as food foraging. 
Basically therefore large fishes browse on algal turfs but could not crop it as close to the rock surface as compared to molluscan grazers. There is a short term advantage for molluscan grazers in that they can easily bulldoze algal sporelings distributed on these shores and affect their distribution but algal escapes, turfs and foliose algae which survive early grazing of molluscan herbivores cannot be mowed by limpets and snails once it has grown in size. Previous studies such as by Castenholz (1961), Dayton, (1975) and Menge (1977) all agree that limpets and littorinids are primarily scrapers by nature and through their rasping control of the radula, they exert control on marine benthic diatoms, cyanobacteria, sporelings and germlings. Other observations also show that chitons can excavate deeper than most of these molluscan grazers are able to penetrate through the biofilm, coralline crusts and leathery macrophytes including filamentous algae (Steneck 1982; Steneck and Watling 1982).

The most plausible explanation for apparent reduction of algal cover once it has grown to more than 0.5 and $1 \mathrm{~cm}$ would be cropping by fishes and crabs in these shores (pers. obs.). The crab, G. albolineatus, often forage in groups and has been observed in the open to browse on algal turfs and scratch on the surface of encrusting algae for food such as on the open, roof and control treatments. The similarity of the effects of molluscs and crabs to control treatments or nonsignificance of comparison between the controls and the roof treatment suggests that there are no artifacts in our set-ups. This may also mean that the effects of crabs and molluscs would be to crop down any algae that grows from a barren surface. Previous studies on crabs in Hong Kong (Kennish et al. 1996; Kennish 1997) show that these feed preferentially on algal turfs compared to foliose algae such as Ulva and Porphyra. In the study of Kennish et al. (1996), faecal analysis revealed that a greater proportion of algal food is consumed in the winter suggesting that the crab digests filamentous algae more efficiently than encrusting algae. The feeding preferences of $G$. aIbolineatus appear to be influenced by a number of factors such as including the availability, digestibility and morphology of algae. The foraging behavior and cheliped morphology of the crab also affect food choice which means that the cheliped structure of this crab (Grapsus albolineatus) could not handle foliose leaf as well as it can crop algal turfs (Kennish et al. 1996). Reports (Vinueza et al. 2006) of crabs such as the sally light-foot crabs (G. grapsus) in the Galapagos show preference to red algal turfs and Ulva and some amounts of filamentous greens but these crabs avoided encrusting algae, including filamentous brown algae. 
On two separate occasions, the fish Entomacrodus stellifer was found trapped inside the cage treatment, one was large and the other was comparatively of small size. These fishes are the most abundant near shore and bottom dwelling fishes in Hong Kong shores and thought to graze on algae. Previous observations of these two consumers reveal that they can both feed on erect algae and on sporelings of green turfs while immersed during high tide (Hutchinson and Williams 2001). Williams (1994) and Kaehler and Williams (1996) discount the possibilities that these herbivores play as important a role compared to molluscs in these shores; this assumption was quite simplistic and this study suggests that the effects of fishes and crabs can be more subtle than expected. For example, the reduced algal turf in fenced treatments could only be attributed to the grazing effects of fishes and crabs but not molluscs since these herbivores cannot crop such turfs once they have grown (pers. obs.). These herbivores therefore have an indirect role of complementing the grazing pressure found in these shores which are primarily effected by molluscan grazers.

Thus, on the question whether one particular guild of consumers has a larger impact on relative algal abundance than others, fish and crab do not appear to dominate on these shores nor are large predatory fishes on molluscs present to hinder or affect their grazing behavior. In addition, the herbivorous crab, G. albolineatus, does not appear to compete with molluscan grazers directly since the latter prefers to feed on microalgae or on the biofilm as compared to erect algae or foliose algae. An indirect effect of this however would be to produce less amount of erect algae which the crabs prefer to graze on.

Since crabs are mobile organisms, these can feed during high tide and low tide and feed by scratching rock surfaces for turf algae, algal sporelings as well as microalgae (Kennish et al. 1996). Other fast mobile predators like herbivorous fishes are not limited to one rock bench for a feeding ground making fishes highly dispersive agents in benthic ecology. In the long term, it appears that fishes and crabs are mostly limited to grazing on algal turfs and algal escapes in the midshore. Given the seasonal trend of annual die offs during the hot summer season in Hong Kong and low algal growth (Williams 1993a, 1994; Kaehler and Williams 1996), fishes and crabs can only have an effect on the shore during the winter season where most turfs and foliose algae recruit abundantly due to reduced stress. Subtidal and low shore algal growths during the 
summer can be the source of nourishment for these organisms during extreme periods of heat stress as in summer. Upward colonization of low shore algae on the mid shores are hindered for two reasons, the summer heat would kill most of the foliose and erect algae that recruited during the summer on the midshore (Williams 1993a; 1994) and algae that recruited during the winter are grazed by molluscan grazers. So what erect algae that remains on the shores during the winter, these are destroyed by heat and desiccation during the summer.

On the question as how do consumers affect algal abundances and distribution in these shores algal preys are not limited merely by post settlement mortality processes such as bulldozing and herbivory by molluscs. These are also affected by mortality during its growth such as by crabs and fishes which can reduce its cover close to the rock surface. This means that what escapes from the scraping of limpets and other molluscan grazers, either crabs or fishes crops it back to the surface of the rock. This could possibly explain the bare cover of the rocky shore during most of the time year round. Other studies such as those in Panama (Menge et al. 1986) observes this complementary effect of fishes on cropping algal cover but Sauer Machado et al (1996) did not observe such to occur in the Brazillian rocky shores they studied.

In summary, this study reveals that different consumer groups have indeed different effects on the algal assemblage and functional groups. Molluscan grazers mainly eliminate or reduce the relative abundances of erect algae without necessarily selecting for it by feeding on algal recruits and sporelings. By this way, molluscs control the relative abundance and of foliose and turf algae. Fishes and crabs on the other hand, browse on turfs and foliose algae that escaped the control of molluscs and are indirectly affected by the grazing of molluscs on algal sporelings. The impact of consumers on algal communities can be summed up as molluscs $>$ fishes and crabs; fishes $=$ crabs. 


\subsection{Conclusions and broader implications}

This study on tropical rocky shores provides new insights on spatial variability of grazing and on the roles of fishes and crabs on tropical rocky shores where molluscan herbivores dominate. The present findings confirm significant differences between treatments, sites and shores across time. This significant differences between treatments occurred not only in microalgal abundance between treatments but also in the functional groups of macroalgae evaluated (turfs, foliose, erect and encrusting algal cover) between treatments in examined plots. Our study reveals that local processes acting on small scales such us on plots (centimeters) and within sites (meters to tens of meters) can drive observed variations even to larger scales such as shores and locations. The main difference between the results of the present study and those previously of Williams (1993a, 1994) stems mainly from lower site replications in the earlier studies and therefore failure to detect significant differences between treatments in the midshore. In both studies, vigorous algal growth was observed in fenced treatments.

The spatial variation observed in sites and shores seems to be rooted on the influence and control of molluscan grazers affecting mainly algal sporelings, germlings and new recruits. This can then influence the recruitment patterns of different functional groups of algae on the shore such as foliose, turf and encrusting algae on plots, sites and shores. Our study reveals that algal recruitment patterns in tropical rocky shores can be mainly influenced by molluscs as opposed to fishes. The reduction of macroalgal cover during the cool winter season could be explained mainly as a result of grazer control.

Further consumer effects study show that the most important group of consumers in these shores are the molluscan grazers which mainly account for the observed effect of reduction of algal cover. Although crabs and fishes are present in these shores, the role of these consumers is mainly to enhance the effect of molluscan herbivores by reducing erect algal cover. An indirect effect of molluscan grazers on fishes and crabs though would be to reduce their food supply by non-selective feeding on algal sporelings which include all kinds of microalgae including the turf formers. Thus, even though the environment can be benign in a tropical rocky shore, it does not necessarily support the view that herbivorous fishes will dominate over other consumers found in the area. Fast mobile herbivores such as fishes and crabs can have long term effects such as 
reducing algal cover in their foraging areas but this depends on two factors to be carried out (1) the density of herbivorous fishes and crabs in the area determines the relative impact on the community (2) although slow moving herbivores, gastropods with larger numbers can create an effective grazing pressure that actually controls the overall assemblage of plants in the area. In this case, number 2 is true in Hong Kong shores and the relative impact is: molluscs $>$ fishes\&crabs; fishes $=$ crabs. Algal prey diversity could have been less stated, grazing reduced the number of algal prey species that recruited into shores while the low grazing intensity set-ups of fenced and cage treatments showed marked succession from micro (diatoms and cyanobacteria) to macroalgae (turfs and foliose).

Thus in the end, post recruitment processes such as grazing does influence the distribution and abundance of algae in this area. Our findings show that although environmental harshness can be reduced during the winter season and thereby seem to alleviate the conditions of recruitment of sessile algal species in these shores, complete coverage of the mid-shore by erect algal species remain elusive because of the presence of the grazers. This can lead to what we observe as patchy distribution and cover in open areas in the mid-shore.

\subsection{Recommendations}

One of the limitations of this study was inability to observe direct changes of algal communities in the summer. Effects of seasonality have not been examined on this study although it would have been better if it covered this period to observed transitional changes occurring in the algal community. A regular monitoring of grazer abundance and sessile preys using fixed transects along the vertical gradient of tidal heights are needed to quantify effects of seasonality over a long period of time. This will enable us to predict in the long run any environmental perturbations that can cause sudden changes on these communities. Temporal variation is as important as spatial variation in determining and revealing community changes and patterns (Hutchinson and Williams 2001; Underwood 2000b). It is therefore recommended that another similar study be conducted with temporal variation in mind and to further confirm the findings of this study. In addition the seven treatments used in the consumer studies were not done across several shores but only on one shore (Cape d' Aguilar). A two or three shore study with a lesser 
number of treatments can be set-up rather than making use of a 7 treatment study (see Vinueza et al. 2006 for similar treatments and modifications). As this study showed, there were no significant differences or artifacts between the means of the control treatments including to that of the roof or partial treatments. A modified 5 treatment study such as cage, fence, roof, open and a modified partial cage would be sufficient to do another consumer effects study as all of the controls in this study detected no cage effects. As many other studies (Jenkins et al. 2001; Coleman et al. 2006; Freidenburg et al. 2007) showed an increasing variability of grazing when scaled up, other relevant combined factors to study would be the effects of temperature and nutrients at the same time. With the increasing effect of climate change being felt such as rising temperature (Vitousek et al 1997; Capili et al. 2005), studies of multiple stressors on our ecosystem are needed in order to accumulate results which are usable for modeling and forecasting future scenarios of impacts of climate change. The rocky shore community, with short generational times of organisms and accessibility remains to be tractable for testing many of these challenging scenarios and impacts. This study did not directly manipulated temperature (i.e. warm and cool) as well as using time released nutrients to see its effects on the diversity of assemblage found on these shores. Relevant combined studies are much more fruitful when these give us ideas on how large the impacts of the factors we study really are on prey organisms. Other than this, tropical rocky shore modeling should be started using the previous studies to understand and simulate other disturbance events that could affect both grazers and sessile algal preys from species abundance, distribution, range as well as physiological response (Underwood 2000b; Wooton 2001; Thompson et al. 2002). Some examples of how simulation models of rocky shore communities can be built is on the basis of qualitative rules derived from observation (e.g. Burrows and Hawkins 1998) or individual based approaches (e.g. Johnson et al. 1998). These models are useful in predicting future changes and responses of rocky shore organisms given current trends of threats to the ecosystem such as species extinction, pollution, temperature rise and habitat destruction (Thompson et al. 2002). Regular monitoring allows us to find patterns and learn about processes which are useful for predicting environmental perturbations or disturbances in the environment (Unerwood and Petraitis 1993; Thompson et al. 2002). 
P a g e $\mid 95$

Epilogue

"The grass withers and lours with fire..."

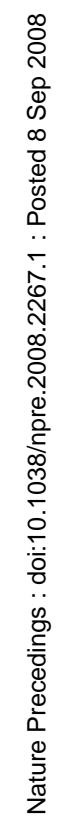




\subsection{References}

Anderson MJ, Underwood AJ (1997) Effects of gastropod grazers on recruitment and succession of an estuarine assemblage: a multivariate and univariate approach. Oecologia 109:442-453

Archambault P, Bourget E (1996) Scales of coastal heterogeneity and benthic intertidal species richness, diversity and abundance. Mar Ecol Progr Ser 136:111-121

Bazterrica MC, Silliman BR, Hidalgo FJ, Crain CM, Bertness MD (2007) Limpet grazing on a physically stressful Patagonian rocky shore. J Exp Mar Biol Ecol 353:22-34

Benedetti-Cecchi L, Maggia E, Bertoccia I, Vasellia S, Michelib F, Osioa GC, Cinelli F (2003) Variation in rocky shore assemblages in the northwestern Mediterranean: contrasts between islands and the mainland . J Exp Mar BioI Ecol 293 193-215

Benedetti-Cecchi L, Bulleri F, Cinelli F (2000) The interplay of physical and biological factors in maintaining mid-shore and low-shore assemblages on rocky coasts in the north-west Mediterranean. Oecologia 123: 406-417

Benedetti-Cecchi L, Pannacciulli F, Bulleri F, Moschella PS, Airoldi L, Relini G, Cinelli F (2001) Predicting the consequences of anthropogenic disturbance: large-scale effects of loss of canopy algae on rocky shores. Mar Ecol Prog Ser 214:137-150

Bertness MD, Garrity SD, Levings SC (1981) Predation Pressure and Gastropod Foraging: A Tropical-Temperate Comparison. Evolution 35:995-1007

Blaxter JHS (1968) Light intensity, vision, and feeding in young plaice. J Exp Mar BioI Ecol 2:293-307

Blaxter JHS (1986) Development of sense organs and behavior of teleost larvae with special reference to feeding and predator avoidance. Transactions of the American Fisheries Society 115:98-114

Bovhjerg R V (1965) Breeding and dispersal in the Snail Stagnicola reflexa (Basommatophora:Ly) mnaeidae).Malacol. 2: 199-207

Brosnan DM (1992) Ecology of tropical rocky shores plant animal interactions in tropical and temperate latitudes. In:John OM, Hawkins SJ, Price JH (eds) Plant-animal interactions in the marine benthos. Clarendon Press, Oxford, p 101-131

Burrows MT, Hawkins SJ (1998) Modelling patch dynamics on rocky shores using deterministic cellular automata. Mar Ecol Prog Ser 167: 1-13 
Bustamante RH, Branch GM, Eekhout S (1995) Maintenance of an exceptional intertidal grazer biomass in South Africa: Subsidy by subtidal kelps. Ecology 76: 2314-2329

Callow, P (1970) Studies on the natural diet of Lymanea pereger obtusa (Kobelt)and its possible ecological implication:Proc. Malacol. Soc. London 39:203-215

Callow, P (1973) The food of Ancylus fluviatilis (Mull), a littoral stone dwelling herbivore Oecologia 13:113-133

Capili EB, Ibay ACS , Villarin JRT (2005) Climate Change Impacts and Adaptation on Philippine Coasts.

Proceedings of the International Oceans 2005 Conference. 19-23 September 2005, Washington D.C., USA. Pp. 1-8

Cates, RG (1975) The interface between slugs and ginger: Some evolutionary aspects. Ecology $56: 391-400$

Cates RG, Orians JH (1975) Successional status and the palatability of plant to generalized herbivores. Ecology 56:401-418

Castenholz RW (1961) The effect of grazing on marine littoral diatom populations. Ecology 42: 783-794

Castenholz RW (1963) An experimental study of the vertical distribution of littoral marine diatoms. Limnol. Oceanogr. 8: 450-462

Clarke KR (1993) Non-parametric multivariate analyses of changes in community structure. Austral Ecology 18:117-143

Coleman MA (2002) Small-scale spatial variability in intertidal and subtidal turfing algal assemblages and the temporal generality of these patterns. J Exp Mar BioI Ecol 267: 53- 74

Coleman RA, Underwood AJ, Benedetti-Cecchi L, A berg PA, Arenas F, Arrontes J, Castro J, Hartnoll RG, Jenkins SR, Paula J, Della-Santina P, Hawkins SJ (2006) A continental scale evaluation of the role of limpet grazing on rocky shores. Oecologia 147:556-564

Connell J H (1961) Effects of competition, predation by Thati lap\&s, and other factors on natural populations of the barnacle Balanus balanoides. Ecol Monogr 31: 61-104 
Dayton P K (1971) Competition, disturbance and community organization: The provision and subsequent utilization of space in a rocky intertidal community. Ecol Monogr 41: 351-389

Dayton PK, Tegner MJ (1984) The importance of scale in community ecology: a kelp forest example with terrestrial analogs. A new ecology: novel approaches to interactive systems. . P. W. Price, Slobodchikoff, C.N., Gaud, W.S., Wiley: 457-483

Denley EJ, Underwood AJ (1979) Experiments on factors influencing settlement, survival and growth of two species of barnacles in New South Wales. J Exp Mar Biol Ecol 36: 269-293

Dendrinos P, Dewan, S, Thorpe, JP (1984) Improvement in the feeding efficiency of larval, post larval and juvenile dover sole (Solea solea) by the use of staining to improve the visibility of Artemia used as food. Aquaculture 38:137-144

Deysher L, Norton TA (1982) Dispersal and colonisation in Sargassum muticum (Yendo) Fensholt. J Exp Mar Biol Ecol 156:179-195

Fretwell SD (1977) The regulation of plant communities by food chains exploiting them. Persp Biol and Med 20:169-185

Fretwell SD (1987) Food chain dynamics: The central theory of ecology? Oikos 50:291-301

Freidenburg TL, Menge BA, Halpin PM, Webster M, Sutton-Grier A (2007) Cross-scale variation in top-down and bottom-up control of algal abundance. J Exp Mar Biol Ecol 347:8-29

Field JG, Clarke KR, Warwick RM (1982) A Practical Strategy for Analysing Multispecies Distribution Patterns. Mar Ecol Prog Ser 8:37-52

Garrity SD (1984) Some adaptations of gastropods to Physical stress on a tropical rocky shore. Ecology 65:559-574

Garrity SD, Levings SC (1981) A Predator-Prey interaction between two physically and biologically constrained tropical rocky shore gastropods: direct, indirect and community effects. Ecol Monogr 51:268-286

Garrity SD, Levings SC, Caffey HM (1986) Spatial and temporal variation in shell crushing by fishes on rocky shores of Pacific Panama. J Exp Mar Biol Ecol 103:131-142

Grime JP (1977) Evidence for the existence of three prinary strategies in plants and its relevance to ecological and evolutionary theory. Am Natur 111:1169-1194 
Guidetti P, Dulcic J (2007) Relationships among predatory fish, sea urchins and barrens in Mediterranean rocky reefs across a latitudinal gradient Marine Environmental Research 63:168184

Harper KD, Williams GA (2001) Variation in abundance and distribution of the chiton Acanthopleura japonica and associated molluscs on a seasonal, tropical, rocky shore. J Zool Lond 253:293-300

Hawkins SJ, Hartnoll RG (1983) Grazing of intertidal algae by marine invertebrates. Oceanogr Mar Biol Annu Rev 21:195-282

Hay ME (1984) Patterns of Fish and Urchin Grazing on Caribbean Coral Reefs: Are Previous Results Typical? Ecology 65: 446-454

HMSO (1986) The determination of chlorophyll $a$ in aquatic environments In Methods for the examination of water and associated materials Vol. 4 Section 2. HMSO London

Hodgkiss I J (1984) Seasonal patterns of intertidal algal distribution in Hong Kong. Asian Marine Biology 1: 49-57

Hoffmann AJ, Ugarte R (1985) The arrival of propagules of marine macroalgae in the intertidal zone. J Exp Mar Biol Ecol 92:83-95

Hutchinson, N (1999) Spatial variation in tropical rocky shores: the role of herbivory and disturbance. PhD thesis, The University of Hong Kong, Hong Kong

Hutchinson N, Williams GA (2001) Spatio-temporal variation in recruitment on a seasonal, tropical rocky shore: the importance of local versus non-local processes. Mar Ecol Prog Ser 215:57-68

Hutchinson N, Williams GA (2003a) An assessment of variation in molluscan grazing pressure on Hong Kong rocky shores. Mar Biol 142:495-507

Hutchinson N, Williams GA (2003b) Disturbance and subsequent recovery of mid-shore assemblages on seasonal, tropical, rocky shores. Mar Ecol Prog Ser 249:25-38

Jenkins SR, Arenas F, Arrontes J, Bussell J, Castro J, Coleman RA, Hawkins SJ, Kay S, Martinez B, Oliveros J, Roberts MF, Sousa S, Thompson RC, Hartnoll RG (2001) Europeanscale analysis of seasonal variability in limpet grazing activity and microalgal abundance. Mar Ecol Prog Ser 211:193-203

Johnson MP, Burrows MT, Hawkins SJ (1998) Individual based simulations of the direct and indirect effects of limpets on a rocky shore Fucus mosaic. Mar Ecol Prog Ser 169: 
$179-188$

Kaehler S (1996) Causes and consequences of the spatial and temporal distribution of encrusting algae on tropical rocky shores. PhD thesis, University of Hong Kong

Kaehler S, Williams GA (1996) Distribution of algae on tropical rocky shores: spatial and temporal patterns of non-coralline encrusting algae in Hong Kong. Mar Biol 125:177-187

Kaehler S, Williams GA (1997) Do factors influencing recruitment ultimately determine the distribution and abundance of encrusting algae on seasonal tropical shores? Mar Ecol Prog Ser 156:87-96

Kaehler S, Williams GA (1998) Early development of algal assemblages under different regimes of physical and biotic factors on a seasonal tropical rocky shore. Mar Ecol Prog Ser 172: 61-71

Kennish R, Williams GA, Lee SY (1996) Algal seasonality on anexposed rocky shore in Hong Kong and the dietary implications for the herbivorous Grapsus albolineatus. Mar Biol 125: 5564

Kennish, R (1996)Diet composition influences the fitness of the herbivorous crab Grapsus albolineatus. Oecologia 105: 22-29

Kennish, R (1997) Seasonal patterns of food availability: influences on the reproductive output and body condition of the herbivorous crab Grapsus albolineatus. Oecologia 109: 209-218

Kohler KE, Gill SM (2006) Coral Point Count with Excel extensions (CPCe): A Visual Basic program for the determination of coral and substrate coverage using random point count methodology. Computers and Geosciences 32:1259-1269

Kolkovski S, Arieli A, Tandler A (1997) Visual and chemical cues stimulate microdiet ingestion in sea bream larvae. Aquaculture International 5:527-536

Levin SA ( 1992) The problem of pattern and scale in ecology. Ecology 73: 1943-1967

Littler MM, Littler DS (1980) The evolution of thallus form and survival strategies in benthic marine macroalgae: field and laboratory tests of a functional form model, . Am Natur 116:25-44

Lubchenco J, Menge, B.A. (1978) Community Development and Persistence in a Low Rocky Intertidal Zone. Ecol Monogr 48:67-94 
MacLulich, JH (1987) Variations in the density and variety of intertidal epilithic microflora Mar Ecol Prog Ser 40 285-293.

McCook LJ, Chapman ARO (1991) Community succession following massive ice-scour on an exposed rocky shore: effects of Fucus canopy algae and of mussels during late succession. J Exp Mar Biol Ecol 154:137-169

McCook LJ, Chapman ARO (1993) Community succession following massive ice-scour on a rocky intertidal shore: recruitment, competition and predation during early, primary succession. Mar Biol 115:565-575

McQuaid CD, Dower KM (1990) Enhancement of habitat heterogeneity and species richness on rocky shores inundated by sand. Oecologia 84: 142-143

Menge BA, Daley, B.A., Lubchenco, J., Sanford, E., Dahlhoff, E., Halpin, P.M., Hudson, G., Burnaford, J.L. (1999) Top-Down and Bottom-Up Regulation of New Zealand Rocky Intertidal Communities. Ecol Monogr 69:297-330

Menge BA, Sanford E, Daley BA, Freidenburg TL, Hudson G, Lubchenco J (2002) Interhemispheric comparison of bottom-up effects on community structure: Insights revealed using the comparative-experimental approach. Ecological Research 17:1-16

Menge JL (1977) Plant species diversity in a marine intertidal community: Importance of herbivore food preference and algal competitive abilities. Am Natur 112:23-39

Menge BA, Lubchenco J (1981) Community organization in temperate and tropical intertidal habitats: prey refuges in relation to consumer pressure gradients. Ecol Monogr 51 429-450

Menge BA, Lubchenco J, Ashkenas LR (1985) Diversity, heterogeneity and consumer pressure in a tropical intertidal community. Oecologia 65394-405

Menge BA, Lubchenco J, Ashkenas LR (1986a) Experimental separation of effects of consumers on sessile prey in the low zone of a rocky shore in the Bay of Panama: direct and indirect consequences of food web complexity. J Exp Mar BioI Ecol 100 225-269

Menge BA, Lubchenco J, Gaines SO, Ashkenas LR (1986b) A test of the Menge-Sutherland model of community organization in a tropical rocky intertidal food web. Oecologia 71:75-89

Menge BA, Olson AM (1990) Role of scale and environmental factors in regulation of community structure. Trends Ecol Evol 5: 52-57 
Menge BA, Sutherland JP (1976) Species Diversity Gradients: Synthesis of the Roles of Predation, Competition, and Temporal Heterogeneity. Am Natur 110:351-369

Menge BA, Sutherland JP (1987) Community regulation: variation in disturbance, competition, and predation in relation to environmental stress and recruitment. Am Natur 130:730-757

Nagarkar S (1996) The ecology of intertidal epilithic biofilms with special reference to cyanobacteria. $\mathrm{PhD}$ thesis, The University of Hong Kong

Nagarkar S, Williams GA (1997) Comparative techniques to quantify cyanobacteria dominated epilithic biofilms on tropical rocky shores. Mar Ecol Prog Ser 154:281-291

Nakai S, Miura O, Maki M, Chiba S (2006) Morphological and habitat divergence in the intertidal limpet. Mar Biol 149:515-523

Nicotri, M E (1977) Grazing effects of four marine intertidal herbivores on the microflora. Ecology 58: 1020-1032

Oksanen L, Fretwell SD, Arruda J, Niemela P (1981) Exploitation ecosystems in gradients of primary productivity. Am Natur 118:240-261

Paine RT (1966) Food web complexity and species diversity. Am Natur 100:65-75

Paine RT (1994) Marine rocky shores and community ecology: an experimentalist's perspective. International Ecology Institute. Oldendorf, Luhe, Germany

Patrick R (1972) Benthic communities in streams. Trans. Conn. Acad. Arts Sci. 44: 69-2-84

Petraitis PS (1983) Grazing patterns of the periwinkle and their effect on sessile intertidal organisms. Ecology 64: 522-533

Power ME, Dudley TL, Cooper SD (1989) Grazing catfish, fishing birds, and attached algae in a Panamanian stream. Environmental Biology of Fishes 26:285-294

Quinn GP, Keough M (2002) Experimental design and data analysis for biologists. University of Cambridge, University Press, Cambridge UK

Randall JE (1961) Overgrazing of algae by herbivorous marine fishes. Ecology. 42:812

Randall JE (1965) Grazing effect on seagrass by herbivorous reef fishes in the West Indies. Ecology 46: 255-266 
Rilov G, Schiel DR (2006a) Seascape-dependent subtidal -intertidal trophic linkages. Ecology, 87:731-744

Rilov G, Schiel DR (2006b) Trophic linkages across seascapes: subtidal predators limit effective mussel recruitment in rocky intertidal communities. Mar Ecol Prog Ser 327: 83-93

Sauer Machado KRS, Chapman ARO, Coutinho R (1996) Consumer species have limited and variable roles in community organization on a tropical intertidal shore. Mar Ecol Prog Ser $134: 73-83$

Shima JS (1999) Variability in relative importance of determinants of reef fish recruitment Ecology Letters 2 (5) , 304-310

Sousa WP (1984) Intertidal mosaics: patch size, propagule availability and spatially variable patterns of succession. Ecology 65:1918-1935

Steneck RS (1982) A limpet-coralline alga association: adaptations and defenses between a selective herbivore and its prey. Ecology 63(2): 507-522

Steneck RS, Dethier MN (1994) A functional group approach to the structure of algal-dominated communities. Oikos 69: 476-498

Steneck RS, Watling L (1982) Feeding capabilities and limitation of herbivorous molluscs: a functional group approach. Mar BioI 68:299-319

Thompson RC, Johnson LE, Hawkins SJ (1997) A method for spatial and temporal assessment of gastropod grazing intensity in the field: the use of radula scrapes on wax surfaces. J Exp Mar Biol Ecol 218: 63-76

Thompson RC, Crowe TP, Hawkins SJ (2002) Rocky intertidal communities: past environmental changes, present status and predictions for the next 25 years. Environmental Conservation Biology 29(2): 168-191

Underwood AJ (1980) The effects of grazing by gastropods and physical factors on the upper limits of distribution of intertidal macroalgae. Oecologia 46: 201-213

Underwood AJ (1981) Structure of a rocky intertidal community in New South Wales: Patterns of vertical distribution and seasonal changes. J Exp Mar BioI Ecol 51(1): 57-85

Underwood AJ, Denley, E.J., Moran, M.J. (1983) Experimental Analyses of the Structure and Dynamics of Mid-shore Rocky Intertidal Communities in New South Wales. Oecologia (Berlin) $56: 202219$ 
Underwood AJ (1984) The vertical distribution and seasonal abundance of intertidal microalgae on a rocky shore in New South Wales. J Exp Mar BioI Ecol 78(3): 199-220

Underwood AJ (1985) Physical factors and biological interactions: the necessity and nature of ecological experiments. In P. G. Moore \& R. Seed (eds), The Ecology of rocky coasts. Hodder \& Stoughton, Lond.: $372-390$

Underwood AJ (1997) Experiments in ecology: Their logical design and interpretation using the analysis of variance. University of Cambridge, University Press, Cambridge UK

Underwood AJ, Denley EJ (1984) Paradigms, explanations, and generalizations in models for the structure of intertidal communities on rocky shores. In: Strong DR, Simberloff D, Abele LG, Thistle AB (eds) Ecological communities: conceptual issues and the evidence. Princeton University Press, Princeton, New Jersey, pp 151-180

Underwood AJ, Petraitis PS (1993) Structure of intertidal assemblages in different locations: how can local processes be compared? In: Ricklefs R, Schluter D (eds) Species diversity in ecological communities. University Chicago Press, Chicago, p 38-51

Underwood AJ (1993a) The mechanics of spatially replicated sampling programmes to detect environmental impacts in a variableworld. Australian Journal of Ecology 18: 99-116

Underwood AJ (1993b) Exploitation of species on the rocky coast of New South Wales (Australia) and options for its management. Ocean and Coastal Management 20: 41-62

Underwood AJ, Chapman MG, Connell SD (2000) Observations in ecology: you can't make progress on processes without understanding the patterns. Journal of Experimental Marine Biology and Ecology 250(1-2): 97-115

Underwood AJ (2000a) Importance of experimental design in detecting and measuring stresses in marine populations. Journal of Aquatic Ecosystem Stress and Recovery 7: 3-24

Underwood AJ (2000b) Experimental ecology of rocky intertidal habitats: what are we learning? J Exp Mar BioI Ecol 250: 51-76

Underwood A J, Jemakoff P (1984) The effects of tidal height, wave exposure, seasonality and rock pools on grazing and distribution of intertidal macroalgae in New South Wales. J Exp Mar BioI Ecol 75: 71-96 
Vadas RL (1985) Herbivory. In: Littler MM, Littler DS (eds) The handbook of phycological methods and ecological field methods: macroalgae. Cambridge University Press, Cambridge,pp $531-572$

Vinueza L R, Branch GM, Branch ML, Bustamante RH (2006) Top-down herbivory and bottomup El nino effects on Galapagos rocky shore communities. Ecol Monogr 76: 111-131

Vitousek PM, Howarth RW, Likens GE, Matson PA, Schindler DW, Schlesinger WH, Tilman DG (1997) Human alteration of the global nitrogen cycle: sources and consequences. Ecol Appl 7:737-750

Wai TC, Williams GA (2006) Monitoring spatio-temporal variation in molluscan grazing pressure in seasonal, tropical rock pools. Mar Biol 149: 1139-1147

Williams GA (1993a) The relationship between herbivorous molluscs and algae on moderately exposed Hong Kong shores. In: B.S. Morton, I.J. Hodgkiss, M.S. Mak (eds) Proceedings of the first international conference on the Biology of the South China Sea. Hong Kong University Press, Hong Kong

Williams GA (1993b) Seasonal variation in algal species richness and abundance in the presence of molluscan herbivores on a tropical rocky shore. J Exp Mar Biol Ecol 167:261-275

Williams GA (1994) The relationship between shade and molluscan grazing in structuring communities on a moderately-exposed tropical rocky shore. J Exp Mar Biol Ecol 178: 79-95

Williams GA, Morritt D (1995) Habitat partitioning and thermal tolerance in a tropical limpet, Cellana grata Mar Ecol Prog Ser 124:89-103

Williams GA, Davies MS, Nagarkar S (2000) Primary succession on a seasonal tropical rocky shore: the relative roles of spatial heterogeneity and herbivory. Mar Ecol Prog Ser 203:81-94

Worm B, Lotze HK, Boström C, Engkvist R, Labanauskas V,Sommer U (1999) Marine diversity shift linked to interactions among grazers, nutrients and propagule banks. Mar Ecol Prog Ser 185:309-314

Wooton JT (2001) Local interactions predict large-scale pattern in empirically derived cellular automata. Nature 413: 841-842 